\title{
WestVirginiaUniversity
}

THE RESEARCH REPOSITORY @ WVU

Graduate Theses, Dissertations, and Problem Reports

2016

\section{In-Cylinder Diagnostics Using Feedback from Resonant Cavity Ignition Sources}

James F. Hunsucker III

Follow this and additional works at: https://researchrepository.wvu.edu/etd

\section{Recommended Citation}

Hunsucker III, James F., "In-Cylinder Diagnostics Using Feedback from Resonant Cavity Ignition Sources" (2016). Graduate Theses, Dissertations, and Problem Reports. 5840.

https://researchrepository.wvu.edu/etd/5840

This Thesis is protected by copyright and/or related rights. It has been brought to you by the The Research Repository @ WVU with permission from the rights-holder(s). You are free to use this Thesis in any way that is permitted by the copyright and related rights legislation that applies to your use. For other uses you must obtain permission from the rights-holder(s) directly, unless additional rights are indicated by a Creative Commons license in the record and/ or on the work itself. This Thesis has been accepted for inclusion in WVU Graduate Theses, Dissertations, and Problem Reports collection by an authorized administrator of The Research Repository @ WVU. For more information, please contact researchrepository@mail.wvu.edu. 


\title{
In-Cylinder Diagnostics Using Feedback from Resonant Cavity Ignition Sources
}

\section{James F. Hunsucker III, BSEE}

\author{
Thesis submitted \\ to the Benjamin M. Statler College of Engineering \\ at West Virginia University \\ in partial fulfillment of the requirements for the degree of \\ Master of Science in \\ Mechanical Engineering
}

James E. Smith, Ph.D., Committee Chair

Roy Nutter, Ph.D.

Andrew Lowery, Ph.D.

Department of Mechanical Engineering

West Virginia University

Morgantown, West Virginia

2016

Keywords: Plasma ignition, in-cylinder diagnostics, resonator, QWCCR, engine, resonant frequency

(C) 2016 James F. Hunsucker III 


\begin{abstract}
In-Cylinder Diagnostics Using Feedback from Resonant Cavity Ignition Sources
\end{abstract}

James F. Hunsucker III

The Quarter-Wave Coaxial Cavity Resonator (QWCCR) Plasma Igniter is a spark ignition replacement system based on a novel technology. This system creates coronal plasma through the use of radio frequency voltage step-up. Because this device is an open loop resonant structure, it is sensitive to changes in the environment it operates in, the physical and the combustion environment. A relationship can be developed between the effects of the pressure in the combustion environment and the changes in resonance frequency experienced by the igniter. These diagnostic capabilities can be utilized to detect and alleviate misfires, incomplete fuel burns, etc. in an engine cycle.

A series of tests were conducted to prove these principles. The QWCCR plasma igniter was inserted into the Cooperative Fuel Research (CFR) test engine. Data was collected via an incylinder pressure computer and a network analyzer. The engine was set at different increments in crank angle to map the changes in the parameters at different volumes throughout the compression and power strokes. During these tests there was no fuel or combustion only air as the medium in-cylinder.

The results compare a baseline frequency calculated from the in-cylinder pressure data and an experimental frequency that was collected using the network analyzer. The percent error between these two is at a maximum $1.725 \%$. Three-dimensional plots were created from this data to show that frequency and pressure can be predicted and to show that this is a valid means of tracking changes in the combustion chamber. The results demonstrate that QWCCR Plasma igniter can be used as a diagnostics tool. This validation provides numerous additional opportunities for diagnostic capabilities using the other fundamental parameters of the igniter physical and electromagnetic properties. 


\section{Tables of Contents}

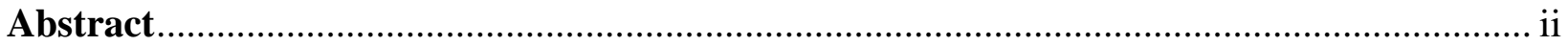

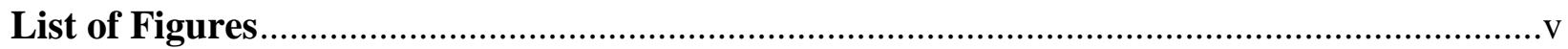

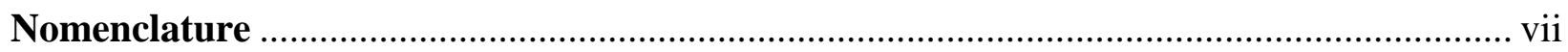

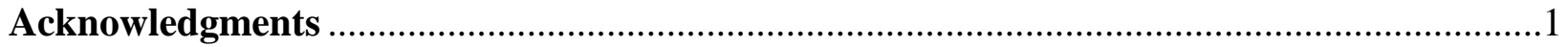

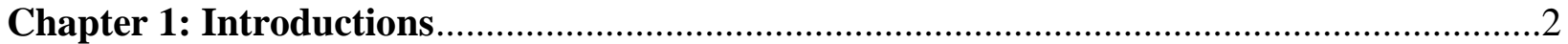

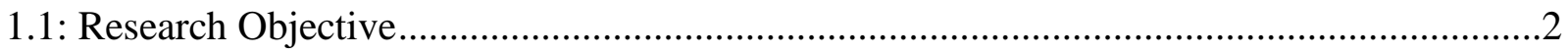

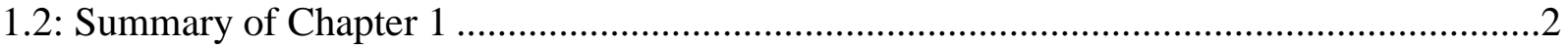

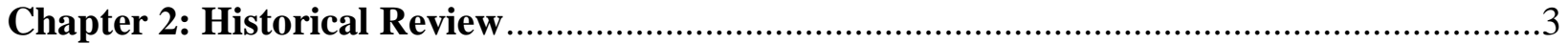

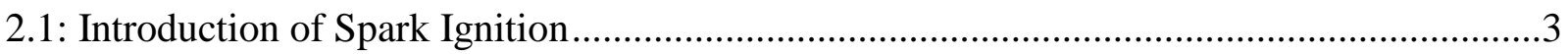

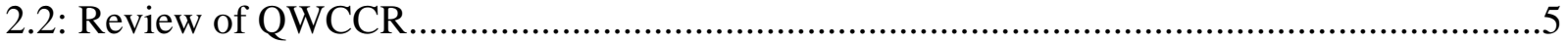

2.3: Review of Other Plasma Ignition Systems ......................................................... 10

2.4: Resonator - Frequency, Temperature, Pressure ...........................................................19

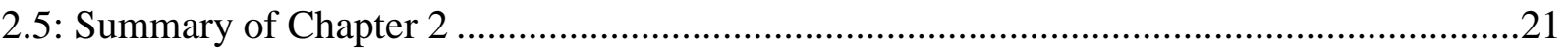

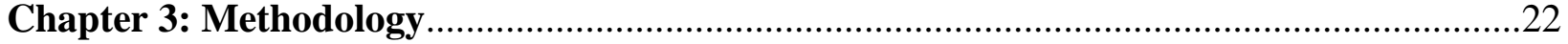

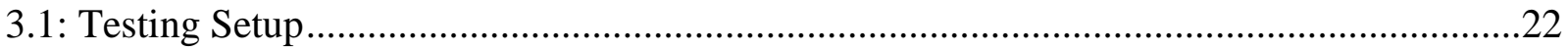

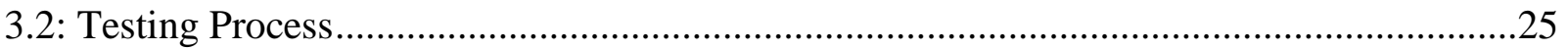

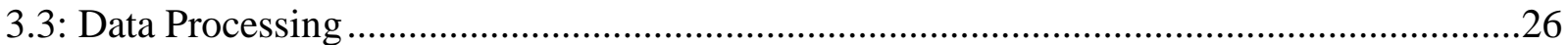

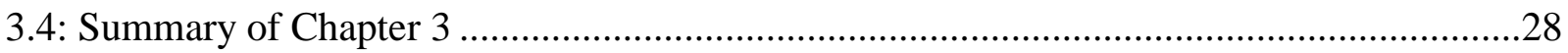

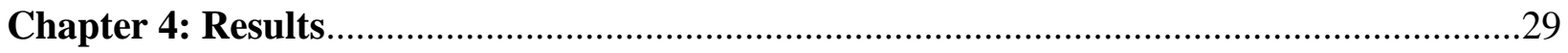

4.1: Results Compared to Baseline and Percent Error .......................................................30

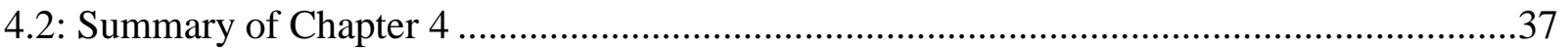

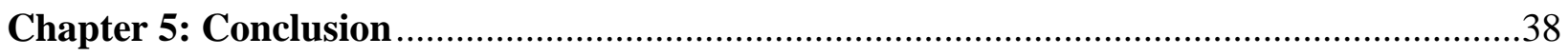

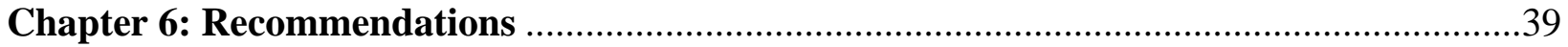

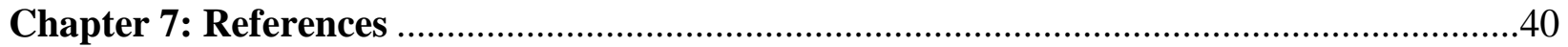

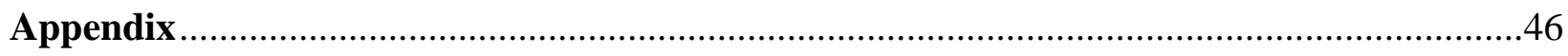

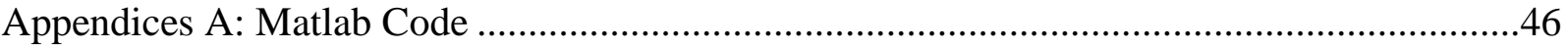

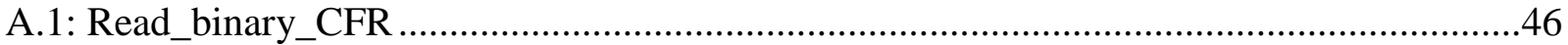

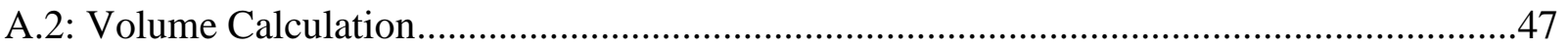

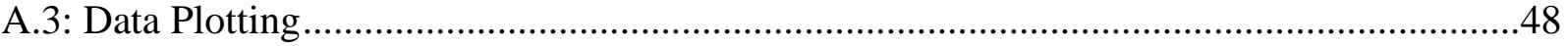




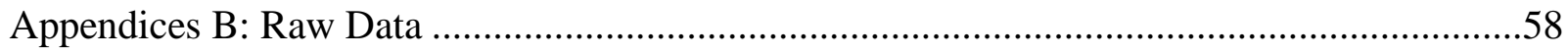

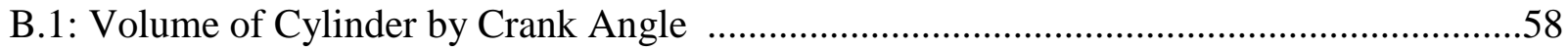

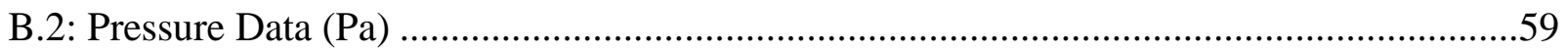

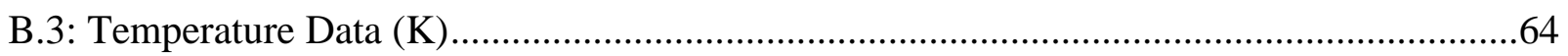

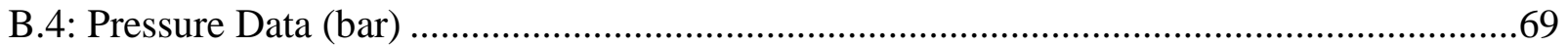

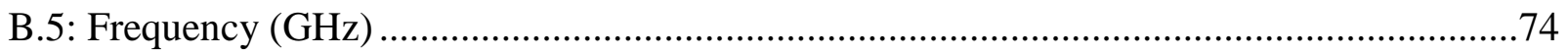

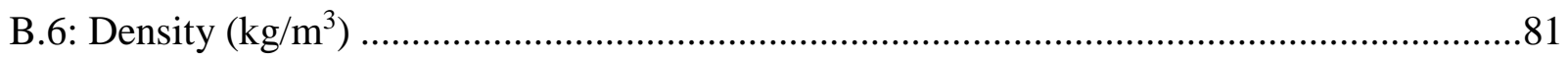




\section{List of Figures}

Figure 1: Cylinder Pressure (Pa) vs Crank Angle (degrees) ...................................................... 5 Figure 2: Figure 3 from US 5,361,737, Radio frequency coaxial cavity resonator as an ignition

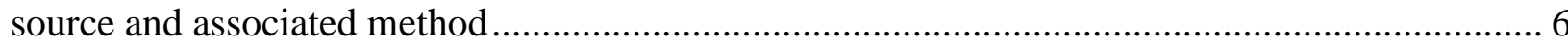

Figure 3: Diagram from U.S. 7,721,697 B2, 25 May 2010 of new form of apparatus .................. 7

Figure 4: Diagram from US 8783220 B2, 22 Jul 2014, showing the component breakdown ....... 8 Figure 5: Diagram from US 8887683 B2, 18 Nov 2014, showing the folded cavity that permits the coaxial caivty resonator to resonate at a lower operating frequency than the unfolded varient

Figure 6: Diagram from US Patent 20150287574, 8 October 2015, showing the dual signal

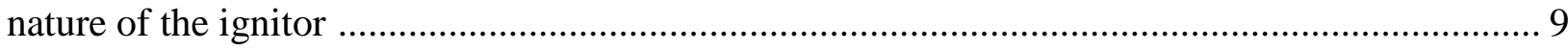

Figure 7: QWCCR Plasma Igniter .................................................................................. 10

Figure 8: Diagram from US Patent 20140226252, 14 August 2014, showing how the control

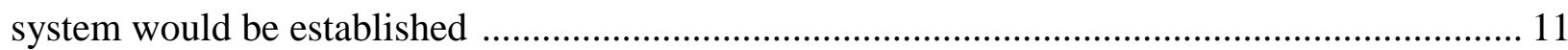

Figure 9: Diagram from US Patent 8217560 B2, 10 July 2012, showing the structure of the ignition device 12

Figure 10: Diagram from US Patent 8767372 B2, 01 July 2014, showing the general structure and compenents that is outlined in the patent 12 Figure 11: Diagram from US Patent 8226901 B2, 24 July 2012, showing general structure of ignition device

Figure 12: Diagram from US Patent 8638540 B2, 28 January 2014, showing the compnents of the corona igniter including the ignition coil................................................................... 15 Figure 13: Diagram from US Patent 8839752 B2, 23 September 2014, showing the magnetic screening 16 Figure 14: Diagram from US Patent 8839753 B2, 23 September 2014, showing the electrode gap

Figure 15: Diagram from US Patent 8844490 B2, 30 September 2014, showing the wider shell gap.

Figure 16: Example plot of temperature vs. normalized operating frequency ……………….... 20

Figure 17: Example plot of pressure vs. normalized operating frequency .................................. 20

Figure 18: Example plot of temperature vs. pressure vs. normalized operating frequency ......... 21

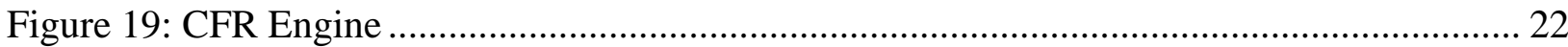

Figure 20: Plasma Igniter in CFR engine connected via n-type cable....................................... 23

Figure 21: Network analyzer, signal generator, and oscilloscope ………………...................... 24

Figure 22: Plot of Baseline Pressure (Pa) vs Change in Crank Angle........................................ 29

Figure 23: Plot of Baseline Frequency and Resonant Frequency from network analyzer vs

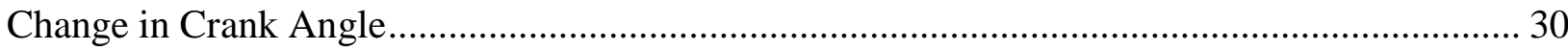

Figure 24: Percent error between experimental frequency and baseline frequency ..................... 31

Figure 25: Plot of baseline density and density calculated from the frequency ……………....... 32

Figure 26: Percent error between experimental density and baseline density ............................... 33 
Figure 27: Plot of Baseline Pressure and Baseline Frequency, and Baseline Pressure and Experimental Frequency vs Crank Angle .......................................................................... 35

Figure 28: Plot of Baseline Density and Baseline Frequency, and Experimental Density and Experimental Frequency vs Crank Angle ..................................................................... 37 


\section{Nomenclature}

\begin{tabular}{|c|c|c|}
\hline$\Gamma$ & reflection coefficient & N/A \\
\hline$\varepsilon_{0}$ & free-space permittivity & $(\mathrm{F} / \mathrm{m})$ \\
\hline$\varepsilon_{\mathrm{r}}$ & relative permittivity & $(\mathrm{F} / \mathrm{m})$ \\
\hline$\varepsilon_{\mathrm{rN}}$ & permittivity of gas/vapor under standard temperature and pressure & $(\mathrm{F} / \mathrm{m})$ \\
\hline$\theta$ & temperature & $(\mathrm{K})$ \\
\hline$\theta_{\mathrm{N}}$ & standard temperature & $(\mathrm{K})$ \\
\hline$\lambda$ & wavelength & $(\mathrm{m})$ \\
\hline$\mu_{0}$ & free-space permeability & $(\mathrm{H} / \mathrm{m})$ \\
\hline$\mu_{\mathrm{r}}$ & relative permeability & $(\mathrm{H} / \mathrm{m})$ \\
\hline$\rho$ & material specific resistivity & $(\Omega / \mathrm{m})$ \\
\hline$\rho$ & magnitude of reflection coefficient & N/A \\
\hline$\varphi$ & phase & $\left({ }^{\circ}\right)$ \\
\hline$\omega$ & angular frequency & $(\mathrm{rads} / \mathrm{s})$ \\
\hline $\mathrm{C}$ & capacitance & (C) \\
\hline $\mathrm{c}_{0}$ & speed of light & $(\mathrm{m} / \mathrm{s})$ \\
\hline$f$ & frequency & $(\mathrm{Hz})$ \\
\hline$f_{r}$ & resonance frequency & $(\mathrm{Hz})$ \\
\hline $\mathrm{J}$ & joules & $(\mathrm{J})$ \\
\hline $\mathrm{L}$ & inductance & $(\mathrm{H})$ \\
\hline $\mathrm{n}$ & number of moles & $(\mathrm{mol})$ \\
\hline $\mathrm{P}$ & pressure & (bar, $\mathrm{Pa}$ ) \\
\hline$P_{f}$ & time-varying forward power & $(\mathrm{W})$ \\
\hline $\mathrm{P}_{\mathrm{N}}$ & standard pressure & (bar) \\
\hline
\end{tabular}




$\begin{array}{lll}\mathrm{P}_{\mathrm{r}} & \text { time-varying reflected power } & (\mathrm{W}) \\ \mathrm{R} & \text { gas constant } & \left(\mathrm{J} / \mathrm{K}^{*} \mathrm{~mol}\right) \\ \mathrm{R} & \text { resistance } & (\Omega) \\ \mathrm{R}_{0} & \text { standard resistance } & (\Omega) \\ \mathrm{SWR} & \text { standing wave ratio } & \mathrm{N} / \mathrm{A} \\ \mathrm{SWR}\left(\mathrm{f}_{0}\right) & \text { standing wave ratio at the operating frequency } & \mathrm{N} / \mathrm{A} \\ \mathrm{v} & \text { velocity } & (\mathrm{m} / \mathrm{s}) \\ \mathrm{V} & \text { volume } & \left(\mathrm{m}^{3}\right) \\ \mathrm{V}_{\mathrm{I}} & \text { voltage of incident signal } & (\mathrm{V}) \\ \mathrm{V}_{\mathrm{R}} & \text { voltage of reflected signal } & (\mathrm{V}) \\ \mathrm{VSWR} & \text { voltage standing wave ratio } & \mathrm{N} / \mathrm{A} \\ \mathrm{X}_{\mathrm{C}} & \text { impedance of capacitor } & (\Omega) \\ \mathrm{X}_{\mathrm{L}} & \text { impedance of inductor } & (\Omega) \\ \mathrm{Z}_{\mathrm{I}} & \text { impedance of incident signal } & (\Omega) \\ \mathrm{Z}_{\mathrm{R}} & \text { impedance of reflected signal } & (\Omega)\end{array}$




\section{Acknowledgments}

There are many people I would like to thank that have helped to make this research a possibility.

I'd like to thank my advisor and committee chair Dr. James E. Smith for his support and constant push for my success and betterment. A great deal of opportunities have been presented to me because of my academic relationship with him. And for these I am very grateful. I feel that we have come to know each other quite well through this experience. We've come to know each other's strengths and weaknesses and how to overcome the latter. I look forward to continuing my education, in my pursuit for a doctorate, and my career under the direction of Dr. Smith.

I'd also like to thank Dr. Andrew Lowery. As office mates I often find myself looking to him for help and guidance. Drew's help in the setup, testing process, and data analysis of this research was invaluable. I look forward to working on many more projects with him in the future.

I also want to thank Dr. Roy S. Nutter. He was one of my professors during my undergraduate degree in electrical engineering. I've always found him to be a very helpful and intelligent individual. I look forward to a continued professional relationship.

I'd like to thank the Center for Alternative Fuels Engines and Emissions (CAFEE) for allowing me access to their CFR engine. Specifically I'd like to thank Ross Ryskamp and Jackson Wolfe. They both played pivotal roles in the testing process of this research. Jackson was there to run the CFR engine to allow the collection of data. And Ross was there to help answer my never ending stream of questions.

I'd also like to thank my partner in life, Nikole. We've been through so much together and I look forward to everything yet to come. You've helped get me through this whole process. I appreciated everything you do for me and us.

Finally, I'd like to thank my mom and dad. They have been the ever needed support to help me fulfill my dreams. I love you both dearly and do my best to make you proud. 


\section{Chapter 1: Introduction}

The Quarter-Wave Coaxial Cavity Resonator (QWCCR) Plasma Igniter is a novel microwave plasma source replacement for a spark plug for internal combustion engines. [1] [2] [3] In a previous series of ignition tests at Wright Patterson Air Force Base this system was proven to provide faster and more complete combustion of unique gaseous mixtures than that of a standard spark ignition system. [4] The other important attribute of the QWCCR is its potential ability to act as a diagnostics tool. The fundamental aspect that allows for diagnostic capabilities is the physical and electro-magnetic characteristics of the coaxial cavity resonator.

In previous publications of this technology the system was primarily mentioned for ignition purposes. These publications did not adequately address the ability of this system to be used as a tool for in-cylinder engine sensing and diagnostics. In these internal combustion engine applications the coaxial cavity resonator is acting as an antenna and has the ability to probe the combustion chamber and react to changes in pressure, temperature, impedance, volume, etc. prior to combustion, during the entire combustion process, and after the coronal discharge has ceased. Since the QWCCR is a dynamic system, when used in an engine environment, this diagnostic information can be useful throughout the engine-cycle process.

The coaxial cavity resonator takes the form of a quarter wave structure. This allows it to be used as a step-up amplifying device to increase the electric field potential. The separating factor between this system and other coaxial cavity systems is these other systems are typically closed loop systems. The QWCCR is an open loop system allowing for it to be sensitive to the local environment. This allows the system to sense changes in pressure, temperature, etc. in the engine environment. All of these factors affect the operation and performance of the QWCCR. Small changes in the combustion environment will have a measureable effect on impedance and resonance frequency. Similarly, changes to the input of the resonator, such as frequency and power delivered, will affect the combustion process and diagnostic capabilities.

1.1: Research Objective: The objective of this research is to prove that the Quarter-Wave Coaxial Cavity Resonator Plasma Igniter can be used as an in-cylinder diagnostics tool by establishing a relationship between in-cylinder pressure and the resonant frequency that can be used to predict the events occurring in the combustion chamber.

\section{2: Summary of Chapter 1}

The QWCCR plasma igniter is an alternative to a spark plug in an ignition system. With the innate capability of being a resonator it is responsive to changes in its operational environment. These changes can be tracked and mapped to be used for diagnostic purposes. There is a relationship that can be shown that relates frequency and in-cylinder pressure. This dependent relationship is the bases for this research. 


\section{Chapter 2: Literature Review}

This chapter is a literature review of the QWCCR Plasma Igniter and other resonator cavity ignition systems. It first goes through a basic introduction to spark ignition starting from the first spark plug. The next section goes into depth the QWCCR Plasma Igniter, how it works and what makes it unique for this diagnostics purpose. The following section reviews other resonator cavity ignition systems in order to show that this has not previously been tested as an aspect of other systems. These sections review patents and published works on these technologies. The last sections go through the science and equations relating to the operation of the QWCCR.

\section{1: Introduction of Spark Ignition}

Power is what moves things. Without the production of power there would be no electricity, automobiles, or air travel. The most abundant way of generating power is to burn or ignite a fuel source. These combustible fuels drive turbines for the creation of electricity or in the case of an automobile an internal combustion engine.

Fossil fuels are a concentrated organic compound. They are used to generate steam, electricity and power automobiles.

Edwin Drake's successful extraction of oil at his well in northwestern Pennsylvania in 1859 marked the dawn of the age of petroleum. Petroleum's first decisive impact was displacing whale oil in lighting in the late 19th century. But it was the victory of the internal combustion engine over steam and electricity as the preferred means to propel the recently-invented automobile in the first decade of the 20th century that thrust petroleum into the prominence it still enjoys today. Fueled by gasoline made from inexpensive and readily available oil, internal combustion cars, notes Alan P. Loeb, "alone offered a combination of speed and power, range and infrastructure that gave motorists the ability to achieve the automotive purposes they desired." [5]

Fossil fuels are the most cost effective and abundant source of fuel creating power, available today. It is this reason that they are the most common fuel used to produce power. The energy released from burning fossil fuels is what is used to drive turbines and engines. In the case of turbines it is used to create steam, and in the case of engines it is used to drive pistons.

The spark plug is essential to providing the initial energy to ignite the fuel in spark-ignited engines. Edmond Berger invented the first spark plug, on February 2, 1839. Etienee Lenoir, however, was the first to use a spark plug in an internal combustion engine. Others creating early patents for spark plugs included Nikola Tesla (1898) [6], Frederick Richard Simms (1898) [7], 
and Robert Bosch (1898) [8]. The spark plug has been in continuous use since its first inception, although the demand of its use has changed.

The automotive industry has been faced with the demanding task of satisfying new emissions standards. There are multiple ways that these issues are being addressed. The one that will be focused on in this review will deal with the spark ignition system. It is known, that currently with standard spark plugs, it is not possible to achieve complete combustion in most cylinder applications. Also the pollutants that are required to be eliminated, or minimized, include unburnt hydrocarbons, carbon monoxide $(\mathrm{CO})$, nitrous oxides $\left(\mathrm{NO}_{\mathrm{x}}\right)$, and sulfur oxide $\left(\mathrm{SO}_{\mathrm{x}}\right)$. All of these pollutants are the result of combustion or the incomplete combustion of fuels.

In order to comply with these new emission standards spark plug manufacturers are attempting to modify or reinvent the spark plug to achieve maximum efficiency and improved combustion. These manufacturers are going about this in a number of ways, from focusing mainly on the modification of already existing spark plug designs to laser ignition and plasma ignition systems. It is these latter advanced technologies that this review will focus on.

For this experiment the engine used will be a four-stroke engine. This four-stroke process is comprised of the intake, compression, power, and exhaust cycles. Specifically this will focus on the compression and power strokes, these are centered on top-dead-center.

In order to verify the forthcoming results engine data from Zweiri is shown for the pressure in relation to crank angle. These results are from a single cylinder engine where top-dead-center is at $360^{\circ}$. [9]

The following graph shows the cylinder pressure in relation to crank angle, with top-dead-center in this case being at $360^{\circ}$. 


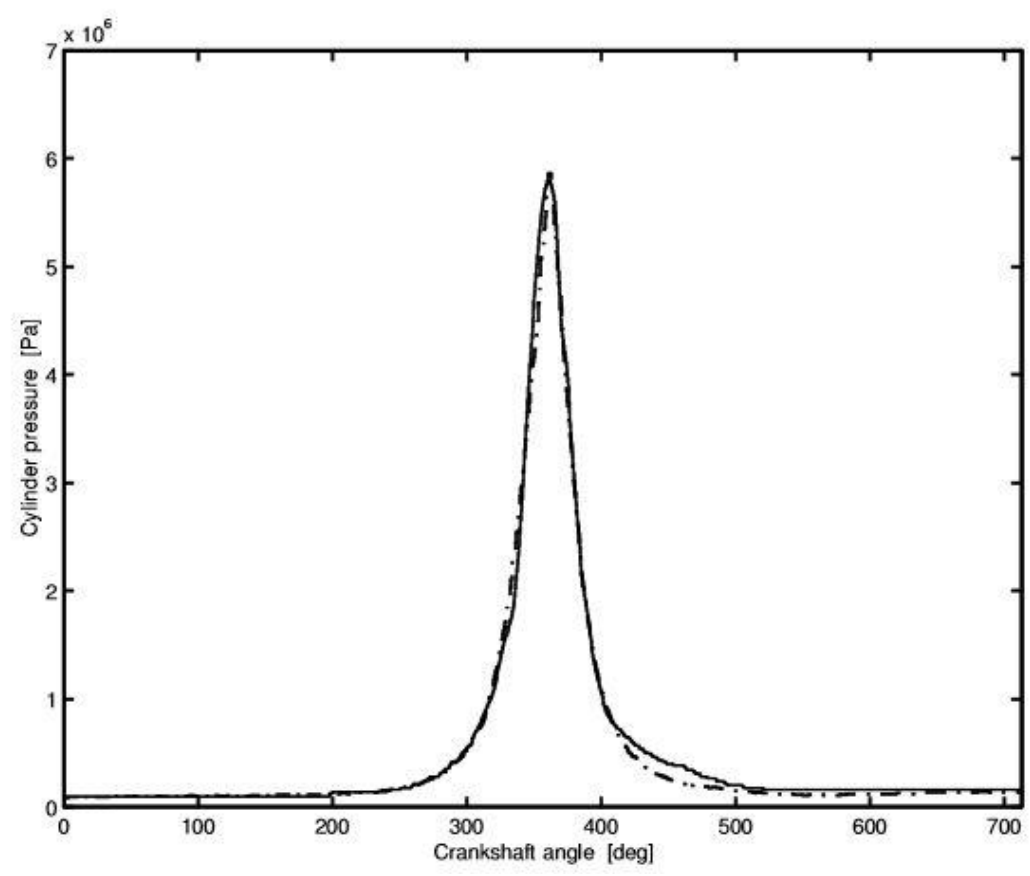

Figure 1: Cylinder Pressure (Pa) vs Crank Angle (degrees)

This is a typical pressure curve versus crank angle for a four-stroke engine during the compression and power strokes.

\section{2: Review of QWCCR}

The original patent for the QWCCR (U.S. 5,361,737, 08 November 1994) and documentation covered the invention of the apparatus of having a radio frequency oscillator, an amplifier, and a coaxial cavity resonator for the purpose of providing an ignition source to an internal combustion engine. The system is also adaptable for communication with the combustion chambers. The system provides a large plasma compared to that of a conventional spark plug. This plasma is created by using a radio frequency voltage and amplifying it, this is then resonated in the coaxial cavity in order to produce the plasma. [10] [11] [12] 


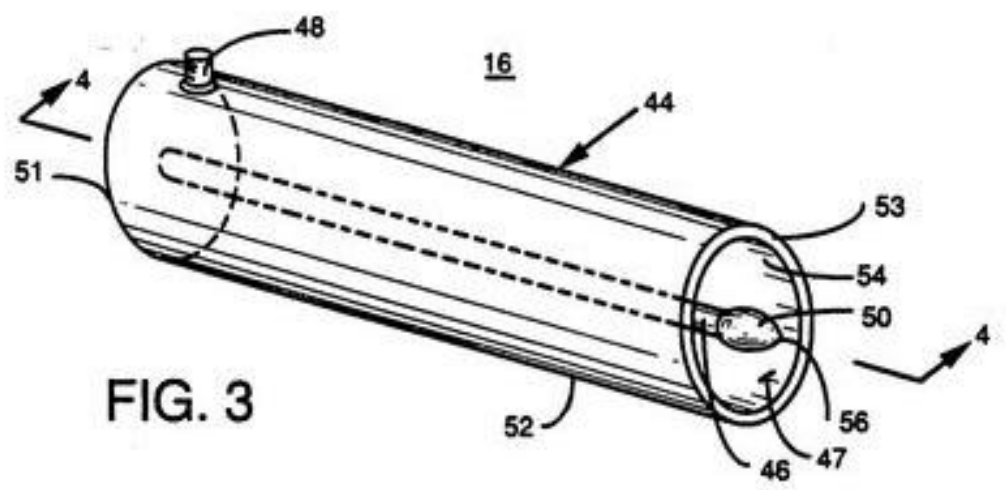

Figure 2: Figure 3 from US 5,361,737, Radio frequency coaxial cavity resonator as an ignition source and associated method [12]

Subsequent documentation follows the development of the plasma igniter in its adaption to a quarter-wave coaxial cavity resonator. This quarter-wave structure allows it to magnify the electric field. The testing for this device showed that it could operate under ambient conditions. [13] A model was made of this system at the $820-900 \mathrm{MHz}$ frequency range. Further pressure testing showed that the device could generate plasma at the same operation pressures as a spark ignition system. [14] Based on the theoretical results from this model three identical igniters were created for engine testing. By testing these in an engine the optimal resonator geometry was determined and the first successful tests in an internal combustion engine were achieved in 2001. [15]

With successful testing several ways of improving the plasma igniter were developed. By adding a dielectric medium in the cavity with the correct dielectric properties the electromagnetic properties of the system could be modified. [16] [17]

From this point a feasibility analysis was conducted on the validity of this system to be used in Spark Ignition Engines. It was found that with some refinement it would be possible to provide the appropriate amount of energy necessary for automotive combustion purposes. [18]

Based upon prior testing and results a new patent (U.S. 7,721,697 B2, 25 May 2010) was created with this new knowledge of the system. [19] This patent covers the system more thoroughly describing in detail how the plasma is created from the radio frequency voltage and the coaxial cavity resonator. [19] A new high-level model of a pulsed microwave igniter is created based on the new designs. This model accounts for a simplistic plasma formation delay, a drop in resonance frequency as a result of plasma formation, and a subsequent change in the associated microwave reflection coefficient. Using this model a control system can be developed based on the variables. [20] 


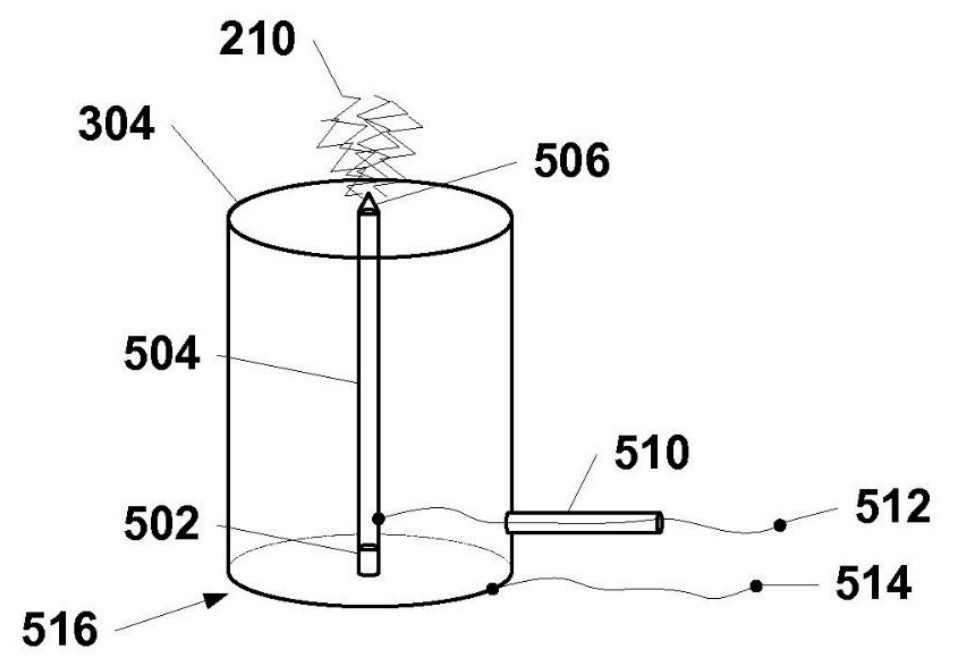

Figure 3: Diagram from U.S. 7,721,697 B2, 25 May 2010 of new form of apparatus [19]

Based on previous testing it has been shown that there is a significant environmental and economic benefit to using this system in an engine, because the system is able to operate at lean conditions. [4] The system also operates at a significantly lower energy requirement compared to that of a conventional spark ignition system. At $150 \mathrm{~W}$, a microwave pulse of $2 \mathrm{~ms}$ can deliver energy of close to $300 \mathrm{~mJ}$ at a large sustained average power level compared to with a convention spark plug. [21] [22]

At this time, 2009, there is a focus on applying the technology to a new geometry that is capable of use in a Briggs and Stratton 16-hp V-twin engine. An analysis is done on the geometric and material parameters in order to adapt the system to this purpose for further testing. [22] This new prototype was used with a Briggs and Stratton engine with Jet A fuel. The Briggs and Stratton is a single cylinder engine with a fuel injection system. Tests were performed to determine the cold-start temperature limit, the lowest temperature the engine could be repeatedly started. [23]

Two more patents (US 8783220 B2, 22 Jul 2014, US 8887683 B2, 18 Nov 2014) were filed in order to protect new designs and methods of operation. A new folded cavity for the resonator is protected as this allows the system to operate at a lower frequency than the previously unfolded cavity. [24] [25] The new compact design was presented to show that the new folded cavity quality factors are comparable to the previously tapered cavity designs. [26] [27] 


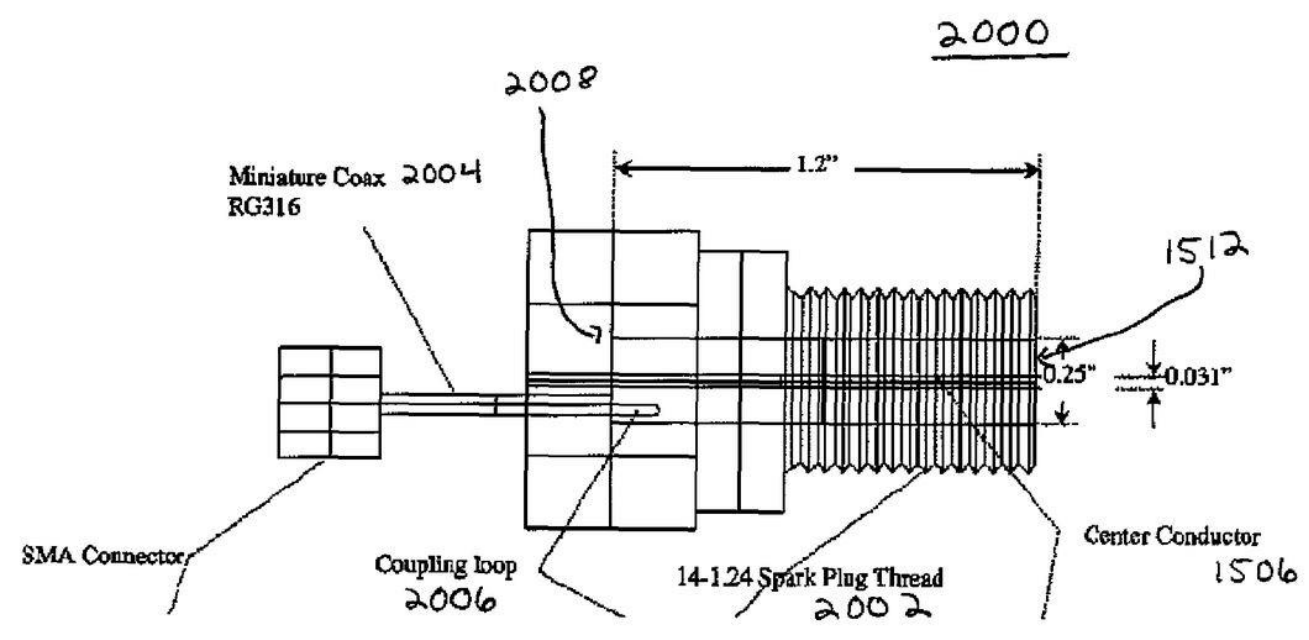

Figure 4: Diagram from US 8783220 B2, 22 Jul 2014, showing the component breakdown [24]

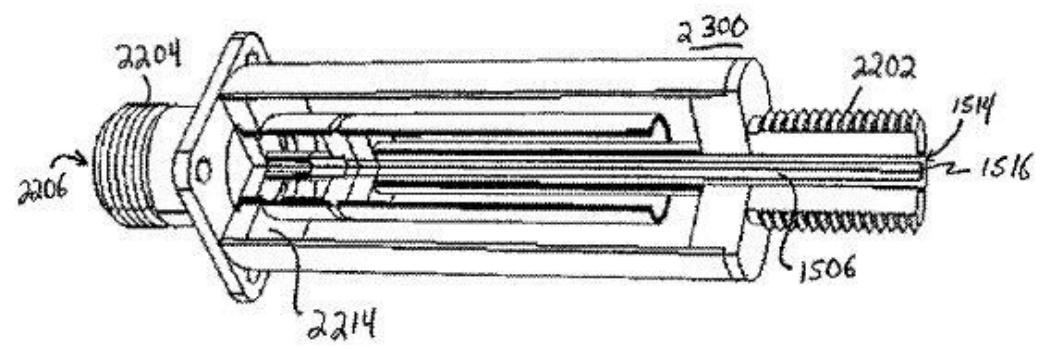

Figure 5: Diagram from US 8887683 B2, 18 Nov 2014, showing the folded cavity that permits the coaxial caivty resonator to resonate at a lower operating frequency than the unfolded varient [25]

The current iteration (US Patent 20150287574, 8 October 2015) of the plasma igniter involves the use of a dual signal. [28] This dual signal is composed of the radio frequency power source and a high voltage source that is used to step-up the total energy. This system allows the plasma igniter to operate at the $\mathrm{mJ}$ level since there is a minimal current present due to the nanosecond pulses. [28] 


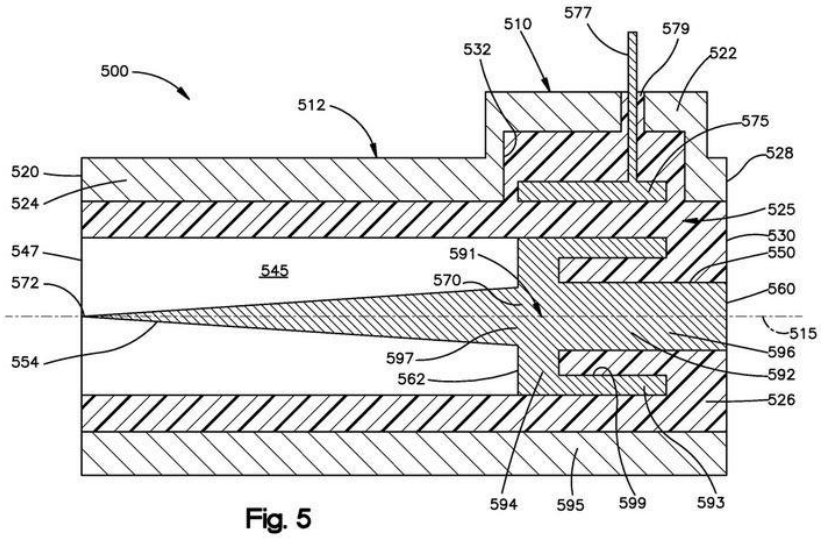

Figure 6: Diagram from US Patent 20150287574, 8 October 2015, showing the dual signal nature of the ignitor [28]

There is currently an active patent application concerning the diagnostics capabilities of this system. [29] This patent covers the use of the plasma igniter as an apparatus for igniting a combustible mixture that consists of a feedback module that is able to sense a condition in the combustion environment by measuring characteristics of the coaxial cavity resonator. This control is meant to process the feedback in order to modulate operation of the coaxial cavity resonator. 
The version of the plasma igniter that was used for these experiments can be seen in Figure 6.

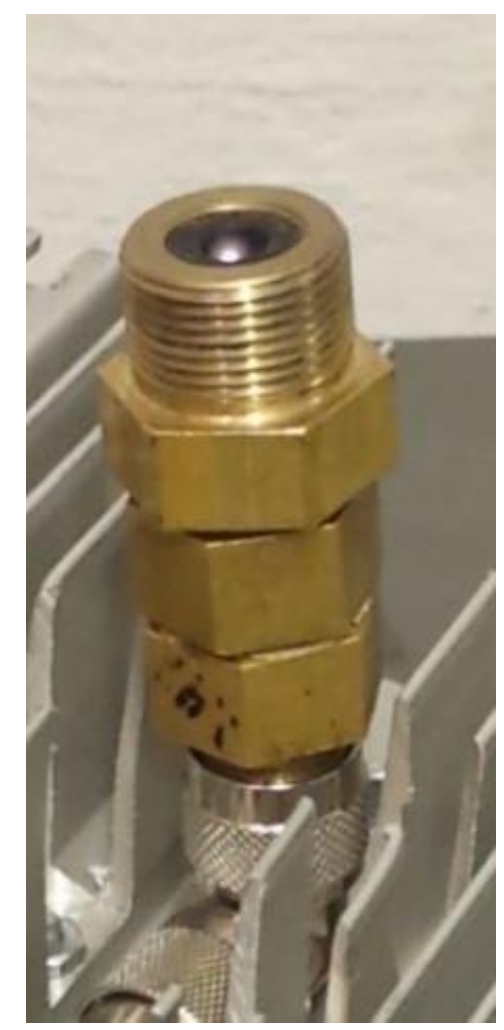

Figure 7: QWCCR Plasma Igniter

\section{3: Review of Other Plasma Ignition Systems}

The following are advanced ignition systems either in current development or production. This section will be a review of these systems and how they relate to this research.

System and method for generating and sustaining a corona electric discharge for igniting a combustible gaseous mixture

This system (US Patent 6883507, 26 Apr 2005) was developed by a company called Etatech. [30] The electric field in the combustion chamber is controlled such that the fuel-air mixture does not experience full dielectric breakdown producing a high current electric arc. This electric field is maintained high, but not high enough to cause complete dielectric breakdown. After the fuel-air mixture has been sufficiently ionized a flame front is developed to propagate throughout the chamber. This process is done by having a center electrode inside the combustion chamber being supplied by an electrical circuit that provides radio frequency power; a ground is established with the walls of the combustion chamber. This voltage differential produces a radio frequency electric field that causes the air-fuel mixture to ionize. [30] A control system (US Patent 8746218 B2, 10 June 2014, US Patent 20140226252, 14 August 2014) was also 
developed separately for this system. The control system consists of measuring the baseline impedance of the circuit with the electrode, the measuring of an actual impedance circuit, the determination of an impedance set point based on the baseline impedance, a comparison of the actual impedance to the impedance set point, and the adjustment of the actual impedance based on the comparison of the actual impedance and the impedance set point. [31] [32] [33]

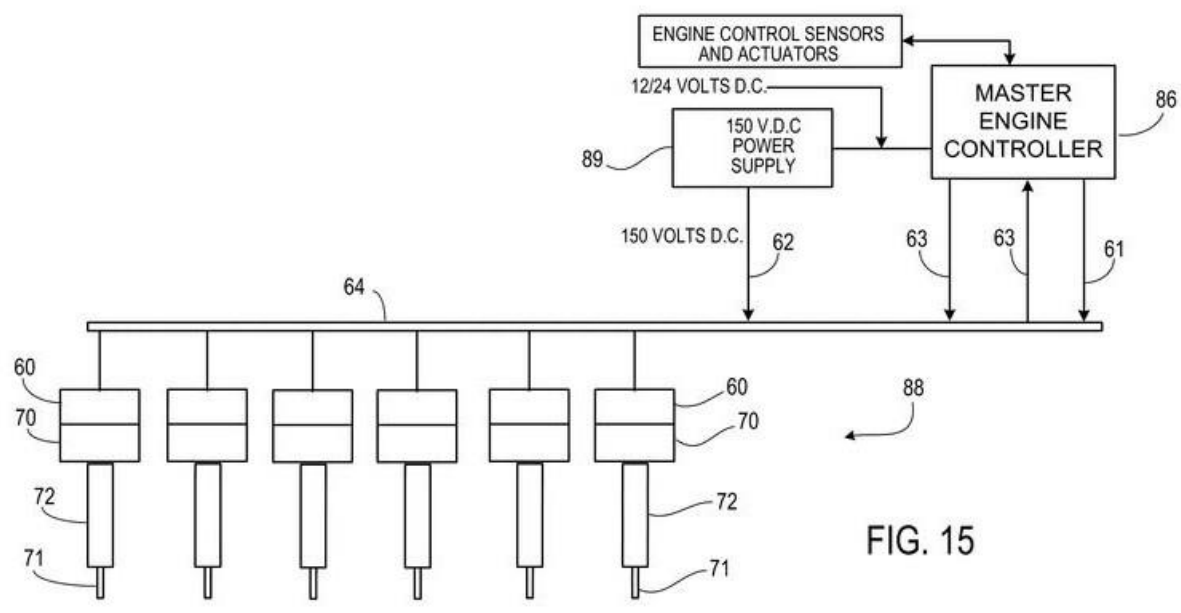

Figure 8: Diagram from US Patent 20140226252, 14 August 2014, showing how the control system would be established [31]

There is another related technology (US Patent 8217560 B2, 10 July 2012) developed by BorgWarner BERU developed by a different group. This technology is a corona ignition device for use in an internal combustion engine that consists of an ignition electrode, an outer conductor that surrounds the electrode, and an insulator between the electrode and outer conductor. The insulator and electrode protrude beyond the outer conductor. The electrode has a number of branches starting at its base. [34] 


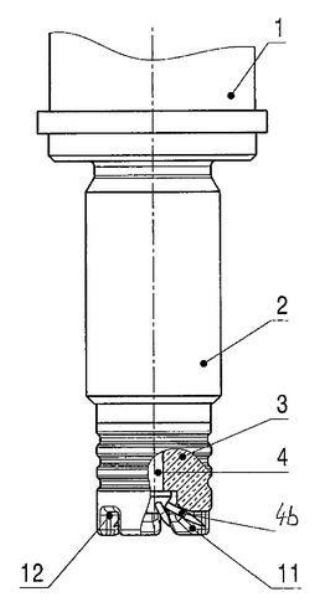

Figure 9: Diagram from US Patent 8217560 B2, 10 July 2012, showing the structure of the ignition device [34]

A high frequency ignition device was patented for use in an internal combustion engine (US Patent 20110146640 A1, 23 June 2011, US Patent 8550048 B2, 08 October 2013, US Patent 8767372 B2, 01 July 2014, US Patent 8860290 B2, 14 October 2014, US Patent 8857396 B2, 14 October 2014). The device consists of a center electrode, and insulating body around this center electrode, a metallic housing that has been threaded for insertion into an internal combustion engine, and an electrical circuit to provide HF excitation to the center electrode. The insulator is made of an electrically conductive coating. The HF for this system is to be at least one $\mathrm{MHz}$ and the voltage is to be a few $\mathrm{kV}$. [35] [36] [37] [38] [39]

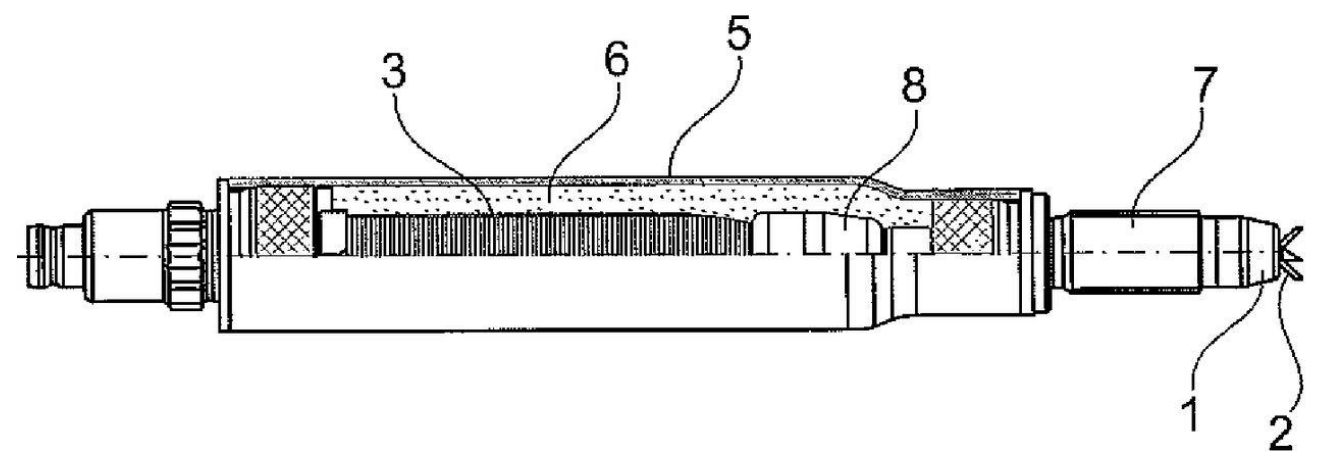

Figure 10: Diagram from US Patent 8767372 B2, 01 July 2014, showing the general structure and compenents that is outlined in the patent [34]

Ignition or plasma generation apparatus

This ignition system is designed to be installed without any modifications to the current engine system. [40] A plasma source is generated by a spark discharge; this is then expanded by radiating a microwave into the plasma. The way that this is generated causes a high electron temperature, but a low gas temperature. The frequency of the microwave is $2.45 \mathrm{GHz}$. This is 
also the frequency of a magnetron from a microwave oven. A spark plug with an antenna was developed in order to adapt the system without changing the current engine system. This antenna is made of tungsten wire and goes around the center electrode. Plasma was successfully generated with this system up to $1.0 \mathrm{MPa}$. When this system was tested against a standard SI system it was shown to start combustion earlier. [40] At an IMEP of $275 \mathrm{kPa}$, the plasma was able to increase the lean limit from 19.3 to 24.1. This system also reduced $\mathrm{CO}, \mathrm{CO}_{2}$, and $\mathrm{NOx}$ emissions as the airflow ratio was increased. This test was done in a single cylinder engine. [41]

This same system was then modified to be operable in a multi-cylinder engine system. This was done without modifying the combustion chamber. In order to adapt the system to be useable with a multi-cylinder system a mixer unit was developed. The mixer operated as a high-voltage and frequency isolator. The system once again showed improved initial combustion initiation. [42]

Patents (US Patent 8226901 B2, 24 July 2012, US Patent 20120258016 A1, 11 October 2012) were developed based on this technology. The first defines the system as having a center electrode that is supplied with energy from a spark discharge and microwaves in order to ignite an air-fuel mixture in an internal combustion chamber. This system includes the mixing circuit to combine the high-voltage pulse and the microwave energy, both of these coming from their respective generators. The nature of the mixing circuit causes the high-voltage pulse and the microwave energy to be superimposed upon each other on the same transmission line. [43] [44] The subsequent patent deals with the reflection of electromagnetic waves. The plasma generating device (U.S. application 20140041611) now includes an electromagnetic wave oscillator and a stub adjustment unit. The stub adjusts a short circuit location during engine operation based on the intensity of a reflected wave of the electromagnetic wave reflected from the antenna on the system. [45] 


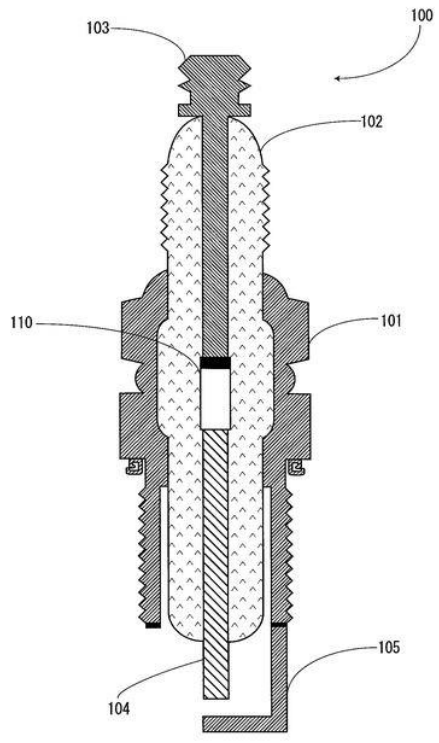

Figure 11: Diagram from US Patent 8226901 B2, 24 July 2012, showing general structure of ignition device [43]

Multi-event corona discharge ignition assembly and method of control and operation

This corona discharge fuel ignition system provides a corona discharge to ignite a fuel-air mixture with the purpose of reducing energy usage and costs compared to other corona discharge systems. The system consists of a power supply to provide radio frequency energy. The system uses pulses to provide the corona discharge. [46]

A corona discharge fuel igniter system and a control system for the long term operation of the system in a combustion environment were developed (US Patent 20120145136 A1, 14 June 2012). [46] The invention provides a corona discharge while incorporating the use of a specified insulator or dielectric material that increases the efficiency of the corona discharge in order to ignite fuel in a combustion environment. The dielectric material's purpose is to extend the life of the igniter system in a combustion environment. The igniter system uses radio frequency to produce the corona discharge. This RF voltage is passed through an electrical conductor to the tip of the igniter device. This conductor is surrounded by a ceramic dielectric material that provides efficiency to the corona discharge. The system also includes an inductor on the emission end of the igniter that increases the RF voltage. A dielectric material also surrounds this inductor. [47] In an attempt to suppress arc from forming when voltage is applied to the igniter various tip shapes were patented. Some of these shapes include angular depressions at the tip in multiple orientations. [48] A modification to the corona igniter's circuit was developed to add a self-tuning power amplifier. [49]

A subsequent patent (US Patent 8638540 B2, 28 January 2014) covers a corona igniter that is provided by a radio frequency electric field with the purpose to ionize a fuel-air mixture and create a corona discharge in the combustion chamber. This system consist of a housing, a coil 
inside the housing to receive energy as a voltage and transmit this energy at a higher voltage, an electrode that is electrically coupled to the coil to receive the energy and provide the RF field, and a coil filler that consists of a resin material with the purpose of reducing capacitance. [50]

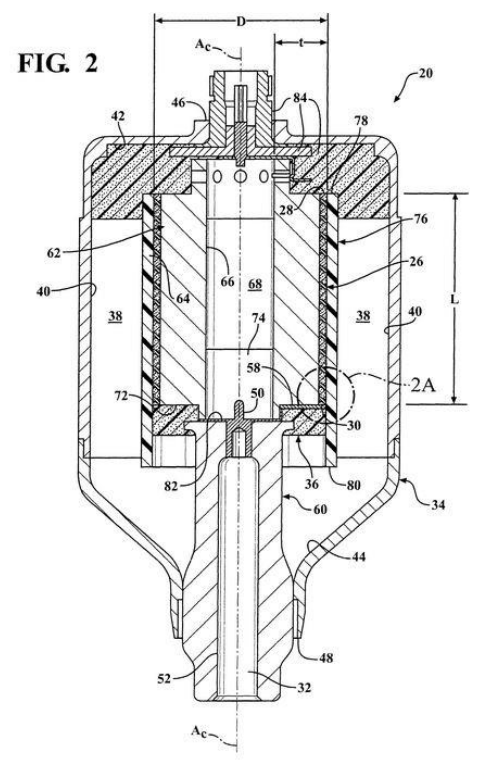

Figure 12: Diagram from US Patent 8638540 B2, 28 January 2014, showing the compnents of the corona igniter including the ignition coil [50]

The following patent (US Patent 8729782 B2, 20 May 2014) in the same series provides a corona ignition system that includes an electrode and insulator that extends along the electrode. [51]This electrode is formed from an electrically conductive material. The insulator contains a matrix of electrically insulating material on the firing end of the electrode. This insulator has the purpose of reducing and/or eliminating arcing during the use of the corona ignition system. The igniter creates controllable and repeatable non-thermal plasma that consists of multiple steams of ions in the form of a corona. This discharge is for the purpose of ignition of a fuel-air mixture with the benefits of improved fuel economy and reduced $\mathrm{CO}_{2}$ emissions. [51]

The next patent in this series (US Patent 8749945 B2, 10 June 2014) builds upon and changes the parts of the previous system. [52] This system consists of an electrode, a corona drive circuit, and an energy storage circuit. This drive circuit provides energy to the electrode to emit a discharge from the electrode. The energy circuit provided is a supplementary system to the drive circuit; it stores energy while the drive circuit is providing energy to the electrode, and after a discharge is detected continues to provide energy in order to maintain the arc discharge being created. This continuous maintenance of the arc discharge is to ensure a robust and reliable ignition. [52]

A following patent (US Patent 8776751 B2, 15 July 2014) provides specifications for the emitting tip to enhance corona discharge. This enhanced tip could be a wire, layer, or sintered mass that is made of a precious metal. This emitting tip is placed upon a base member that is 
made of a nickel alloy. The emitting member has a purpose of being more resistant to erosion and chemical corrosion than the base member. The emitting tip has a small spherical radius in order to concentrate and strengthen the electrical field that is emitted. [53]

Another patent (US Patent 8839752 B2, 23 September 2014) was made to provide this system with magnetic screening. This was achieved by including inductor windings between the housing, and an electric shield located between the housing and these inductor windings. The purpose of this was to prevent magnetic flux from emitting from the device. [54]

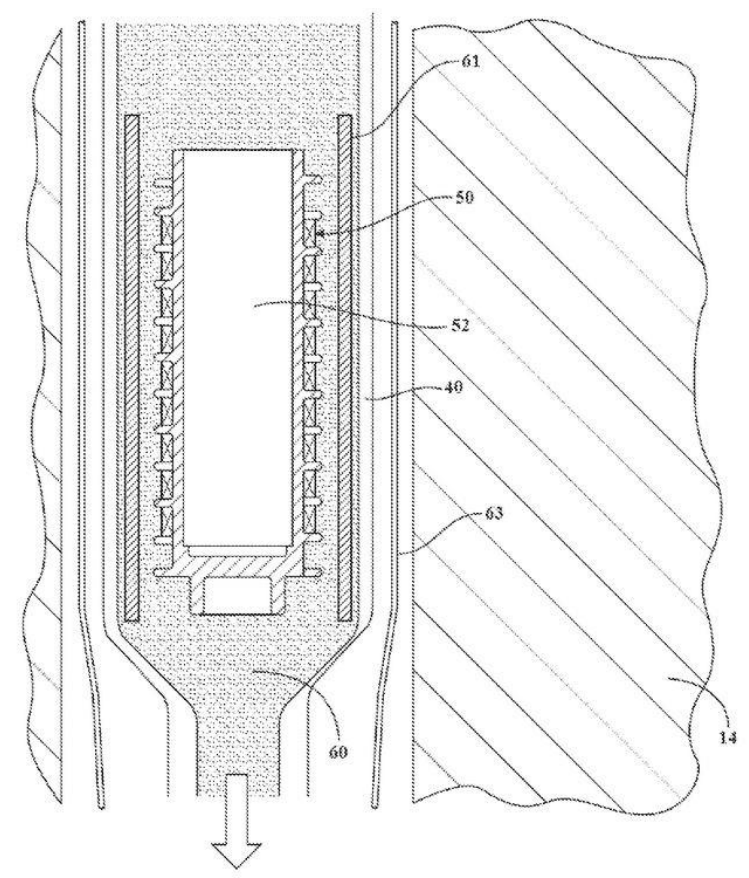

Figure 13: Diagram from US Patent 8839752 B2, 23 September 2014, showing the magnetic screening [54]

A patent (US Patent 8839753 B2, 23 September 2014) concerning the electrode gap further continues upon the structure of the corona igniter in this series. The center electrode is surrounded by an insulating material. There is a space between the electrode and the inner surface of the insulator that is the electrode gap. A shell of electrically conductive material is around the insulator. The space between the insulator and the shell is referred to as the shell gap. In either the electrode gap or the shell gap an electrically conductive coating is applied. These gaps and coatings are used to prevent ionized gas from forming and from a corona discharge being formed in these areas. The purpose is to ensure that a corona discharge is only created at the time of the ignition. [55] 


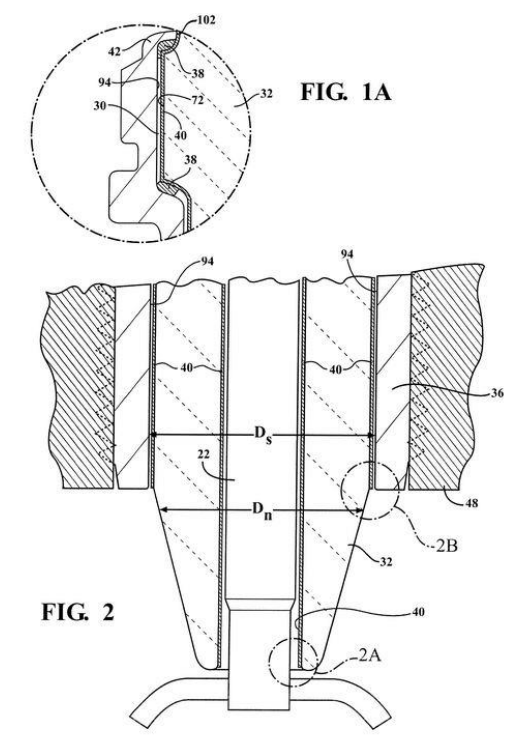

Figure 14: Diagram from US Patent 8839753 B2, 23 September 2014, showing the electrode gap [55]

A patent (US Patent 8844490 B2, 30 September 2014, US Patent 8749126 B2, 10 June 2014) was submitted changing this design to better control the location of the plasma, which consists of a wider shell gap. This wider shell gap is achieved by decreasing the thickness of the shell towards the emitting tip end of the corona igniter. This allows the flow of air into the shell gap. This process enhances the corona discharge along the insulator. [56] [57]

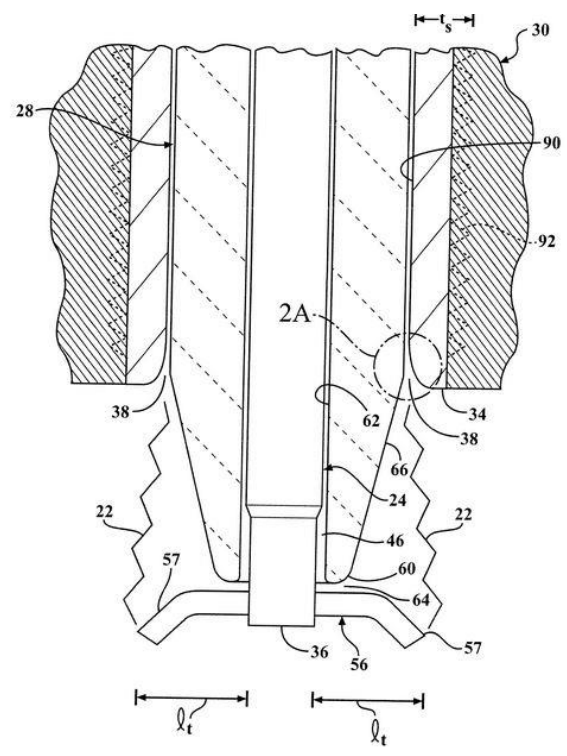

Figure 15: Diagram from US Patent 8844490 B2, 30 September 2014, showing the wider shell gap [56] 
A patent (US Patent 9010294 B2, 21 April 2015) that further builds upon this design changes the electrode so that it consists of a core made of a material such as copper that is clad to another material such as nickel. This core material consists of at least $90 \%$ of the electrode.

The purpose of this modification is to reduce the temperature of the system. [58] This continues to build upon the series of patents in order to prevent the formation of a conductive path between the central electrode and the shell. This is done by adding an abruption extending radially from the center electrode. This abruption increases the thickness of the insulator. The abruption changes the electric field and voltage potential gradient in the shell gap, thus preventing the formation of a conductive path. [59]

Another adjustment to the system (US Patent 9088136 B2, 21 July 2015) was made in order to improve the electrical performance. This electrical performance was achieved by adding an intermediate conductive component between the outer conductive shell and the insulator. [60] An asymmetric firing tip is added to the system. This tip is noted by having one surface area with a sharp edge, and a second surface area having a rounded edge. This sharp area faces the fuel injector, while the round edge faces the cylinder block. This orientation makes it so the corona discharge is emitted from the sharp edge facing the fuel injector. This makes it so there is no arcing occurring between the tip and the cylinder block. [61]

None of these ignition systems provide in-cylinder diagnostics. There are also no currently available systems that can be used for combustion and provide in-cylinder diagnostics in a single system. 


\section{4: Resonators - Frequency, Temperature, Pressure}

There is a fundamental principle in physics that links frequency, propagation velocity, and wavelength. [62] This can be expanded to compare the propagation velocity to that of light in a vacuum. This can further be expanded to include propagation through various mediums:

$$
f_{o}[\mathrm{~Hz}]=\frac{v[\mathrm{~m} / \mathrm{s}]}{\lambda[\mathrm{m}]}=\frac{v[\mathrm{~m} / \mathrm{s}]}{\lambda[\mathrm{m}] \sqrt{\mu_{0} \mu_{r} \varepsilon_{0} \varepsilon_{r}}}=\frac{c_{0}[\mathrm{~m} / \mathrm{s}]}{\lambda[\mathrm{m}] \sqrt{\mu_{r} \varepsilon_{r}}},
$$

where, $\mathrm{f}$ is the operating frequency, $\mathrm{v}$ is the wave velocity, $\lambda$ is the wavelength, $\varepsilon \mathrm{r}$ and $\varepsilon_{0}$ are the relative and free-space permittivity, respectively, and $\mu_{\mathrm{r}}$ and $\mu_{0}$ are the relative and free-space permeability, respectively, and $\mathrm{c}_{0}$ is the speed of light in a vacuum.

This model assumes for the vacuum case that permittivity and permeability of the medium are fixed, time-invariant values. This is not true in an internal combustion engine, where the pressures and temperatures vary with respect to time and the varying positions of the piston, which is affected by the crank angle, in the cylinder during the combustion cycle. The permittivity can thus be modified so that it includes time-varying pressures and temperatures: [63]

$$
\varepsilon_{r}(\theta, P, t)=1+\left[\varepsilon_{r_{N}}\left(\theta_{N}, P_{N}\right)-1\right] \cdot \frac{\theta_{N}[\mathrm{~K}] \cdot P(t)[\mathrm{bar}]}{\theta(t)[\mathrm{K}] \cdot P_{N}[\mathrm{bar}]}
$$

where, $\varepsilon_{r}$ is the calculated permittivity, $\varepsilon_{r N}$ is the permittivity of gas/vapor under standard temperature and pressure, $\theta$ and $P$ are the process temperature and pressure, respectively, and $\theta_{N}$ and $P_{N}$ are standard temperature and pressure.

Most gaseous fuels are non-magnetic, or in rare cases they are paramagnetic. In both of these cases the contribution towards $\mu_{r}$ is close to unity so for this study it will be assumed to be negligible.

This time varying model can be substituted into (1) in order to achieve a time-varying frequency that is dependent on the process temperature and pressure:

$$
f_{o}(\theta, P, t)=\frac{c_{0}}{\lambda \sqrt{1+\left[\varepsilon_{r_{N}}-1\right] \cdot \frac{\theta_{N} \cdot P(t)}{\theta(t) \cdot P_{N}}}}
$$

The following figures were created using a Matlab code created by Dr. Andrew Lowery to show the change in temperature vs. operating frequency for a fixed pressure, $P_{N}(1)$, and pressure vs. frequency for a fixed temperature, $\theta_{N}(2)$. [64] The third figure shows a surface curve of 
temperature vs. pressure vs. frequency over the predicted operating conditions in a combustion environment.

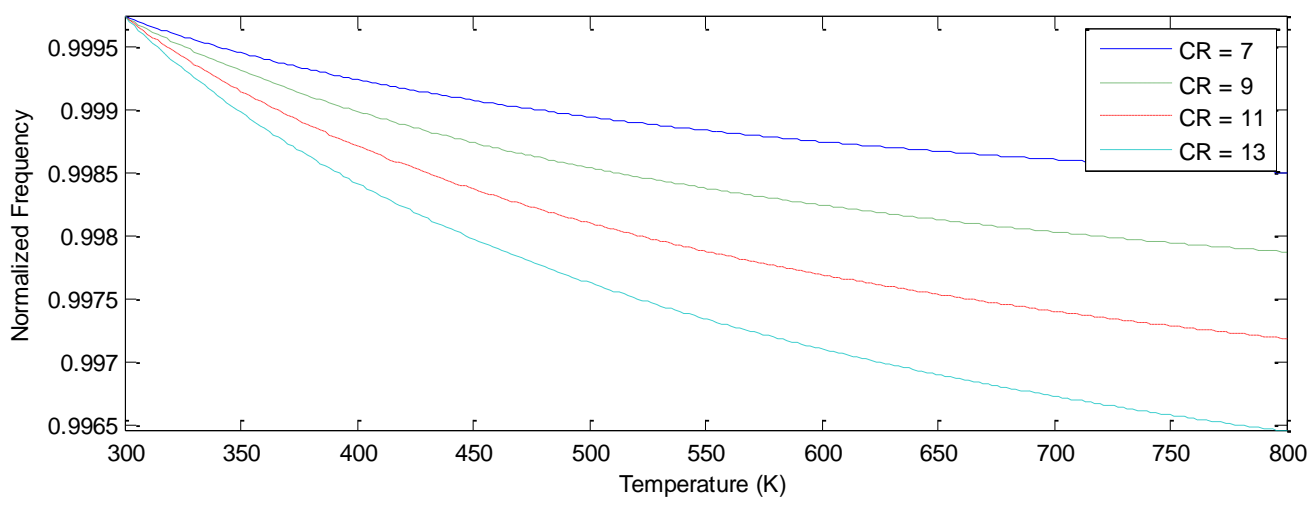

Figure 16: Example plot of temperature vs. normalized operating frequency [64]

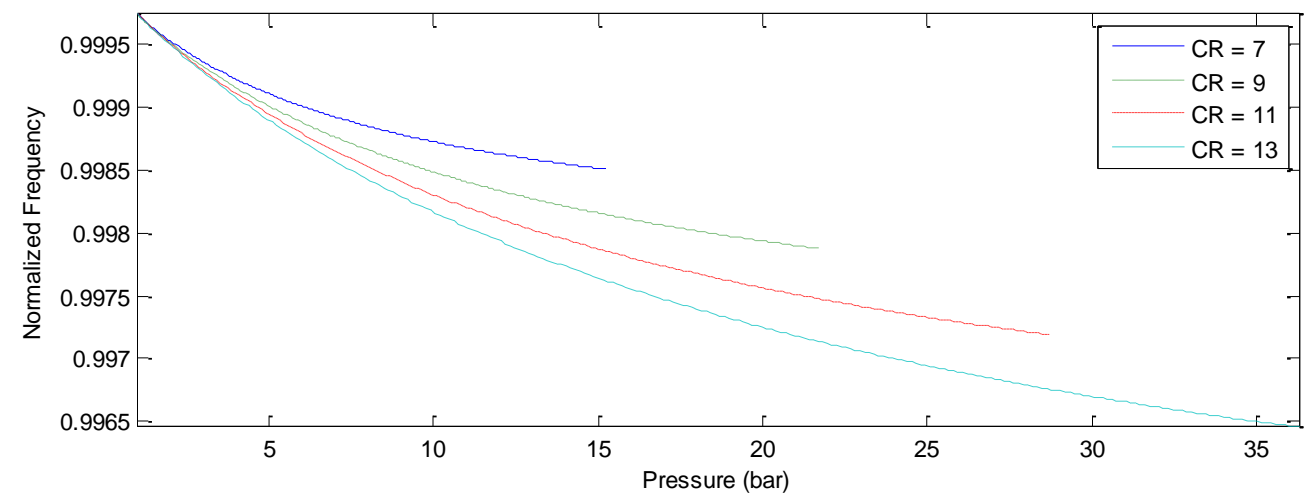

Figure 17: Example plot of pressure vs. normalized operating frequency [64] 


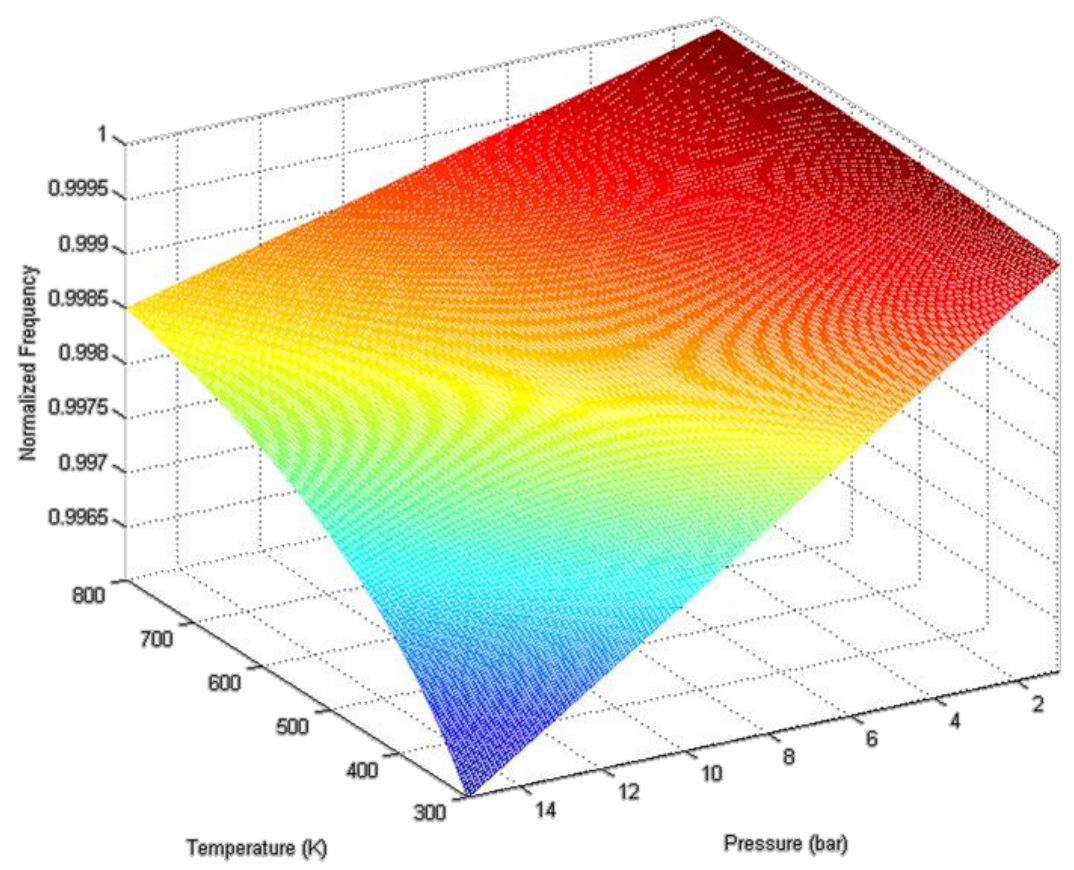

Figure 18: Example plot of temperature vs. pressure vs. normalized operating frequency [64]

It should be noted that continuity exists between all points of temperature and pressure. This demonstrates that knowing one data set, such as an initial set of conditions, the process can be tracked across the entire range of operation.

\section{5: Summary of Chapter 2}

Through reviewing the documentation on the QWCCR a better understanding of how the system works and where it is going in the future is established based on current patent applications. The transition to a dual signal plug allows for it to be operated at lower energies, because of the high voltage signal that is now being used to step up the radio frequency. This takes away the need for large power supplies and moves the system closer to being integrated into an engine. There is currently a provisional patent that is associated with covering the diagnostic capabilities of the QWCCR.

By reviewing other advanced ignition systems including plasma and corona, it can be shown that no other current technologies are utilizing a resonator device for diagnostic purposes. Some of these systems are utilizing the radio frequency power that the QWCCR uses. Because of this the systems should be able to create similar plasma to that of the QWCCR, but will not be able to do so at the same efficiency due to the lack of the dual signal, and more importantly not be able to operate at the high compression ratios of an internal combustion engine.

The QWCCR holds the unique advantage over all other in-cylinder diagnostics tools as it requires no additional modifications in order to perform diagnostics. 


\section{Chapter 3: Methodology}

The following testing was completed in cooperation with the Center for Alternative Fuels Engines and Emissions (CAFEE) at West Virginia University. This testing was done in order to collect data to show the relationship of the pressure and temperature of the engine and the resonant frequency of the QWCCR with respect to the engines crank angle. The CFR engine was chosen for this process because it is a simple, single cylinder engine that the crank angle for data collection can be set. This was necessary to collect the frequency data as the sweep needed to be trigger to collect data only at the specified crank angle.

\section{1: Testing Setup}

The plasma ignition system was integrated into the spark plug port on the Cooperative Fuel Research (CFR) engine and connected to a HP 8753 network analyzer. The trigger from the incylinder pressure computer was imported into the network analyzer in order to sync the data collection. This trigger needed to be boosted in order for the network analyzer to properly receive the signal; this was done by running the signal through a signal generator in order to boost it. The plasma igniter was connected to the analyzer via an n-type cable.

The network analyzer was calibrated out to the n-type cable prior to testing using the n-type 50ohm calibration kit.

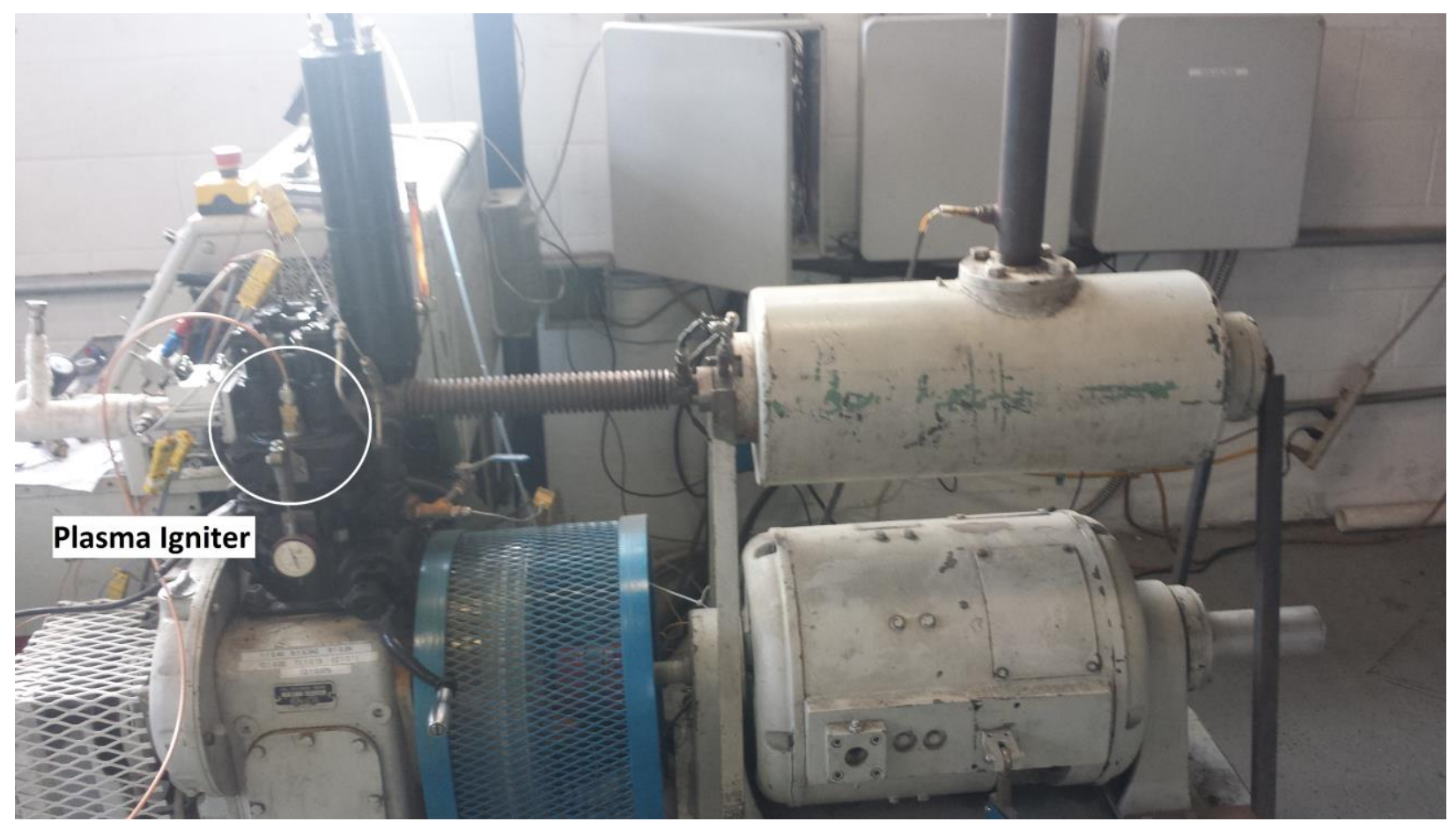

Figure 19: CFR Engine 
This figure shows the plasma igniter inserted into the spark plug port on the CFR engine.

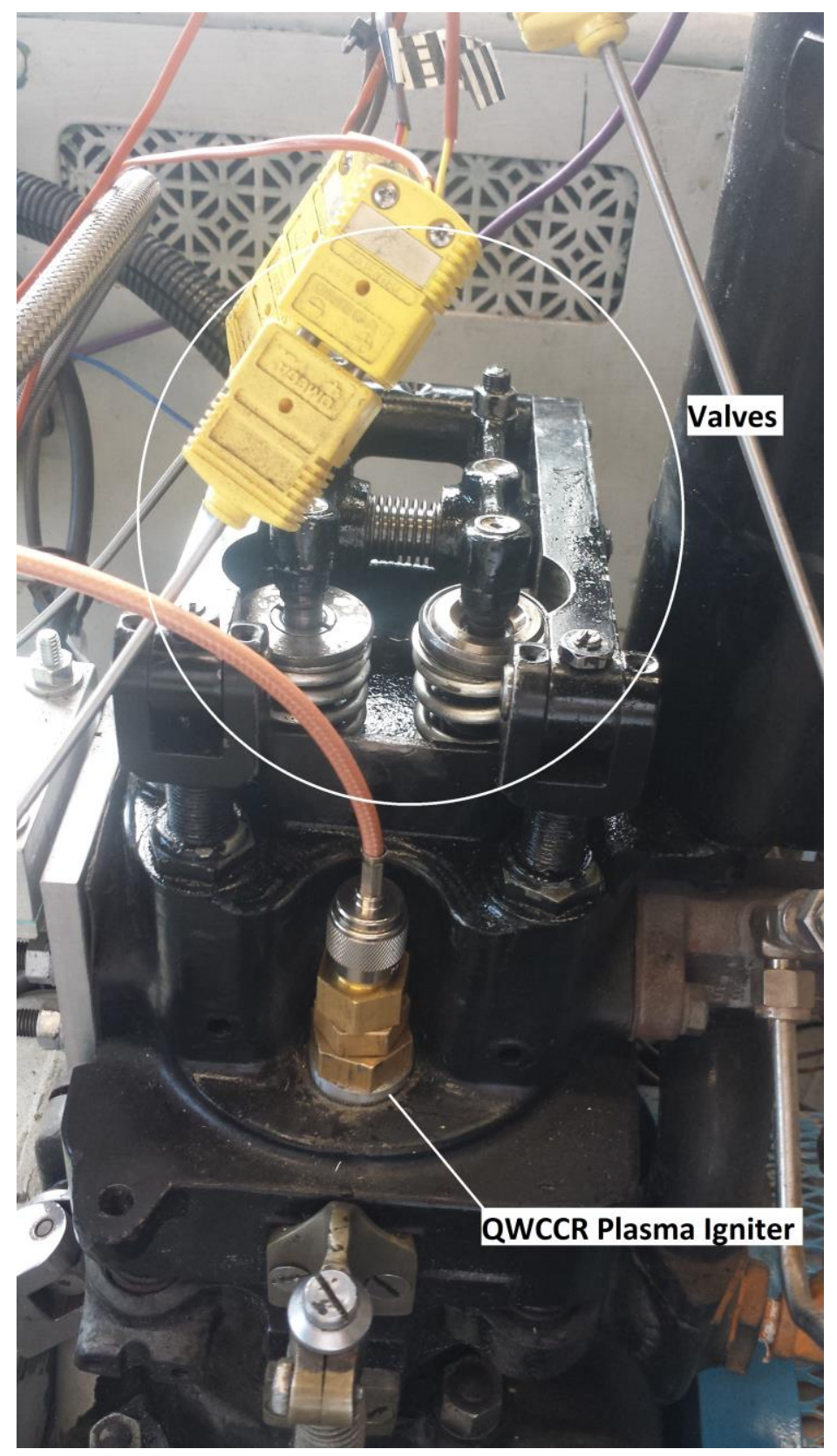

Figure 20: Plasma Igniter in CFR engine connected via n-type cable

This figure provides an up close view of the plasma igniter in the CFR engine. Also in this picture a closer view of the valves has been provided. 


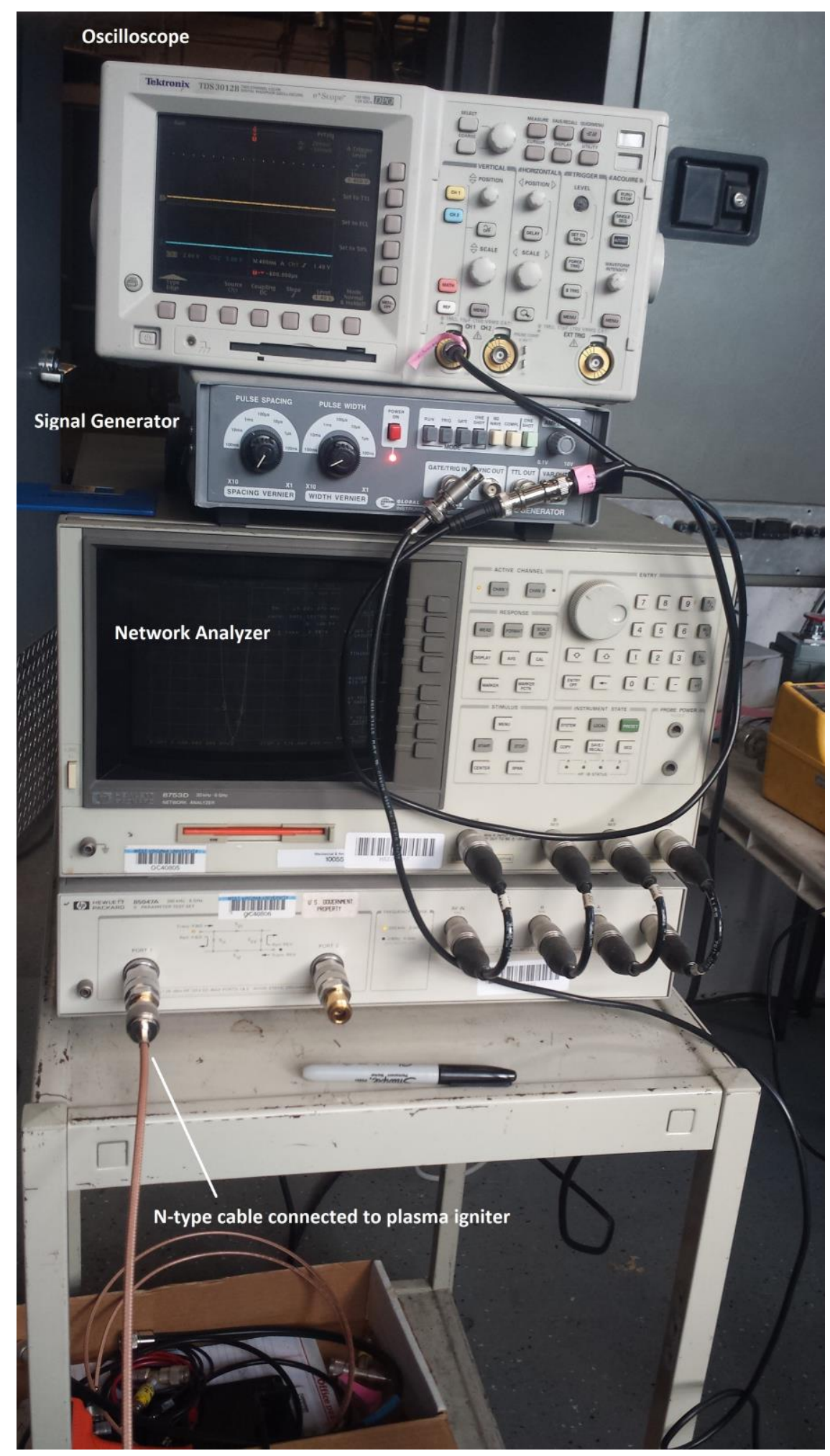

Figure 21: Network analyzer, signal generator, and oscilloscope

This figure shows the other components in the test set up consisting of the Tektronix TDS 3012B two channel color digital phosphor oscilloscope, the Global Specialties 4001: 5 MHZ ultra- 
variable pulse generator, that is being used as a trigger, and the HP 8753 network analyzer that the plasma igniter is connected to via the n-type cable.

\section{2: Testing Process}

In order to collect the needed data a data logger was used to collect the engine data and the network analyzer was used to collect the frequency data. The network analyzer was set to collect data at the desired crank angle set by the computer. It was able to collect these specific points because of the syncing of the triggers.

The data collection consisted of setting up the system as shown, setting the crank angle with the computer, and then having the analyzer perform a sweep. The network analyzer data collection settings were set prior to testing. The range of the sweep was between $2.39-2.53 \mathrm{GHz}$. This range was chosen because prior to this test the plug was examined using the network analyzer and this range covered the curve of the plug. The resolution used for this sweep was 201 data points. The sweep was saved as a data file onto a floppy disk. This data was then later imported into a Matlab file for processing.

The engine was set to run at approximately 500 RPM, with a compression ratio of 5:1. For the purposes of this validation testing no fuel was used in this test. All of the data collection was done with air as the only intake.

The data logger collected data throughout the entire testing process. This consisted of pressure, intake and outtake temperatures, and engine speed. The pressure data was collected from a piezoelectric sensor in the cylinder. [65]

The specific crank angles that were used for data collection were from $-180^{\circ}$ to $180^{\circ}$ at $10^{\circ}$ increments. This range of angles was chosen because they cover the range of the valves being closed. The compression process exhibits an almost sinusoidal structure, so the incrementation of the crank angle of $10^{\circ}$ is suited because this sinusoidal nature and be properly observed with this resolution. This $10^{\circ}$ incrementation provides a good handoff for data collection timing. In a fully implemented system the positions at which are sample could be set to certain degrees that show diagnostic significance or based on timing. This range and incrementation shows the minimums and maximums as well as showing the full broad spectrum.

These angles coincide with the compression and power stroke of the engine. Power stroke is an interesting range to have diagnostic capabilities. During the power stroke misfires and the completeness of fuel combustion can be observed.

All the data collected was in the form of data files that could be imported into spreadsheets. 


\section{3: Data Processing}

A Matlab file was used to calculate the volume of the cylinder based upon the crank angle and geometry of the engine cylinder. This can be found in appendices A:2.

The data collected from the data logger was in the form of text files, however, they were encrypted and needed to be decrypted with the use of a Matlab file, which can be found in appendices A:1. Data received from this file includes: engine speed, intake and exhaust temperatures, cylinder pressure, average temperature, and maximum temperature.

From the data logger in-cylinder pressure at the individual crank angles is determined. Intake and outtake temperature are included in the data collection, however, it is in-cylinder temperature that is desired. In order to calculate this in-cylinder temperature the ideal gas law equation was used:

$$
P V=n R T,
$$

where, $\mathrm{P}$ is the pressure in Pascal's, $\mathrm{V}$ is the volume in $\mathrm{m}^{3}, \mathrm{n}$ is the amount of the substance of gas in moles, $\mathrm{R}$ is the ideal gas constant, and $\mathrm{T}$ is the temperature of the gas in kelvin

The pressure at each crank angle is used, along with the volume at the crank angle. The gas constant $R$ is given as $8314 \mathrm{~J} / \mathrm{K}^{*}$ mol. In order to find the amount of moles (n) the pressure at atmospheric, the volume at $-180^{\circ}$, the gas constant, and the average intake temperature were used. These parameters were chosen as this would determine the amount of air in the cylinder for the testing process. The elevation in Morgantown, WV is $961 \mathrm{ft}$., this gives a local atmospheric pressure of $97855.31426 \mathrm{~Pa}$. The average intake temperature was $288.6613419 \mathrm{~K}$. The $\mathrm{n}$ calculated $\left(2.73 \mathrm{E}^{-5} \mathrm{~mol}\right)$ was considered to be constant, as the amount of gas in the cylinder would not change for this experiment as there was no combustion present. This was deemed to be a good starting point for diagnostics in an ideal situation as there was to be no combustion. And this takes in the assumption that the valves do not leak holding the moles of the gas to be constant.

After establishing the constants $\mathrm{n}$ and $\mathrm{R}$, the temperature was calculated at each crank angle from the pressure at each crank angle and the volume of each crank angle.

A baseline was created for pressure from this data. The average at each crank angle was used for this baseline.

From this pressure and calculated temperature the frequency could be calculated. The following equation shown early as (Equation 3 ) was used:

$$
f_{o}(\theta, P, t)=\frac{c_{0}}{\lambda \sqrt{1+\left[\varepsilon_{r_{N}}-1\right] \cdot \frac{\theta_{N} \cdot P(t)}{\theta(t) \cdot P_{N}}}}
$$


The speed of light is $299792458 \mathrm{~m} / \mathrm{s}$ which was used for $\mathrm{c}_{0}$. The wavelength was calculated based upon the resonant frequency previously determined with the network analyzer, this value was $2.45 \mathrm{GHz}$. The resulting wavelength was $0.122364268571429 \mathrm{~m}$. The dielectric constant for air is $1.00059 \mathrm{~S} / \mathrm{m}$. The sub $\mathrm{n}$ components represent standard conditions, in this case the initial conditions used for the calculation of $\mathrm{n}$ were used, intake temperature and the air pressure (bar) at elevation. The sub t components represent the experimental pressure and temperature.

This equation allows for the calculation of frequency from the in-cylinder pressure previously found. This data was also calculated for every crank angle allowing for the establishment of a frequency baseline. These data sets and baseline are plotted along with the frequency data collected from the network analyzer in the following results section.

From the pressure data the density can also be found by modifying the ideal gas law equation:

$$
\rho_{\text {baseline }}=\frac{P}{R * T},
$$

The frequency data from the network analyzer was also in the form of text files. These individual files for each crank angle were imported into excel and combined. The data is initially imported as SWR. The minimum SWR is used to find the resonant frequency for each sweep.

The data from the baseline was compared to that of the experimental frequency to calculate percent error:

$$
\% \text { error }=\left|\frac{\#_{\text {experimental }}-\#_{\text {baseline }}}{\#_{\text {baseline }}}\right| * 100,
$$

Once again using a previous equation (Equation 3) the relationship between pressure and frequency can be explored to find experimental density:

$$
f_{o}(\theta, P, t)=\frac{c_{0}}{\lambda \sqrt{1+\left[\varepsilon_{r_{N}}-1\right] \cdot \frac{\theta_{N} \cdot P(t)}{\theta(t) \cdot P_{N}}}}
$$

The same initial parameters are used as were used in calculating the frequency from the pressure data. The ratio of $\frac{P(t)}{\theta(t)}$ is found so that it can be used to find the experimental density.

$$
\rho_{\text {experimental }}=\frac{P(t)}{\theta(t)} * \frac{1}{R^{\prime}}
$$

With the baseline pressure, baseline frequency, crank angle, and experimental frequency a 3-D plot can be created. 


\section{4: Summary of Chapter 3}

This section showed the experimental setup, data collection process, and how the data was processed. The setup consisted of the CFR engine, the QWCCR Plasma Igniter, and the equipment needed to collect the data including the data logger and the network analyzer. The collection process explains how the crank angle was set with the computer allowing the network analyzer to perform a sweep at each individual crank angle. The data processing section walks through all the information necessary to process the data into useful information, including the values for specific variables and equations used. From this data plots were created to display the results, which can be seen in the following section. 


\section{Chapter 4: Results}

In this chapter the results will be discussed in detail. A baseline was established for pressure, temperature, and frequency from the data in order to show the consistency of the data collected. Percent error is calculated by comparing the results from individual data runs versus this baseline. The final portion of this chapter will present graphs from another study that tracked similar results for pressure and temperature in relation to crank angle. [9]

\section{1: Results Compared to Baseline and Percent Error}

The object of this study was to establish a connection between the parameters of an engine and the resonance frequency across the crank angles of the engine.

This first plot (Figure 21) shows the change in pressure with respect to crank angle that was collected from the data logger.

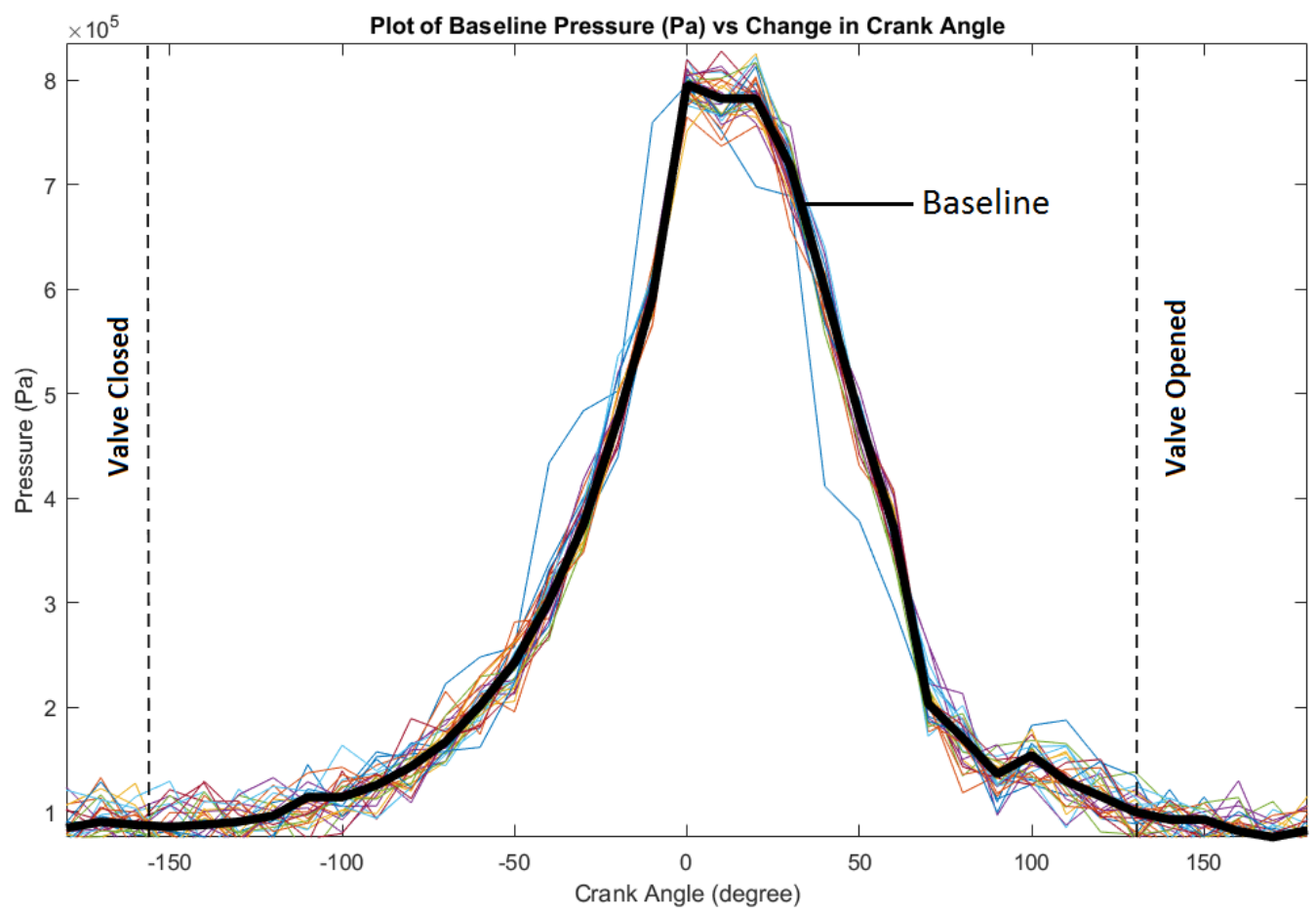

Figure 22: Plot of Baseline Pressure (Pa) vs Change in Crank Angle

The established baseline is shown in black. The two vertical dashed lines show the crank angles where the valves close and open, -156.5 and 130.5. Data outside these lines is susceptible to error, as the cylinder is not fully sealed. The dip at the peak of the pressure curve can also be explained by these valves. This CFR engine is an older system, and its age, wear and tear can be shown by the valves leaking at the peak pressure. 
This next plot (Figure 23) shows the frequency calculated from the pressure the frequency collected from the network analyzer.

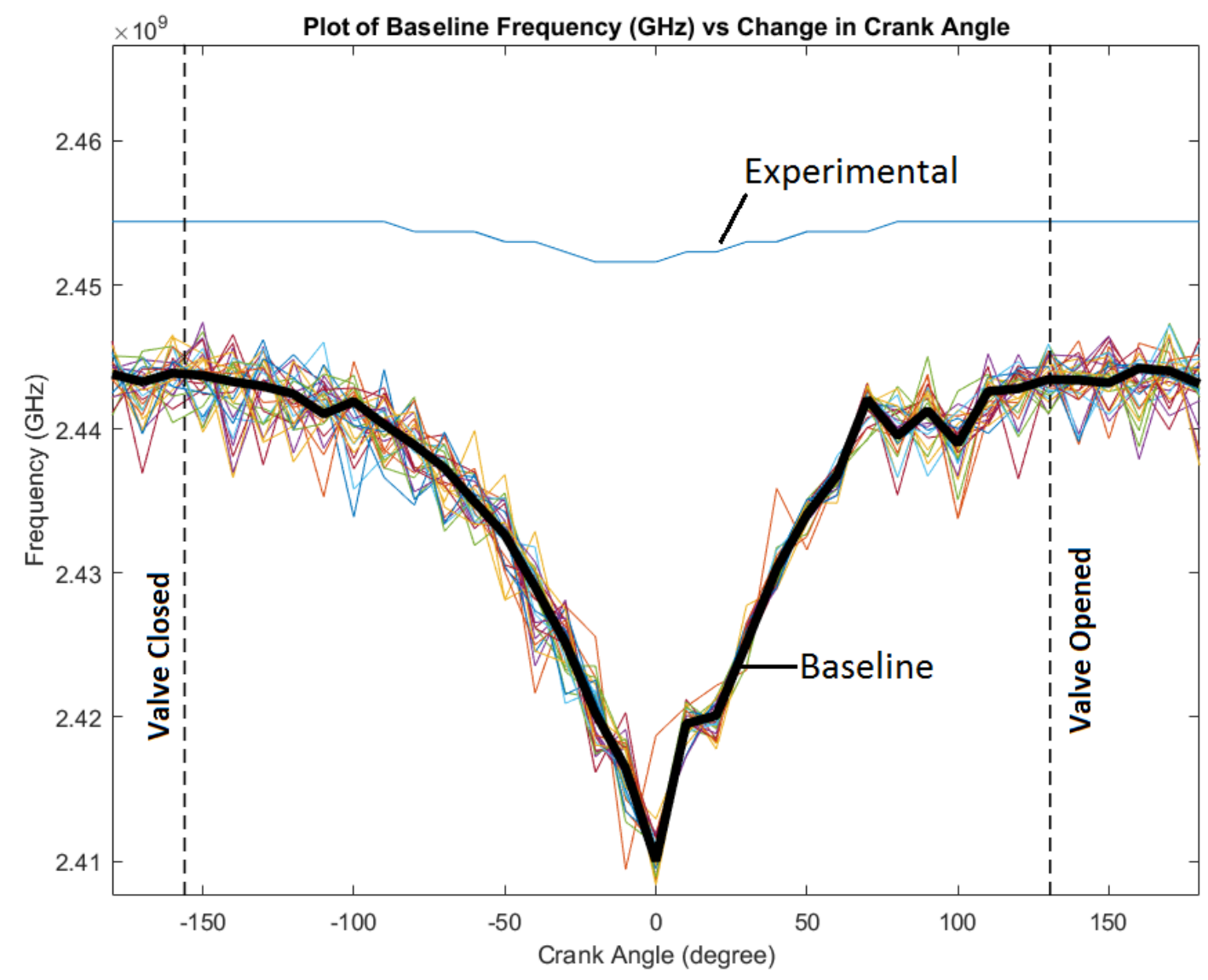

Figure 23: Plot of Baseline Frequency and Resonant Frequency from network analyzer vs Change in Crank Angle

The baseline frequency calculated from the pressure data is shown in black. The frequency from the network analyzer is shown as the blue line. The frequency collected from the network analyzer was found to be discretized, this is due to the number of points selected for the sweep on the network analyzer. This could be improved by increasing the number of points in the sweep.

The next plot (Figure 24) shows that based on the pressure a frequency can be found that is at all points less than $1.725 \%$ error of the resonant frequency found with the network analyzer. However this does not tell the whole story, because of the need to take into account the resonator properties. These two curves do not fall within a $3 \mathrm{~dB}$ bandwidth. This difference would not allow the QWCCR to operate properly; it could not achieve the conditions necessary for ignition. 
There is a clear offset between the two curves of approximately $10 \mathrm{MHz}$. Using this method it can be shown that the resonance frequency can be found during this portion of the engine cycle. Things that cannot be found are the $3 \mathrm{~dB}$ bandwidth, the Q, SWR, and the various power measurements.

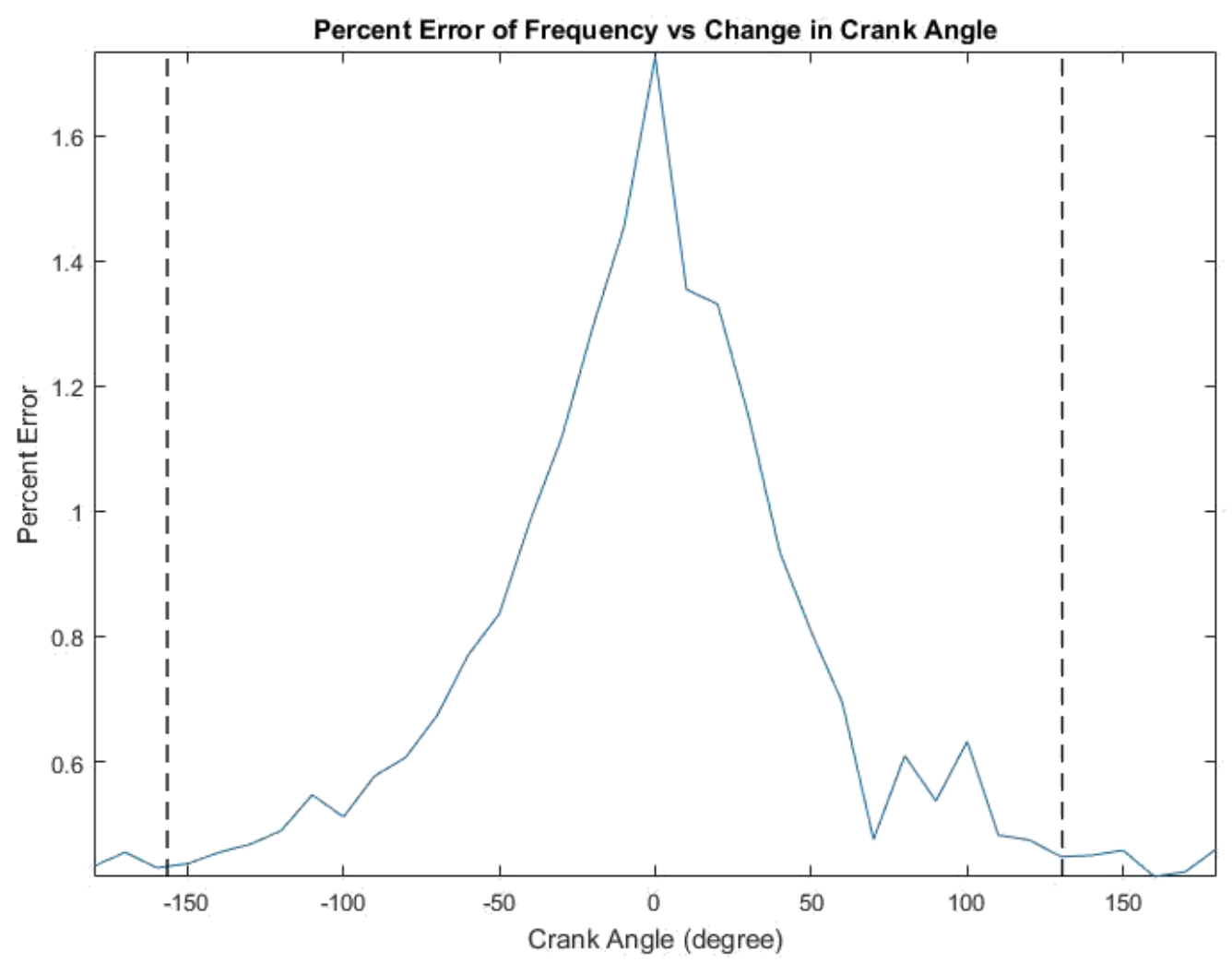

Figure 24: Percent error between experimental frequency and baseline frequency

The next plot (Figure 25) shows the density calculated from the pressure and the density calculated from the frequency found by the network analyzer. 


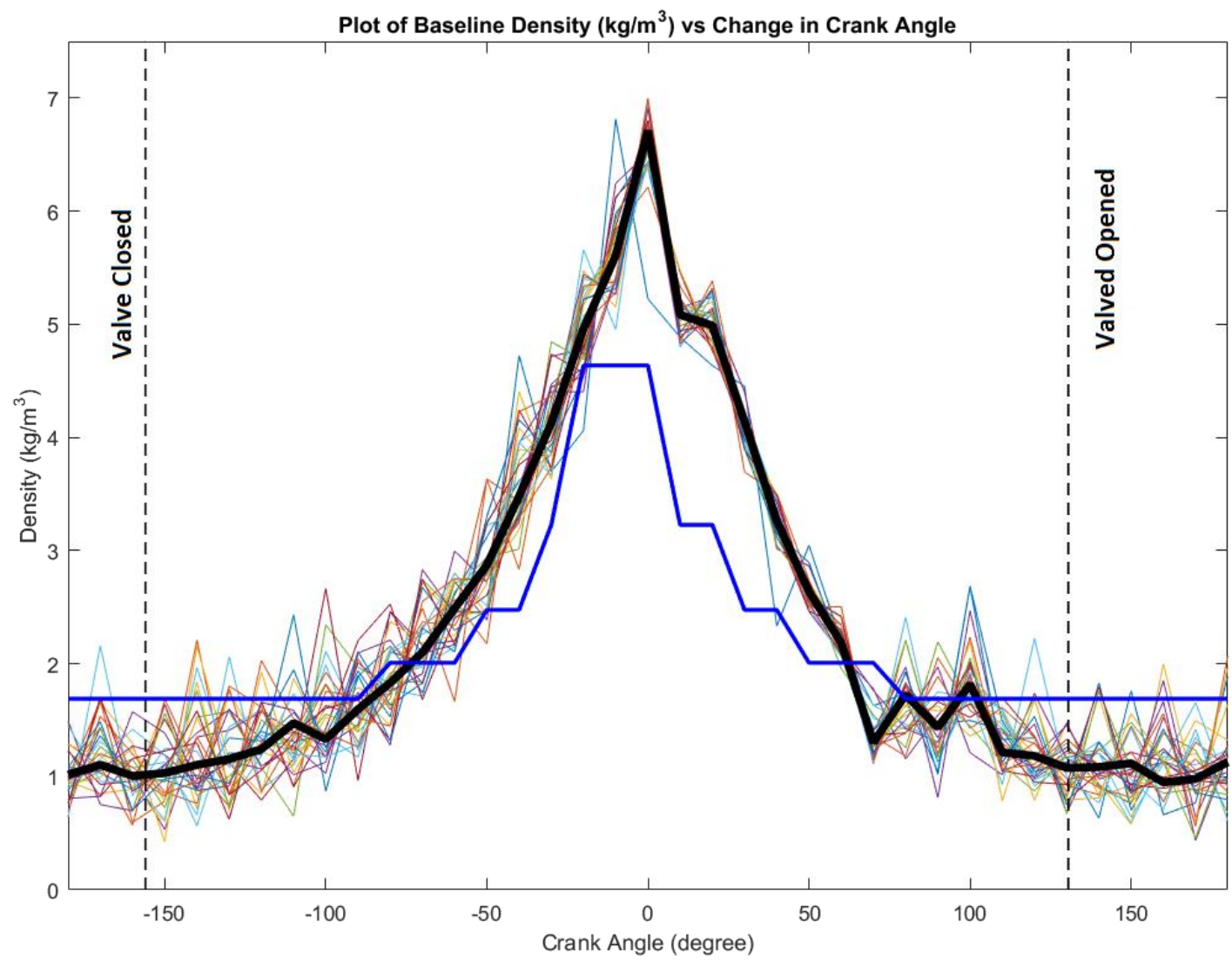

Figure 25: Plot of baseline density and density calculated from the frequency

The baseline density from the pressure is shown in black. The density from the frequency is shown as the blue line. The density from the frequency shows the same discretizion that was found in the frequency from the network analyzer. This could be fixed in the same way as the frequency by increasing the number of points in the sweep. 
The next plot (Figure 26) shows the percent error for the experimental density and baseline density:

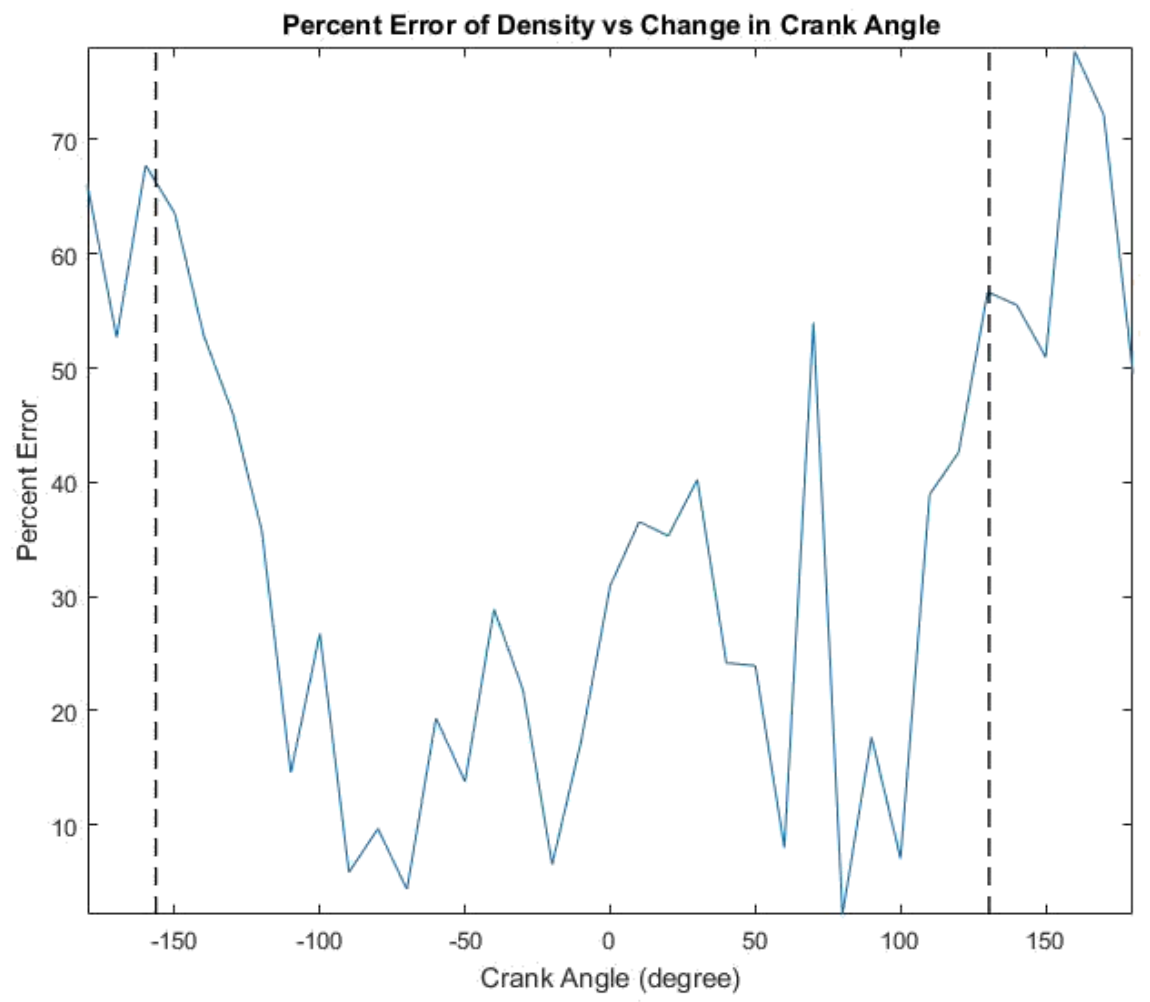

Figure 26: Percent error between experimental density and baseline density

The error at the trailing ends and the top near top dead center of the density are due to the resolution as can be seen in the density plot (Figure 25).

The following table lists the percent error for the frequency and the density. The ranges outside of $-150^{\circ}$ and $130^{\circ}$ are taken out of the error analysis because the system is no longer a closed loop system since the valves are open. The error at top-dead-center is artificially large due to the leaks at maximum pressure and the age of the engine. The error in the range of $60^{\circ}-100^{\circ}$ is due to mechanical linkage slop in the piston motion.

\begin{tabular}{|l|l|l|l|}
\hline Percent Error & Minimum & Maximum & Average \\
\hline Frequency & $0.437031741 \%$ & $1.725585583 \%$ & $0.789007832 \%$ \\
\hline Density & $2.142010431 \%$ & $63.56411371 \%$ & $27.07050832 \%$ \\
\hline
\end{tabular}

The following two 3-D plots (Figure 27 and Figure 28) show the 3-D relationships between pressure, frequency, and crank angle and density, frequency, and crank angle. 
This first plot (Figure 27) shows both the baseline pressure and baseline frequency versus the crank angle of the engine and the baseline pressure and experimental frequency versus the crank angle. This 3-D plot provides a combine view of the two that allows for a comparison. Following what was previously stated with the individual plots as the pressure reaches the maximum at crank angle $0^{\circ}$ the observed frequency changes. 

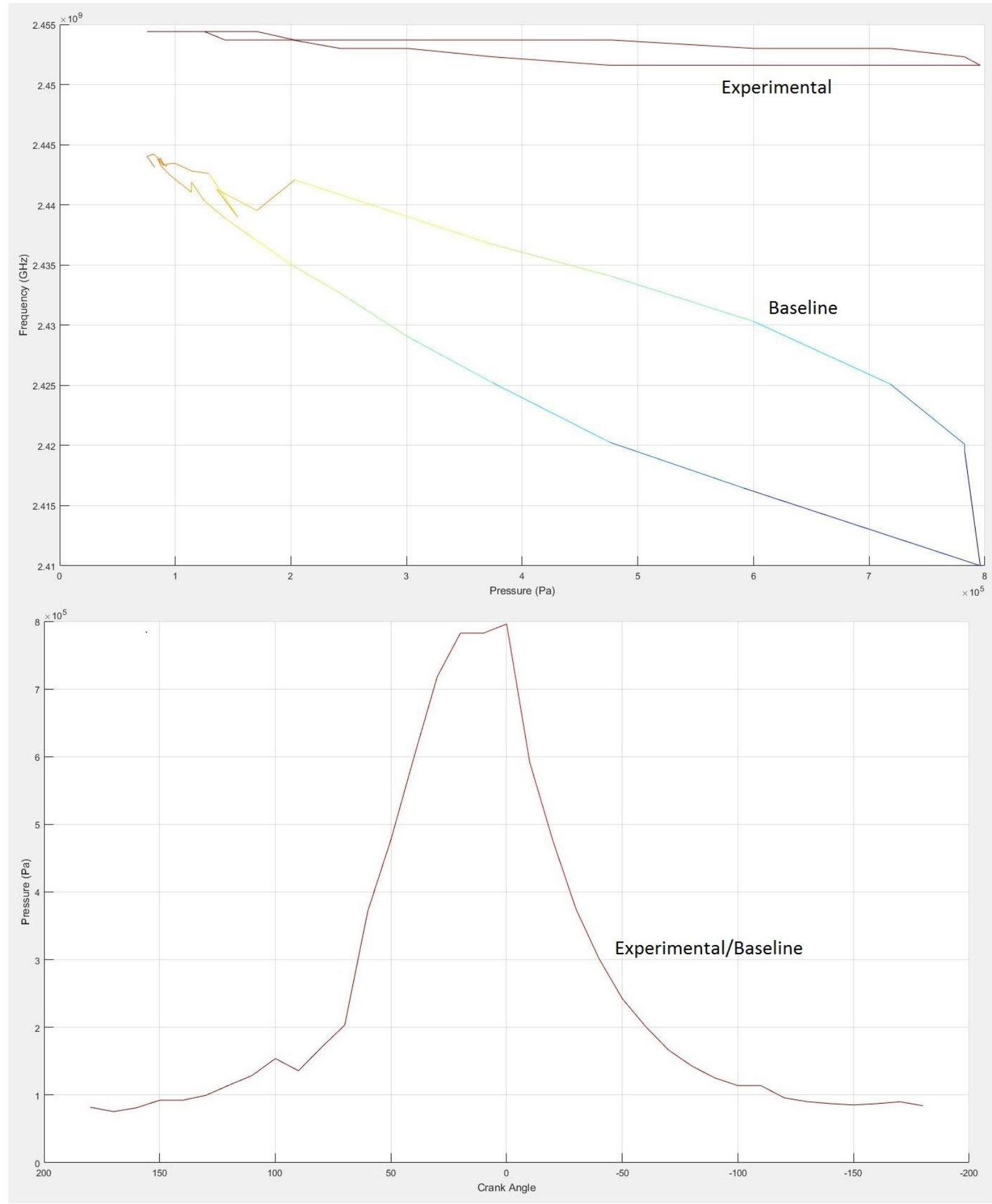

Figure 27: Plot of Baseline Pressure and Baseline Frequency, and Baseline Pressure and Experimental Frequency vs Crank Angle

It can be seen that there is a relationship that can be traced between pressure and frequency. 
The next plot (Figure 28) shows both the baseline density and baseline frequency versus the crank angle of the engine and the experimental density and experimental frequency versus the crank angle. The experimental density shows the same discretizion shown previously with the density plot (Figure 25).
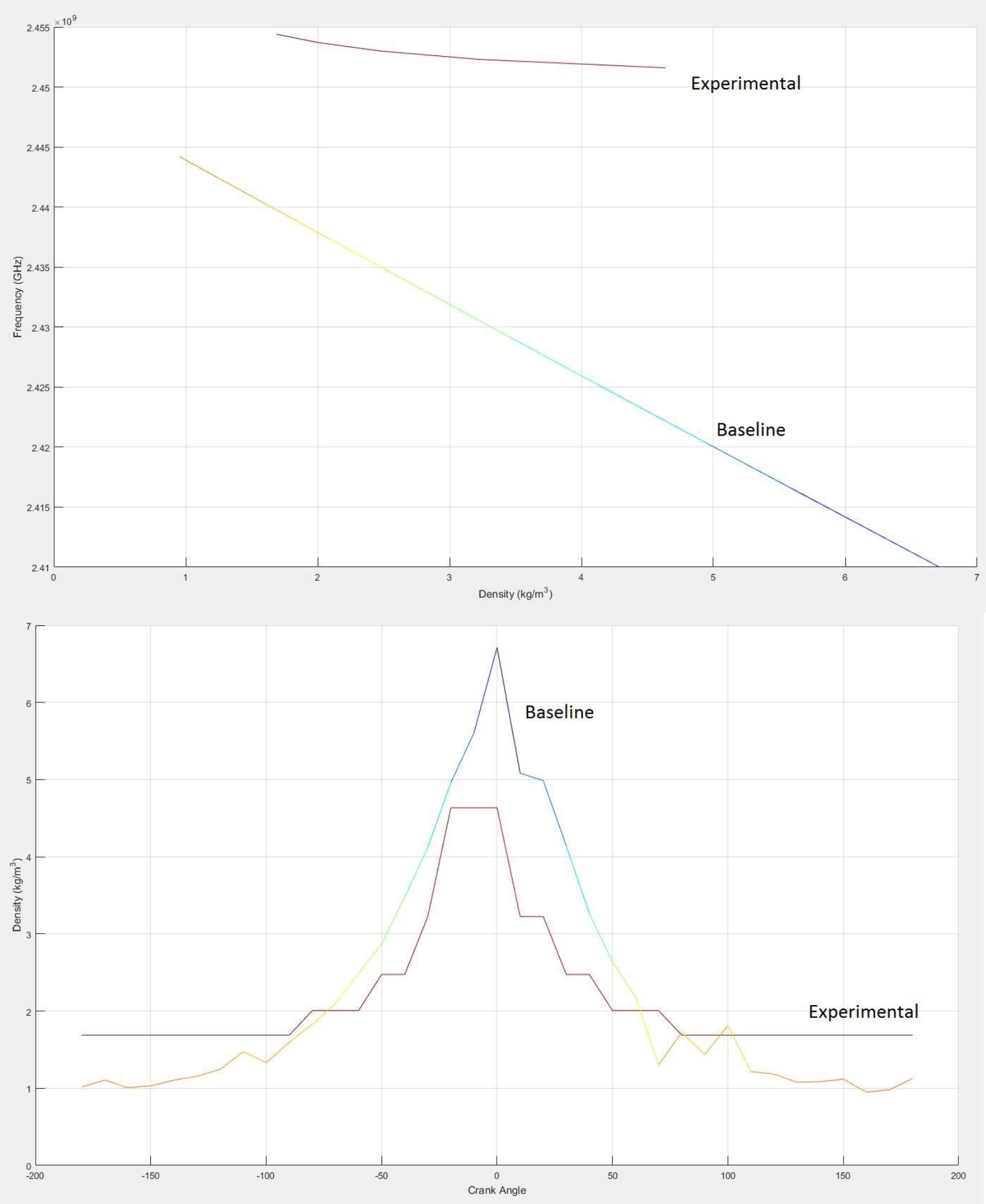
Figure 28: Plot of Baseline Density and Baseline Frequency, and Experimental Density and Experimental Frequency vs Crank Angle

As seen previously with Figure 26 the relationship between density and frequency can be used to trace the events occurring in the cylinder.

\section{2: Summary of Chapter 4}

This chapter went through the results calculated from the raw data. It displays the pressure and frequency curves with respect to the crank angle. The baseline frequency was calculated from the in-cylinder pressure data. This calculated frequency is then compared to the experimental frequency collected from the network analyzer. The percent error between these two is at a maximum approximately $1.725 \%$ throughout the crank angles. From both of these sets of data a density can be found. A baseline density was calculated from the in-cylinder pressure and the experimental density was calculated from the experimental frequency. From these densities the percent error was calculated. The average percent error for the density is approximately $27.07 \%$. Three-dimensional plots were created from this data in order to show how two elements can be traced together against the crank angle of the engine.

By comparing frequency plots it is shown that frequency and pressure can be predicted and that this is a valid means of tracking changes in the combustion chamber. 


\section{Chapter 5: Conclusions}

The results demonstrate that QWCCR Plasma igniter can be used as a diagnostics tool. Based on in-cylinder pressure there is a corresponding frequency. This frequency is comparable to the resonant frequency found with the network analyzer. Thus this system could be used detect changes in the combustion chamber.

In an advanced version of this system deviations from the operating frequency (to be determined for specific engine and system) could allow for the detection of engine events such as misfires and the completeness of the fuel burn.

With further development and integration of the device, and a control system, into an engine environment, this system could be used as an engine diagnostics tool that is self-adjusting. This self-adjusting system could modify the parameters related to operation of the QWCCR Plasma Igniter in order to operate at the desired operating frequency that is correspondent to the desired outcome in the combustion chamber. 


\section{Chapter 6: Recommendations}

My recommendations consist of the furthering of this research. This is the first step as proof-ofconcept to using this device as a diagnostics tool. A feedback and control system is needed to utilize these diagnostic capabilities. With a control system not only would the device be able to detect things such as misfires, it could make the necessary adjustments in order to correct this problem.

By intelligently controlling the QWCCR with a control system that could adapt it would allow for drastically improved combustion. With the capability to detect incomplete fuel burn the system could change appropriately to correct the issue.

Further, more data needs to be collected with varying fuels and combustion. These different fuels will have different densities and thus affect the resonator in different ways. A lookup table should be compiled to show and utilize the differences between the fuels. The effects will also change depending on the combustion environment, as the pressure and temperature are dependent on the volume of the combustion chamber. This means if the system is to be implemented in a different engine it would be suggested to collect data with different fuels in the new engine.

For these further tests it would also be recommended that new equipment be acquire to improve the testing efficiency and reliability. A completely integrated data collection system would drastically improve the data processing step. Being able to collect the SWR and frequency data on a system that is synced and integrated in to the same system that the pressure and temperature data is collected would be beneficial. 


\section{Chapter 7: References}

[1] T. J. Bonazza, K. L. VanVoorhies and J. E. Smith, "RF Plasma Ignition System Concept for Lean Burn Internal Combustion Engines," in SAE Technical Paper 929416, Warrendale, PA, 1992.

[2] K. L. VanVoorhies, T. J. Bonazza and J. E. Smith, "Analysis of RF Corona Discharge Plasma Ignition," in SAE Technical Paper 929502, Warrendale, PA, 1992.

[3] J. E. Smith, R. M. Craven, K. L. VanVoorhies and T. J. Bonzazza, "Radio frequency coaxial cavity resonator as an ignition source and associated method". US Patent US 5,361,737, 08 Nov 1994.

[4] C. A. Stevens, F. A. Pertl, J. L. Hoke, F. R. Schauer and J. E. Smith, "Comparative testing of a novel microwave ignition source, the quarter wave coaxial cavity igniter," Proceedings of the Institute of Mechnical Engineers, Part D: Journal of Automobile Engineering, vol. 225, no. 12, pp. 1633-1640, 2011.

[5] "IER," [Online]. Available: http://instituteforenergyresearch.org/topics/encyclopedia/fossilfuels/. [Accessed 04 Nov 2015].

[6] N. Tesla, "Electrical Igniter for Gas Engines". US Patent US609,250, 16 Aug 1898.

[7] F. R. Simms, "Pulley Toothed Wheel". US Patent US 610,002, 30 Aug 1898.

[8] F. R. Simms and R. Bosch, "Sparking Igniter for Explosion Engines". US Patent US 663,643, 11 Dec 1900.

[9] Y. H. Zweiri, J. F. Whidborne and L. D. Senevirante, "Detailed analytical model of a singlecylinder diseal engine in the crank angle domain," Institution of Mechanical Engineers, vol. Vol 215, no. Part D, 2001.

[10] T. J. Bonazza, K. L. VanVoorhies and J. E. Smith, "RF Plasma Ignition System Concept for Lean Burn Internal Combustion Engines," in SAE Technical Paper 929416, Warrendale, PA, 1992.

[11] K. L. VanVoorhies, T. J. Bonazza and J. E. Smith, "Analysis of RF Corona Discharge Plasma Ignition," in SAE Technical Paper 929502, Warrendale, PA, 1992.

[12] J. E. Smith, R. M. Craven, K. L. VanVoorhies and T. J. Bonazazza, "Radio frequency coaxial cavity resonator as an ignition source and associated method". US Patent 5,361,737, 
08 November 1994.

[13] R. Stiles, G. J. Thompson and J. E. Smith, "Investigation of a Radio Frequency Plasma Ignitor for Possible Internal Combustion Engine Use," in SAE Technical Paper 970071, Warrendale, PA, 1997.

[14] R. D. Stiles and J. E. Smith, "Modeling the Radio Frequency Coaxial Cavity Plasma Ignitor as an Internal Combustion Engine Ignition System," in SAE Technical Paper 980168, Warrendale, PA, 1998.

[15] D. L. Mcintyre, G. J. Thompson and J. E. Smith, "The Coaxial Cavity Resonator as a RF IC Engine Ignition Source," in SAE Technical Paper 2001-01-0987, Warrendale, PA, 2001.

[16] A. L. Lowery, F. A. Pertl and J. E. Smith, "Numerical investigation of the quarter wave coaxial cavity resonator quality factor through wire grid modeling in NEC," 22nd Anual Review of Progress in Applied Computational Electromagnetics, pp. 659-663, 2006.

[17] A. D. Lowery, F. A. Pertl and J. E. Smith, "Experimental investigation of Dielectrics for Use in Quarter Wave Coaxial Resonators," in SAE Technical Paper 2007-01-0256, Warrendale, PA, 2007.

[18] "Feasibility of Pulsed Microwave Plasma Ignition for Use in SI-Engines," ASME 2007 Internal Combustion Engine Division Fall Technical Conference 10.1115/ICEF2007-1776, pp. 715-719, 2006.

[19] J. E. Smith and F. A. Pertl, "Plasma generating igntion system and associated method". US Patent US 7,721,697 B2, 25 May 2010.

[20] F. A. Pertl and J. E. Smith, "High-Level Modeling of an RF Pulsed Quarter Wave Coaxial Resonator with Potential use as an SI Engine Ignition Source," in SAE Technical Paper, Warrendale, PA, 2008.

[21] J. Wilhelm, F. Pertl, P. Willdfire and J. Smith, "Ignition Energy Testing of the Quarter Wave Coaxial Cavity Resonator with Air-Liquefied-Petroleum-Gas Mixtures," in 39th Plasmadynamics and Lasers Conference, American Institute of Aeronautrics and Astronautics, Seattle, WA, 2008.

[22] F. A. Pertl and J. E. Smith, "Electromagnetic design of a novel microwave internal combustion engine ignition source, the quarter wave coaxial cavity igniter," Proceedings of the Institution of Mechnical Engineers, Part D: Journal of Automobile Engineering, vol. 223, no. 11, pp. 1405-1417, 2009. 
[23] P. E. Wildfire, A. J. Nawrocki, F. A. Pertl and J. E. Smith, "Investigation of Cold Start Capability of a Briggs and Stratton Engine Using Jet A Fuel and Microwave Plasma Ignition," in SAE Technical Paper 2009-01-1057, Warrendale, PA, 2009.

[24] J. E. Smith and F. A. Pertl, "Quarter wave coaxial cavity igniter for combustion engines". US Patent US 8783220 B2, 22 Jul 2014.

[25] J. E. Smith and F. A. Pertl, "Compact electromagnetic plasma ignition device". US Patent US 8887683 B2, 18 Nov 2014.

[26] A. D. Lowery, M. Spencer and J. E. Smith, "Finite Element Analysis of a QWCCR with Dielectric Slugs," in 27th Annual Review of Progress in Applied Computational Electromagnetics, ACES 2011-1067, 2011.

[27] F. A. Pertl, M. A. Clarke and J. E. Smith, "Design of a compact quarter wave coaxial cavity resonator for plasma ignition applications," Iternation Journal of Microwave and Wireless Technologies, vol. 3, no. 04, pp. 485-491, 2011.

[28] M. J. Spencer, A. D. Lowery and J. E. Smtih, "Dual Signal Coaxial Cavity Resonator Plasma Generation". US Patent 20150287574, 8 October 2015.

[29] A. D. Lowery, M. J. Spencer and J. E. Smith, "Method and Apparatus for In-cylinder Combustion Diagnostics". US Patent 61/994,332, 16 May 2014.

[30] P. D. Freen, "System and method for generating and sustaining a corona electric discharge for igniting a combustible gaseous mixture". US Patent 6883507, 26 Apr 2005.

[31] P. D. Freen, "Igniting combustible mixtures". US Patent 8746218 B2, 10 June 2014.

[32] P. D. Freen, "Igniting combustible mixtures". US Patent 20140226252, 14 August 2014.

[33] "Spotidoc," [Online]. Available: http://spotidoc.com/doc/1157631/high-frequency-ignitionsystem-based-on-corona-discharge. [Accessed 6 November 2015].

[34] T. Giffels, T. Stifel, S. Bohne, G. Ruan and H. Mueller, "Corona ignition device and method for its manufacture". US Patent 8217560 B2, 10 July 2012.

[35] T. Achstaetter, G. Braeuchle, H. Delesky, T. Giffels and F. Heilmann, "HF Ignition Device". US Patent 20110146640 A1, 23 June 2011.

[36] T. Stifel and T. Giffels, "Corona ignition device". US Patent 8550048 B2, 08 October 2013. 
[37] T. Stifel, T. Giffels and A. Mueller, "Corona ignition device". US Patent 8767372 B2, 01 July 2014.

[38] M. Allgaier, G. Brauchle, T. Giffels and F. Heilmann, "Igniter for igniting a fuel/air mixture in an internal combustion engine using a corona discharge". US Patent 8860290 B2, 14 October 2014.

[39] T. Giffels, T. Stifel, S. Bohne and H. Muller, "Igniter for igniting a fuel-air-mixture using HF corona discharge and engine fitted with such igniters". US Patent 8857396 B2, 14 October 2014.

[40] Y. Ikeda, A. Nishiyama, Y. Wachi and M. Kaneko, "Research and Development of Microwave Plasma Combustion Engine (Part I: Concept of Plasma Combustion and Plasma Generation Technique," in SAE Technical Paper 2009-01-1050, 2009.

[41] Y. Ikeda, A. Nishiyama, H. Katano, M. Kaneko and H. Jeong, "Research and Development of Microwave Plasma Combustion Engine (Part II: Engine Performance of Plasma Combustion Engine)," in SAE Technical Paper 2009-01-1049, 2009.

[42] A. Nishiyama and Y. Ikeda, "Improvement of Lean Limit and Fuel Consumption Using Microwave Plasma Ignition Technology," in SAE technical Paper 2012-01-1139, 2012.

[43] M. Makita and Y. Ikeda, "Ignition or plasma generation apparatus". US Patent 8226901 B2, 24 July 2012.

[44] M. Makita and Y. Ikeda, "Ignition or plasma generation apparatus". US Patent 20120258016 A1, 11 October 2012.

[45] Y. Ikeda and M. Makita, "United States Patent Application 0140041611 - Plasma Generation Device". US 2014.

[46] J. A. Burrows and J. D. Lykowski, "Multi-event corona discharge ignition assembly and method of control and operation". US Patent 20120145136 A1, 14 June 2012.

[47] J. D. Lykowski, W. J. Walker and J. W. Hoffman, "Igniter system for igniting fuel". US Patent 8434443 B2, 07 May 2013.

[48] A. Permuy and K. Hampton, "Corona tip insulator". US Patent 8464679 B2, 18 June 2013.

[49] A. Permuy and K. Hampton, "Corona ignition with self-tuning power amplifier". US Patent 8578902 B2, 28 May 2013. 
[50] J. A. Burrows and J. D. Lykowski, "Corona igniter including ignition coil with improved isolation". US Patent 8638540 B2, 28 January 2014.

[51] J. D. Lykowski, K. Hampton and J. W. W Jr., "Non-thermal plasma ignition arc suppression". US Patent 8729782 B2, 20 May 2014.

[52] J. A. Burrows and J. D. Lykowski, "Electrical arrangement of hybrid ignition device". US Patent 8749945 B2, 10 June 2014.

[53] K. Hampton, J. W. W Jr. and J. D. Lykowski, "Igniter including a corona enhancing electrode tip". US Patent 8776751 B2, 15 July 2014.

[54] J. A. Burrows and J. D. Lykowski, "Corona igniter with magnetic screening". US Patent 8839752 B2, 23 September 2014.

[55] J. A. Burrows, J. D. Lykowski and J. W. Hoffman, "Corona igniter having improved gap control". US Patent 8839753 B2, 23 September 2014.

[56] J. A. Burrows, J. D. Lykowski, A. Permuy and K. Hampton, "Corona igniter having controlled location of corona formation". US Patent 8844490 B2, 30 September 2014.

[57] P. Durham and J. Lykowski, "Corona igniter assembly including corona enhancing insulator geometry". US Patent 8749126 B2, 10 June 2014.

[58] J. A. Burrows and J. D. Lykowski, "Corona igniter including temperature control features". US Patent 9010294 B2, 21 April 2015.

[59] J. A. Burrows and J. D. Lykowski, "Corona igniter having shaped insulator". US Patent 9041273 B2, 26 May 2015.

[60] J. A. Burrows, J. Miller, K. I. Mixell and J. D. Lykowski, "Corona ignition device with improved electrical performance". US Patent 9088136 B2, 21 July 2015.

[61] J. A. Burrows and J. D. Lykowski, "Corona ignition device having asymmetric firing tip". US Patent 9103313 B2, 11 August 2015.

[62] D. K. Cheng, Field and Wave Electromagnetics, Reading, Massachusetts: Addison-Wesley Publishing Co., 1989.

[63] P. Devine, Radar level measurement - The users guide, West Sussex, England: VEGA Controls Ltd., 2000. 
[64] A. Lowery, incylinder_diagnostics_T_P_to_f.m.

[65] P. Piezotronics, Model 112B11 Charge Output Pressure Sensor, March 2013. 


\title{
Appendix
}

\section{Appendices A: Matlab Code}

\author{
A.1: Read_Binary_CFR \\ clear all; \\ fid=fopen('C:IUsers|Trey.Hunsucker|Dropbox \Diagnostics Tests 1-27-16\Data \\ LoggerlData_PSP-001_012716_15;9;48.bin','r');
}

RowsPerChannels=1440;

$\mathrm{i}=1$;

EndOfFile=feof(fid);

while $($ EndOfFile $==0)$

Time(i,1) = fread(fid, 1, 'double');

EngineSpeed(i,1) = fread(fid, 1,'double');

IntakeTemperature(i,1) = fread(fid, 1 ,'double');

ExhaustTemperature(i,1) = fread(fid, 1,'double');

ChannelNumber(i,1) = fread(fid, 1,'int');

Pressure(:,i) = fread(fid, RowsPerChannels, 'int16')/2.0;

if $(\min ($ Pressure $(:, \mathrm{i}))<-1000)$

$\%$ should have been read as unsigned int 16

fseek(fid, -2*RowsPerChannels, 'cof');

Pressure(:,i) $=$ fread(fid, RowsPerChannels,'uint 16')/2.0;

end

$\mathrm{i}=\mathrm{i}+1$;

$\%$ Check end of file

position=ftell(fid);

testEnd=fread(fid, 1,'double');

if $($ feof $($ fid $)==0$ )

fseek(fid,position,'bof');

else

EndOfFile $=1$

end

end

fclose(fid); 


\section{A.2: Volume Calculation}

function $[\mathrm{CA}, \mathrm{V}]=\mathrm{CAV}$ olume(Stroke,Bore,CR,VD,Conn)

$\mathrm{CA}(1)=-180$;

$\mathrm{V}(1)=(\mathrm{VD} /(\mathrm{CR}-1))+\left(\left(\mathrm{pi}^{*}\right.\right.$ Bore $\left.\left.^{\wedge} 2\right) / 4\right) *(\mathrm{Conn}+($ Stroke/2) $\ldots$

$-\left(\left(\right.\right.$ Stroke/2)* $\cos \left(\mathrm{CA}(1)^{*}\right.$ pi/180)+sqrt $\left(\left(\mathrm{Conn}^{\wedge} 2\right) \ldots\right.$

$\left.\left.\left.-\left((\text { Stroke } / 2)^{\wedge} 2\right)^{*}\left(\sin \left(\mathrm{CA}(1)^{*} \mathrm{pi} / 180\right)^{\wedge} 2\right)\right)\right)\right)$;

for $\mathrm{i}=2: 1440$;

$\mathrm{CA}(\mathrm{i}, 1)=\mathrm{CA}(\mathrm{i}-1,1)+.25$;

$\mathrm{V}(\mathrm{i}, 1)=(\mathrm{VD} /(\mathrm{CR}-1))+\left(\left(\mathrm{pi}^{*}\right.\right.$ Bore $\left.\left.^{\wedge} 2\right) / 4\right) *($ Conn $+($ Stroke $/ 2) \ldots$

$-\left((\text { Stroke } / 2)^{*} \cos \left(\mathrm{CA}(\mathrm{i}, 1)^{*} \mathrm{pi} / 180\right)+\operatorname{sqrt}\left(\left(\mathrm{Conn}^{\wedge} 2\right) \ldots\right.\right.$

$\left.\left.\left.-\left((\text { Stroke/2 })^{\wedge} 2\right)^{*}\left(\sin \left(\mathrm{CA}(\mathrm{i}, 1)^{*} \mathrm{pi} / 180\right)^{\wedge} 2\right)\right)\right)\right)$;

end 


\section{A.3: Data Plotting}

clear;clc;

close all

$\%$ Dielectric constant under normal conditions

e_rN $=1.00059 ; \quad \%$ Air

$\mathrm{CR}=5 ; \quad$ \% ICE Compression Ratio

$\%$ Normal conditions

T_N = 269.9407581;

P_N $=0.8433084577$;

\%Import Pressure

P_N_180 = xlsread('DataCLean.xlsx','Baseline','F2:F38'); \% Pressure -180

P_N_170 = xlsread('DataCLean.xlsx','Baseline','G2:G38'); \% Pressure -170

P_N_160 = xlsread('DataCLean.xlsx','Baseline','H2:H38'); \% Pressure -160

P_N_150 = xlsread('DataCLean.xlsx','Baseline','I2:I38'); \% Pressure -150

P_N_140 = xlsread('DataCLean.xlsx','Baseline','J2:J38'); \% Pressure -140

P_N_130 = xlsread('DataCLean.xlsx','Baseline','K2:K38'); \% Pressure -130

P_N_120 = xlsread('DataCLean.xlsx','Baseline','L2:L38'); \% Pressure -120

P_N_110 = xlsread('DataCLean.xlsx','Baseline','M2:M38'); \% Pressure -110

P_N_100 = xlsread('DataCLean.xlsx','Baseline','N2:N38'); \% Pressure -100

P_N_90 = xlsread('DataCLean.xlsx','Baseline','O2:O38'); \% Pressure -90

P_N_80 = xlsread('DataCLean.xlsx','Baseline','P2:P38'); \% Pressure -80

P_N_70 = xlsread('DataCLean.xlsx','Baseline','Q2:Q38'); \% Pressure -70

P_N_60 = xlsread('DataCLean.xlsx','Baseline','R2:R38'); \% Pressure -60

P_N_50 = xlsread('DataCLean.xlsx','Baseline','S2:S38'); \% Pressure -50

P_N 40 = xlsread('DataCLean.xlsx','Baseline','T2:T38'); \% Pressure -40

P_N_30 = xlsread('DataCLean.xlsx','Baseline','U2:U38'); \% Pressure -30

P_N_20 = xlsread('DataCLean.xlsx','Baseline','V2:V38'); \% Pressure -20

P_N_10 = xlsread('DataCLean.xlsx','Baseline','W2:W38'); \% Pressure -10

P_0 = xlsread('DataCLean.xlsx','Baseline','X2:X38'); \% Pressure 0

P_10 = xlsread('DataCLean.xlsx','Baseline','Y2:Y38'); \% Pressure 10

P_20 = xlsread('DataCLean.xlsx','Baseline','Z2:Z38'); \% Pressure 20

P_30 = xlsread('DataCLean.xlsx','Baseline','AA2:AA38'); \% Pressure 30

P_40 = xlsread('DataCLean.xlsx','Baseline','AB2:AB38'); \% Pressure 40

P_50 = xlsread('DataCLean.xlsx','Baseline','AC2:AC38'); \% Pressure 50

P_60 = xlsread('DataCLean.xlsx','Baseline','AD2:AD38'); \% Pressure 60

P_70 = xlsread('DataCLean.xlsx','Baseline','AE2:AE38'); \% Pressure 70

P_80 = xlsread('DataCLean.xlsx','Baseline','AF2:AF38'); \% Pressure 80

P_90 = xlsread('DataCLean.xlsx','Baseline','AG2:AG38'); \% Pressure 90

P_100 = xlsread('DataCLean.xlsx','Baseline','AH2:AH38'); \% Pressure 100

P_110 = xlsread('DataCLean.xlsx','Baseline','AI2:AI38'); \% Pressure 110

P_120 = xlsread('DataCLean.xlsx','Baseline','AJ2:AJ38'); \% Pressure 120

P_130 = xlsread('DataCLean.xlsx','Baseline','AK2:AK38'); \% Pressure 130

P_140 = xlsread('DataCLean.xlsx','Baseline','AL2:AL38'); \% Pressure 140 
P_150 = xlsread('DataCLean.xlsx','Baseline','AM2:AM38'); \% Pressure 150

P_160 = xlsread('DataCLean.xlsx','Baseline','AN2:AN38'); \% Pressure 160

P_170 = xlsread('DataCLean.xlsx','Baseline','AO2:AO38'); \% Pressure 170

P_180 = xlsread('DataCLean.xlsx','Baseline','AP2:AP38'); \% Pressure 180

P_BASELINE $=$ xlsread('DataCLean.xlsx','Baseline','AQ2:AQ38'); \% Pressure Baseline

\%Import Temperature

T_N_180 = xlsread('DataCLean.xlsx','Baseline','F40:F76'); \% Temperature -180

T_N_170 = xlsread('DataCLean.xlsx','Baseline','G40:G76'); \% Temperature -170

T_N_160 = xlsread('DataCLean.xlsx','Baseline','H40:H76'); \% Temperature -160

T_N_150 = xlsread('DataCLean.xlsx','Baseline','I40:I76'); \% Temperature -150

T_N_140 = xlsread('DataCLean.xlsx','Baseline','J40:J76'); \% Temperature -140

T_N_130 = xlsread('DataCLean.xlsx','Baseline','K40:K76'); \% Temperature -130

T_N_120 = xlsread('DataCLean.xlsx','Baseline','L40:L76'); \% Temperature -120

T_N_110 = xlsread('DataCLean.xlsx','Baseline','M40:M76'); \% Temperature -110

T_N_100 = xlsread('DataCLean.xlsx','Baseline','N40:N76'); \% Temperature -100

T_N_90 = xlsread('DataCLean.xlsx','Baseline','O40:O76'); \% Temperature -90

T_N_80 $=$ xlsread('DataCLean.xlsx','Baseline','P40:P76'); \% Temperature -80

T_N_70 = xlsread('DataCLean.xlsx','Baseline','Q40:Q76'); \% Temperature -70

T_N_60 = xlsread('DataCLean.xlsx','Baseline','R40:R76'); \% Temperature -60

T_N_50 = xlsread('DataCLean.xlsx','Baseline','S40:S76'); \% Temperature -50

T_N_40 = xlsread('DataCLean.xlsx','Baseline','T40:T76'); \% Temperature -40

T_N_30 = xlsread('DataCLean.xlsx','Baseline','U40:U76'); \% Temperature -30

T_N_20 $=$ xlsread('DataCLean.xlsx','Baseline','V40:V76'); \% Temperature -20

T_N_10 = xlsread('DataCLean.xlsx','Baseline','W40:W76'); \% Temperature -10

T_0 = xlsread('DataCLean.xlsx','Baseline','X40:X76'); \% Temperature 0

T_10 = xlsread('DataCLean.xlsx','Baseline','Y40:Y76'); \% Temperature 10

T_20 = xlsread('DataCLean.xlsx','Baseline','Z40:Z76'); \% Temperature 20

T_30 = xlsread('DataCLean.xlsx','Baseline','AA40:AA76'); \% Temperature 30

T_40 = xlsread('DataCLean.xlsx','Baseline','AB40:AB76'); \% Temperature 40

T_50 = xlsread('DataCLean.xlsx','Baseline','AC40:AC76'); \% Temperature 50

T_60 = xlsread('DataCLean.xlsx','Baseline','AD40:AD76'); \% Temperature 60

T_70 = xlsread('DataCLean.xlsx','Baseline','AE40:AE76'); \% Temperature 70

T_80 = xlsread('DataCLean.xlsx','Baseline','AF40:AF76'); \% Temperature 80

T_90 = xlsread('DataCLean.xlsx','Baseline','AG40:AG76'); \% Temperature 90

T_100 = xlsread('DataCLean.xlsx','Baseline','AH40:AH76'); \% Temperature 100

T_110 = xlsread('DataCLean.xlsx','Baseline','AI40:AI76'); \% Temperature 110

T_120 = xlsread('DataCLean.xlsx','Baseline','AJ40:AJ76'); \% Temperature 120

T_130 = xlsread('DataCLean.xlsx','Baseline','AK40:AK76'); \% Temperature 130

T_140 = xlsread('DataCLean.xlsx','Baseline','AL40:AL76'); \% Temperature 140

T_150 = xlsread('DataCLean.xlsx','Baseline','AM40:AM76'); \% Temperature 150

T_160 = xlsread('DataCLean.xlsx','Baseline','AN40:AN76'); \% Temperature 160

T_170 = xlsread('DataCLean.xlsx','Baseline','AO40:AO76'); \% Temperature 170

T_180 = xlsread('DataCLean.xlsx','Baseline','AP40:AP76'); \% Temperature 180

T_BASELINE = xlsread('DataCLean.xlsx','Baseline','AQ40:AQ76'); \% Temperature Baseline 
\%Import Frequency

F_N_180 = xlsread('DataCLean.xlsx','Baseline','F116:F152'); \% Frequency -180

F_N_170 = xlsread('DataCLean.xlsx','Baseline','G116:G152'); \% Frequency -170

F_N_160 = xlsread('DataCLean.xlsx','Baseline','H116:H152'); \% Frequency -160

F_N_150 = xlsread('DataCLean.xlsx','Baseline','I116:I152'); \% Frequency -150

F_N_140 = xlsread('DataCLean.xlsx','Baseline','J116:J152'); \% Frequency -140

F_N_130 = xlsread('DataCLean.xlsx','Baseline','K116:K152'); \% Frequency -130

F_N_120 = xlsread('DataCLean.xlsx','Baseline','L116:L152'); \% Frequency -120

F_N_110 = xlsread('DataCLean.xlsx','Baseline','M116:M152'); \% Frequency -110

F_N_100 = xlsread('DataCLean.xlsx','Baseline','N116:N152'); \% Frequency -100

F_N_90 = xlsread('DataCLean.xlsx','Baseline','O116:O152'); \% Frequency -90

F_N_80 = xlsread('DataCLean.xlsx','Baseline','P116:P152'); \% Frequency -80

F_N_70 $=$ xlsread ('DataCLean.xlsx','Baseline','Q116:Q152'); \% Frequency -70

F_N_60 = xlsread('DataCLean.xlsx','Baseline','R116:R152'); \% Frequency -60

F_N_50 = xlsread('DataCLean.xlsx','Baseline','S116:S152'); \% Frequency -50

F_N_40 = xlsread('DataCLean.xlsx','Baseline','T116:T152'); \% Frequency -40

F_N_30 = xlsread('DataCLean.xlsx','Baseline','U116:U152'); \% Frequency -30

F_N_20 = xlsread('DataCLean.xlsx','Baseline','V116:V152'); \% Frequency -20

F_N_10 = xlsread('DataCLean.xlsx','Baseline','W116:W152'); \% Frequency -10

F_0 = xlsread ('DataCLean.xlsx','Baseline','X116:X152'); \% Frequency 0

F_10 = xlsread('DataCLean.xlsx','Baseline','Y116:Y152'); \% Frequency 10

F_20 = xlsread('DataCLean.xlsx','Baseline','Z116:Z152'); \% Frequency 20

F_30 = xlsread('DataCLean.xlsx','Baseline','AA116:AA152'); \% Frequency 30

F_40 = xlsread('DataCLean.xlsx','Baseline','AB116:AB152'); \% Frequency 40

F_50 = xlsread('DataCLean.xlsx','Baseline','AC116:AC152'); \% Frequency 50

F_60 = xlsread('DataCLean.xlsx','Baseline','AD116:AD152'); \% Frequency 60

F_70 = xlsread('DataCLean.xlsx','Baseline','AE116:AE152'); \% Frequency 70

F_80 = xlsread('DataCLean.xlsx','Baseline','AF116:AF152'); \% Frequency 80

F_90 = xlsread('DataCLean.xlsx','Baseline','AG116:AG152'); \% Frequency 90

F_100 = xlsread('DataCLean.xlsx','Baseline','AH116:AH152'); \% Frequency 100

F_110 = xlsread('DataCLean.xlsx','Baseline','AI116:AI152'); \% Frequency 110

F_120 = xlsread('DataCLean.xlsx','Baseline','AJ116:AJ152'); \% Frequency 120

F_130 = xlsread('DataCLean.xlsx','Baseline','AK116:AK152'); \% Frequency 130

F_140 = xlsread('DataCLean.xlsx','Baseline','AL116:AL152'); \% Frequency 140

F_150 = xlsread('DataCLean.xlsx','Baseline','AM116:AM152'); \% Frequency 150

F_160 = xlsread('DataCLean.xlsx','Baseline','AN116:AN152'); \% Frequency 160

F_170 = xlsread('DataCLean.xlsx','Baseline','AO116:AO152'); \% Frequency 170

F_180 = xlsread('DataCLean.xlsx','Baseline','AP116:AP152'); \% Frequency 180

F_BASELINE = xlsread('DataCLean.xlsx','Baseline','AQ116:AQ152'); \% Frequency Baseline

F_E = xlsread('DataCLean.xlsx','Baseline','E2:E38'); \% Frequency Experimental

\%Import Density

D_N_180 = xlsread('DataCLean.xlsx','Baseline','F193:F229'); \% Density -180

D_N_170 = xlsread('DataCLean.xlsx','Baseline','G193:G229'); \% Density -170

D_N_160 = xlsread('DataCLean.xlsx','Baseline','H193:H229'); \% Density -160

D_N_150 = xlsread('DataCLean.xlsx','Baseline','I193:I229'); \% Density -150 
D_N_140 = xlsread('DataCLean.xlsx','Baseline','J193:J229'); \% Density -140

D_N_130 = xlsread('DataCLean.xlsx','Baseline','K193:K229'); \% Density -130

D_N_120 = xlsread('DataCLean.xlsx','Baseline','L193:L229'); \% Density -120

D_N_110 = xlsread('DataCLean.xlsx','Baseline','M193:M229'); \% Density -110

D_N_100 $=$ xlsread('DataCLean.xlsx','Baseline','N193:N229'); \% Density -100

D_N_90 = xlsread('DataCLean.xlsx','Baseline','O193:O229'); \% Density -90

D_N_80 = xlsread('DataCLean.xlsx','Baseline','P193:P229'); \% Density -80

D_N_70 = xlsread('DataCLean.xlsx','Baseline','Q193:Q229'); \% Density -70

D_N_60 = xlsread('DataCLean.xlsx','Baseline','R193:R229'); \% Density -60

D_N_50 = xlsread('DataCLean.xlsx','Baseline','S193:S229'); \% Density -50

D_N_40 $=$ xlsread('DataCLean.xlsx','Baseline','T193:T229'); \% Density -40

D_N_30 = xlsread('DataCLean.xlsx','Baseline','U193:U229'); \% Density -30

D_N_20 $=$ xlsread('DataCLean.xlsx','Baseline','V193:V229'); \% Density -20

D_N_10 = xlsread('DataCLean.xlsx','Baseline','W193:W229'); \% Density -10

D_0 = xlsread('DataCLean.xlsx','Baseline','X193:X229'); \% Density 0

D_10 = xlsread('DataCLean.xlsx','Baseline','Y193:Y229'); \% Density 10

D_20 = xlsread('DataCLean.xlsx','Baseline','Z193:Z229'); \% Density 20

D_30 = xlsread('DataCLean.xlsx','Baseline','AA193:AA229'); \% Density 30

D_40 = xlsread('DataCLean.xlsx','Baseline','AB193:AB229'); \% Density 40

D_50 = xlsread('DataCLean.xlsx','Baseline','AC193:AC229'); \% Density 50

D_60 = xlsread('DataCLean.xlsx','Baseline','AD193:AD229'); \% Density 60

D_70 = xlsread('DataCLean.xlsx','Baseline','AE193:AE229'); \% Density 70

D_80 = xlsread('DataCLean.xlsx','Baseline','AF193:AF229'); \% Density 80

D_90 = xlsread('DataCLean.xlsx','Baseline','AG193:AG229'); \% Density 90

D_100 = xlsread('DataCLean.xlsx','Baseline','AH193:AH229'); \% Density 100

D_110 $=$ xlsread('DataCLean.xlsx','Baseline','AI193:AI229'); \% Density 110

D_120 = xlsread('DataCLean.xlsx','Baseline','AJ193:AJ229'); \% Density 120

D_130 = xlsread('DataCLean.xlsx','Baseline','AK193:AK229'); \% Density 130

D_140 = xlsread('DataCLean.xlsx','Baseline','AL193:AL229'); \% Density 140

D_150 = xlsread('DataCLean.xlsx','Baseline','AM193:AM229'); \% Density 150

D_160 = xlsread('DataCLean.xlsx','Baseline','AN193:AN229'); \% Density 160

D_170 = xlsread('DataCLean.xlsx','Baseline','AO193:AO229'); \% Density 170

D_180 = xlsread('DataCLean.xlsx','Baseline','AP193:AP229'); \% Density 180

D_BASELINE = xlsread('DataCLean.xlsx','Baseline','AQ193:AQ229'); \% Density Baseline

D_E = xlsread('DataCLean.xlsx','Baseline','H231:H267'); \% Density from Frequency

CA = xlsread('DataCLean.xlsx','Baseline','A2:A38');

\% Temperature and pressure ranges

Num_points $=37$;

for index $=1$ :length $(\mathrm{CR})$

F(index,:) $=$ linspace $(300,500$, Num_points $)$;

$\mathrm{P}($ index,$:)=$ linspace $(1, \mathrm{CR}($ index $) . \wedge 1.4$, Num_points $)$; 


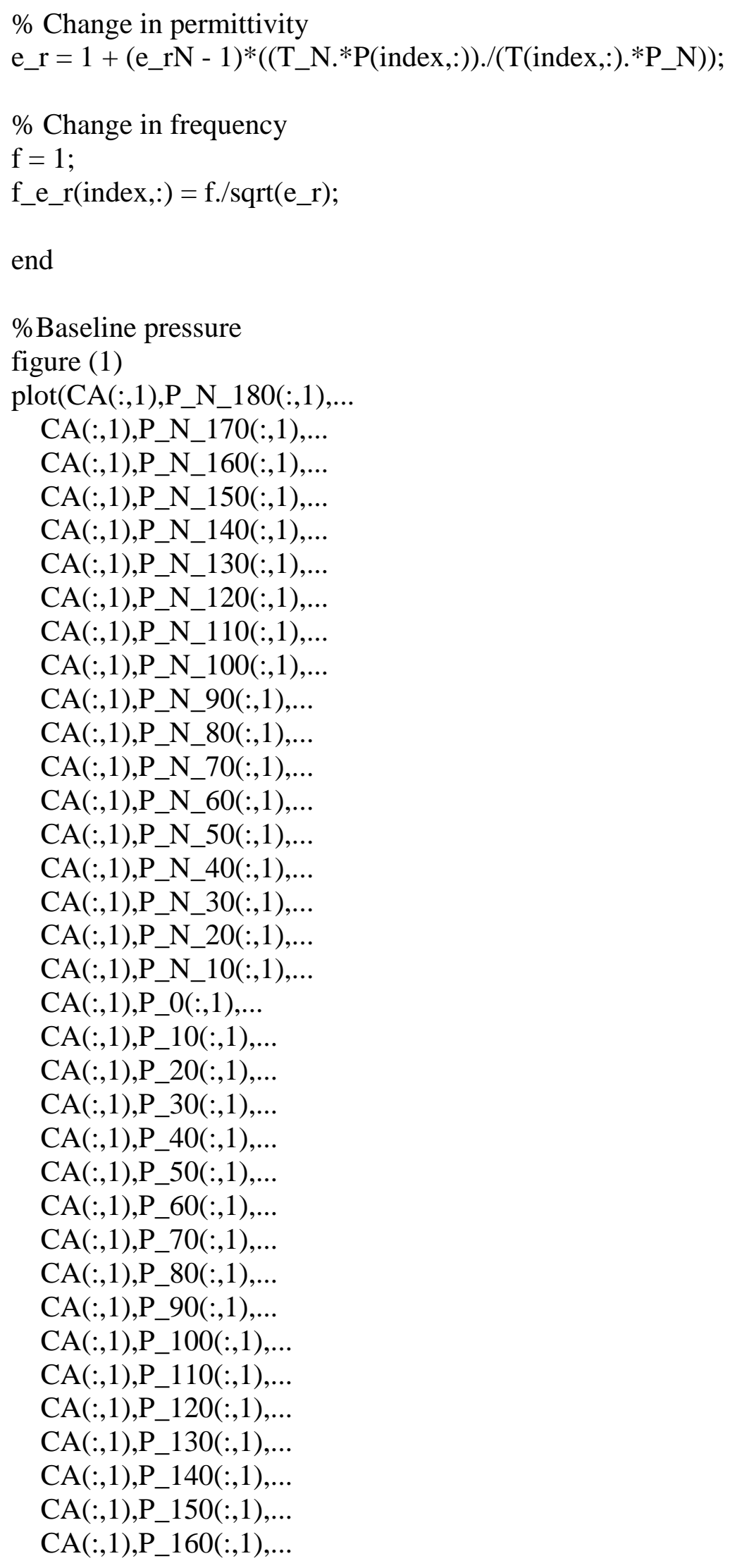




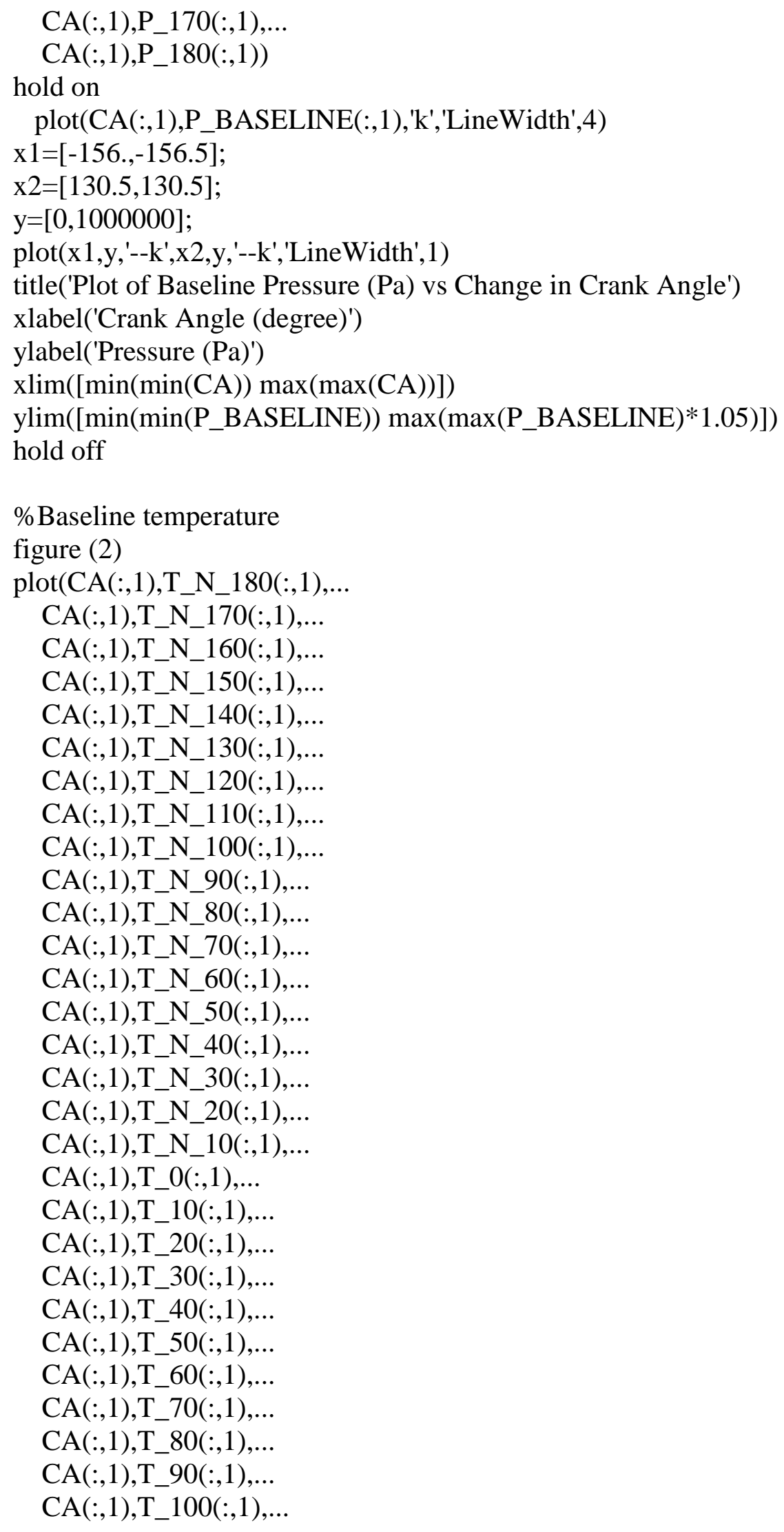




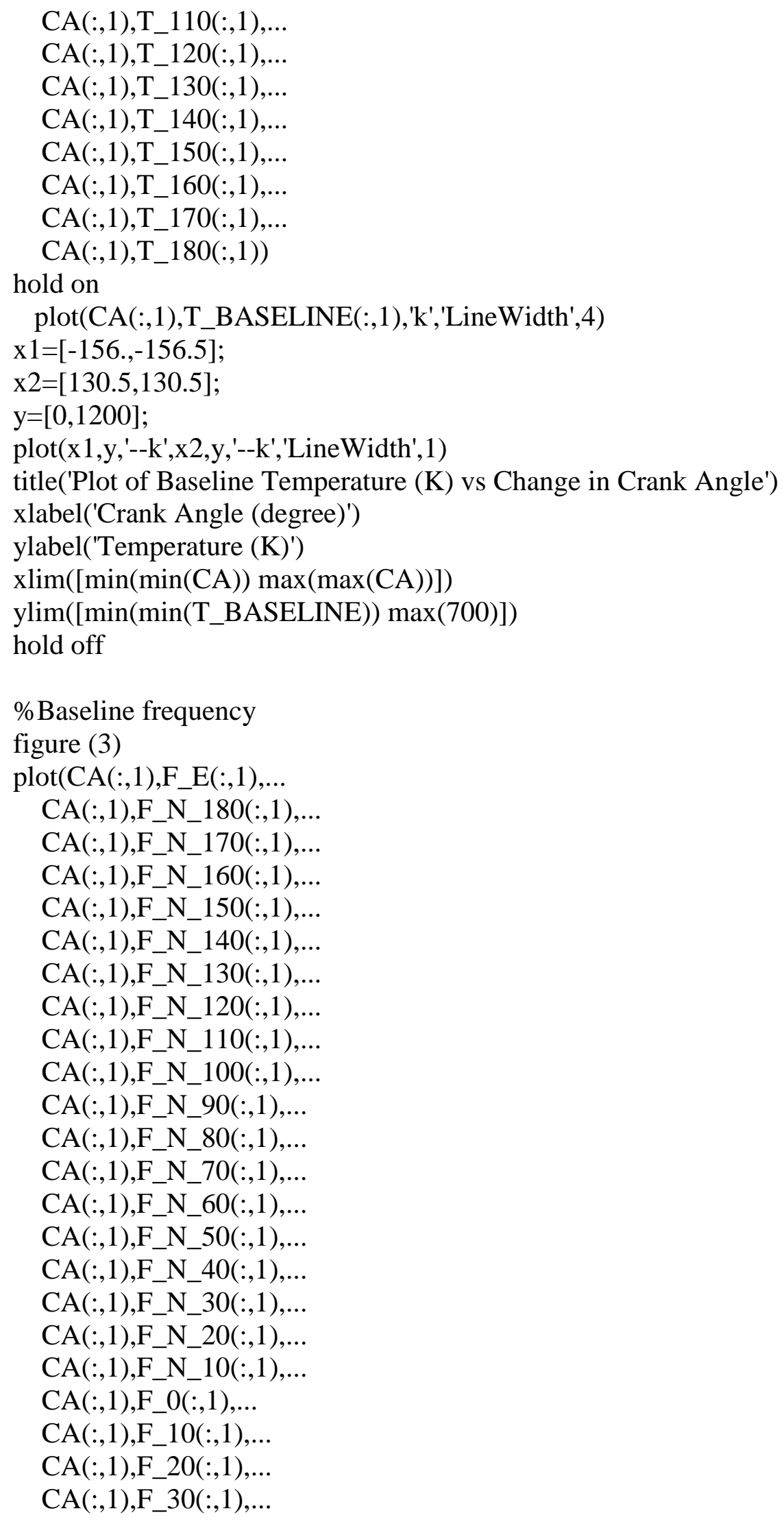


$\mathrm{CA}(:, 1), \mathrm{F} \_40(:, 1), \ldots$

CA(:,1),F_50(:,1),...

CA(:,1),F_60(:,1),...

CA(:,1),F_70(:,1),...

CA(:,1),F_80(:,1),...

CA(:,1),F_90(:,1),...

CA(:,1),F_100(:,1),...

$\mathrm{CA}(:, 1), \mathrm{F}_{-} 110(:, 1), \ldots$

$\mathrm{CA}(:, 1), \mathrm{F}_{-} 120(:, 1), \ldots$

$\mathrm{CA}(:, 1), \mathrm{F}_{-} 130(:, 1), \ldots$

CA(:,1),F_140(:,1),...

$\mathrm{CA}(:, 1), \mathrm{F}_{-} 150(:, 1), \ldots$

CA(:,1),F_160(:,1),...

CA(:,1),F_170(:,1),...

$\left.\mathrm{CA}(:, 1), \mathrm{F}_{-} 180(:, 1)\right)$

hold on

$\operatorname{plot}(\mathrm{CA}(:, 1), \mathrm{F}$ _BASELINE(:,1),'k','LineWidth',4)

$\mathrm{x} 1=[-156 .,-156.5]$;

$\mathrm{x} 2=[130.5,130.5]$;

$\mathrm{y}=[0,10000000000000]$;

plot(x1,y,'--k',x2,y,'--k','LineWidth',1)

title('Plot of Baseline Frequency (GHz) vs Change in Crank Angle')

xlabel('Crank Angle (degree)')

ylabel('Frequency $(\mathrm{GHz})$ ')

$x \lim ([\min (\min (\mathrm{CA})) \max (\max (\mathrm{CA}))])$

$\operatorname{ylim}\left(\left[\min \left(\min \left(\right.\right.\right.\right.$ F_BASELINE)*.999) $\left.\left.\max \left(\max (\text { F_E })^{*} 1.005\right)\right]\right)$

hold off

$\%$ Density

figure (4)

$\operatorname{plot}\left(\mathrm{CA}(:, 1), \mathrm{D} \_\right.$N_180(:,1),...

CA(:,1),D_N_170(:,1),...

CA(:,1),D_N_160(:,1),...

CA(:,1),D_N_150(:,1),...

CA $(:, 1)$, D_N_140(:,1),...

CA(:,1),D_N_130(:,1),...

CA(:,1),D_N_120(:,1),...

CA(:,1),D_N_110(:,1),...

CA(:,1),D_N_100(:,1),...

CA(:,1),D_N_90(:,1),...

CA(:,1),D_N_80(:,1),...

CA(:,1),D_N_70(:,1),...

CA(:,1),D_N_60(:,1),...

CA(:,1),D_N_50(:,1),...

CA(:,1),D_N_40(:,1),...

CA(:,1),D_N_30(:,1),... 
CA(:,1),D_N_20(:,1),...

CA(:,1),D_N_10(:,1),...

CA(:,1),D_0(:,1),...

CA(:,1),D_10(:,1),...

CA(:,1),D_20(:,1),...

CA(:,1),D_30(:,1),...

CA(:,1),D_40(:,1),,..

CA(:,1),D_50(:,1),...

CA(:,1),D_60(:,1),...

CA(:,1),D_70(:,1),...

CA(:,1),D_80(:,1),...

CA(:,1),D_90(:,1),...

CA(:,1),D_100(:,1),...

CA(:,1),D_110(:,1),...

CA(:,1),D_120(:,1),...

CA(:,1),D_130(:,1),...

CA(:,1),D_140(:,1),,..

CA(:,1),D_150(:,1),...

CA(:,1),D_160(:,1),...

CA(:,1),D_170(:,1),...

CA(:,1),D_180(:,1))

hold on

plot(CA(:,1),D_BASELINE(:,1),'k','LineWidth',4)

plot(CA(:,1),D_E(:,1),'b','Linewidth',2)

$\mathrm{x} 1=[-156 .,-156.5]$;

$\mathrm{x} 2=[130.5,130.5]$;

$\mathrm{y}=[0,1000] ;$

plot(x1,y,'--k',x2,y,'--k','LineWidth',1)

title('Plot of Baseline Density ( $\mathrm{kg} / \mathrm{m}^{\wedge} 3$ ) vs Change in Crank Angle')

xlabel('Crank Angle (degree)')

ylabel('Density $\left.\left(\mathrm{kg} / \mathrm{m}^{\wedge} 3\right)^{\prime}\right)$

$x \lim ([\min (\min (\mathrm{CA})) \max (\max (\mathrm{CA}))])$

$\operatorname{ylim}([\min (\min (0)) \max (\max (7.5))])$

hold off

\%Surface plot for CR(1);

$[\mathrm{T}, \mathrm{P}]=\operatorname{meshgrid}(\mathrm{T}(1,:), \mathrm{P}(1,:))$;

f_e_r $=$ f./sqrt $\left(1+(\right.$ e_rN -1$\left.) *\left(\left(T \_N . * P\right) . /\left(T . * P \_N\right)\right)\right)$;

figure(5)

mesh(P_BASELINE,CA,F_BASELINE)

xlabel('Pressure (Pa)')

ylabel('Crank Angle') 
zlabel('Frequency $(\mathrm{GHz})$ ')

$x \lim \left(\left[\min \left(\min \left(\mathrm{P} \_B A S E L I N E\right)\right) \max \left(\max \left(\mathrm{P} \_B A S E L I N E\right)\right)\right]\right)$

$\operatorname{ylim}([\min (\min (\mathrm{CA})) \max (\max (\mathrm{CA}))])$

$\operatorname{zlim}\left(\left[\min \left(\min \left(F \_B A S E L I N E\right)\right) \max \left(\max \left(F \_B A S E L I N E\right)\right)\right]\right)$

$\operatorname{view}([-120120])$

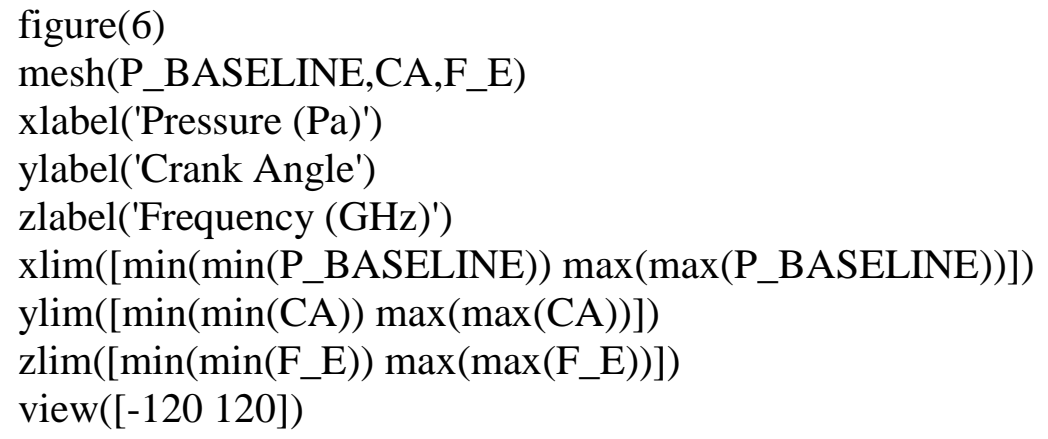




\section{Appendices B: Raw Data}

\section{B.1: Volume of Cylinder by Crank Angle}

\begin{tabular}{|r|r|}
\hline & Volume (m^3) \\
\hline-180 & 0.000764745 \\
\hline-170 & 0.000761128 \\
\hline-160 & 0.000750298 \\
\hline-150 & 0.000732328 \\
\hline-140 & 0.000707364 \\
\hline-130 & 0.000675667 \\
\hline-120 & 0.000637659 \\
\hline-110 & 0.000593974 \\
\hline-100 & 0.000545509 \\
\hline-90 & 0.000493451 \\
\hline-80 & 0.000439281 \\
\hline-70 & 0.000384745 \\
\hline-60 & 0.000331786 \\
\hline-50 & 0.000282445 \\
\hline-40 & 0.00023874 \\
\hline-30 & 0.000202541 \\
\hline-20 & 0.000175446 \\
\hline-10 & 0.000158677 \\
\hline 0 & 0.000153 \\
\hline 10 & 0.000158677 \\
\hline 20 & 0.000175446 \\
\hline 30 & 0.000202541 \\
\hline 40 & 0.00023874 \\
\hline 50 & 0.000282445 \\
\hline 60 & 0.000331786 \\
\hline 70 & 0.000384745 \\
\hline 80 & 0.000439281 \\
\hline 90 & 0.000493451 \\
\hline 100 & 0.000545509 \\
\hline 110 & 0.000593974 \\
\hline 120 & 0.000637659 \\
\hline 130 & 0.000675667 \\
\hline 140 & 0.000707364 \\
\hline 150 & 0.000732328 \\
\hline 160 & 0.000750298 \\
\hline 170 & 0.000761128 \\
\hline 180 & 0.000764745 \\
\hline & \\
\hline
\end{tabular}




\section{B.2: Pressure Data (Pa)}

\begin{tabular}{|c|c|c|c|c|c|c|c|c|c|c|c|c|c|}
\hline & -180 & -170 & -160 & P -150 & -140 & -130 & P -120 & $P-110$ & $P-100$ & P -90 & P -80 & P -70 & $r-c$ \\
\hline-180 & & & & & & & & & & 63500 & & & \\
\hline & & & & & & & & & & & & & \\
\hline-160 & & & & & & & & & & & & & \\
\hline-150 & 87261 & 0000 & 87000 & 46000 & 77500 & 107500 & & & 56500 & & 15000 & & 05000 \\
\hline-14 & & & & & & & & & & & & & \\
\hline-13 & 91072 & 0 & 0 & 725 & 0 & 121 & & & & & & 500 & 000 \\
\hline-120 & & & & & & & & & & & & & \\
\hline-110 & 19 & & & 00 & & & & & & & & & \\
\hline-10 & & & & & & & & & & & & & \\
\hline-9 & & & & & & & & & & & & & \\
\hline-80 & 741 & & & 0 & & & & & & & & & \\
\hline-7 & & & & & & & & & & & & & \\
\hline-60 & 47953 & & & 00 & 000 & 00 & & & & & & & \\
\hline-50 & & & & 00 & & 00 & & & & & & & \\
\hline-40 & 3644 & & 23000 & 78000 & 309000 & & & & & & & & \\
\hline-30 & 3744 & & & 00 & 348000 & 000 & & & & & & & \\
\hline-20 & & & & 00 & & & & & & & & & \\
\hline-10 & & & & & & & & & & & & & \\
\hline 0 & 795806 & & & & 5000 & 807 & & & & & & & \\
\hline 10 & & & & & & & & & & & & & \\
\hline 20 & 698348 & & & 00 & 768000 & 787500 & & 790000 & & 765000 & & & \\
\hline 30 & 689361 & & & & 500 & & & 000 & & 500 & & & \\
\hline 40 & & & & & & & & & & & & & \\
\hline 50 & & & & & & & & & & & & & \\
\hline 60 & 296040 & 338500 & 387500 & 349500 & 377000 & 358500 & 385000 & 361000 & 378500 & 385000 & 352500 & 338500 & 364500 \\
\hline
\end{tabular}




\begin{tabular}{|c|c|c|c|c|c|c|c|c|c|c|c|c|c|}
\hline 70 & 202100 & 219500 & 213000 & 260500 & 204000 & 228000 & 185000 & 191000 & 176500 & 218000 & 260500 & 219500 & 172000 \\
\hline 80 & 170726 & 134000 & 149500 & 146500 & 175000 & 157500 & 165000 & 178500 & 189500 & 163500 & 180500 & 134000 & 201500 \\
\hline 90 & 139107 & 163000 & 124000 & 125500 & 117500 & 153000 & 114500 & 112000 & 125000 & 147500 & 131000 & 163000 & 127000 \\
\hline 100 & 129888 & 168000 & 143000 & 144500 & 138000 & 162000 & 159500 & 126000 & 153500 & 125000 & 155500 & 168000 & 138000 \\
\hline 110 & 126565 & 165000 & 157500 & 134000 & 105000 & 163000 & 117500 & 115500 & 137000 & 129500 & 112000 & 165000 & 152000 \\
\hline 120 & 93465 & 132000 & 93500 & 102000 & 102500 & 118500 & 98000 & 116500 & 111500 & 116500 & 99000 & 132000 & 115500 \\
\hline 130 & 88405 & 138000 & 111500 & 121000 & 81000 & 106000 & 105000 & 77500 & 96000 & 76000 & 116000 & 138000 & 124500 \\
\hline 140 & 90973 & 106000 & 78500 & 95000 & 69500 & 109500 & 99000 & 121000 & 74000 & 111000 & 97000 & 106000 & 112000 \\
\hline 150 & 75910 & 73000 & 65000 & 64500 & 64500 & 63000 & 108000 & 76000 & 54000 & 76000 & 92500 & 73000 & 59000 \\
\hline 160 & 79806 & 93500 & 58500 & 91000 & 93000 & 65000 & 78000 & 86000 & 69500 & 80000 & 96500 & 93500 & 64500 \\
\hline 170 & 77923 & 109500 & 83000 & 75000 & 49500 & 102000 & 96500 & 84000 & 69500 & 91500 & 88500 & 109500 & 67500 \\
\hline 180 & 82303 & 71500 & 105500 & 71500 & 98500 & 88000 & 101000 & 77500 & 77000 & 80000 & 106000 & 71500 & 80500 \\
\hline
\end{tabular}

\begin{tabular}{|c|c|c|c|c|c|c|c|c|c|c|c|c|c|}
\hline P -50 & $\mathrm{P}-40$ & $P-30$ & $P-20$ & $\mathrm{P}-10$ & $\mathrm{PO}$ & P 10 & P 20 & P 30 & P 40 & P 50 & P 60 & P 70 & P 80 \\
\hline 101500 & 72500 & 57000 & 77500 & 63500 & 67000 & 74500 & 102500 & 63500 & 107000 & 79500 & 123500 & 83500 & 106000 \\
\hline 91500 & 95500 & 84500 & 74500 & 88000 & 53500 & 83500 & 81500 & 104500 & 113000 & 92500 & 90000 & 116000 & 122000 \\
\hline 84500 & 89000 & 97500 & 90000 & 58500 & 81000 & 114000 & 91000 & 87500 & 62000 & 96500 & 60500 & 78000 & 106000 \\
\hline 121000 & 82000 & 80000 & 67000 & 91000 & 106500 & 129000 & 106000 & 88000 & 99000 & 77500 & 63500 & 115500 & 60500 \\
\hline 109500 & 67000 & 56500 & 94000 & 75500 & 86500 & 67500 & 127500 & 129000 & 99000 & 69000 & 81500 & 89000 & 103000 \\
\hline 110000 & 72500 & 91000 & 80000 & 108000 & 71000 & 87000 & 71000 & 97000 & 65000 & 109500 & 116000 & 80000 & 64500 \\
\hline 74500 & 74000 & 125500 & 112000 & 101000 & 100500 & 118000 & 101000 & 87500 & 112500 & 81000 & 132500 & 85000 & 106000 \\
\hline 69500 & 145000 & 93000 & 109000 & 103500 & 128500 & 109500 & 74000 & 98000 & 137000 & 89000 & 108500 & 91000 & 88500 \\
\hline 139000 & 95000 & 122500 & 114500 & 80000 & 113000 & 163500 & 79000 & 118000 & 142500 & 128500 & 92000 & 124500 & 101500 \\
\hline 92500 & 123500 & 144500 & 113000 & 115500 & 136000 & 139000 & 120000 & 136500 & 124000 & 134500 & 127500 & 119500 & 98000 \\
\hline 142000 & 166000 & 155500 & 150500 & 159000 & 108500 & 163500 & 189000 & 112500 & 146000 & 121500 & 139500 & 126000 & 145000 \\
\hline 170500 & 160500 & 215000 & 170500 & 160500 & 170500 & 179000 & 176500 & 171500 & 192000 & 172000 & 148000 & 192000 & 175500 \\
\hline 182500 & 198000 & 174000 & 228000 & 212500 & 202000 & 187000 & 206000 & 180500 & 218000 & 230000 & 215500 & 229000 & 192000 \\
\hline
\end{tabular}




\begin{tabular}{|c|c|c|c|c|c|c|c|c|c|c|c|c|c|}
\hline 215000 & 36000 & 65000 & 262000 & 212500 & 249500 & 252500 & 225000 & 245000 & 259500 & 263500 & 245500 & 235000 & 218000 \\
\hline 325500 & 8000 & 5000 & 98000 & & & 2000 & & 8500 & & & & 18500 & 03000 \\
\hline 366000 & 72500 & 10500 & 00 & 00 & 0 & 52000 & 00 & & & & & & \\
\hline & & & & & & & & & & & & & \\
\hline 590000 & 95500 & 83000 & 607500 & 621000 & 06000 & 578000 & 608500 & 609500 & 565000 & 566500 & 580500 & 620500 & 586500 \\
\hline 805000 & 81500 & 91500 & & & & 76000 & & 820000 & & & & & \\
\hline 810 & & & & & & & & & & & & & \\
\hline 785500 & 97500 & 500 & 500 & 774000 & 000 & 500 & 000 & 000 & 500 & & 000 & 000 & 000 \\
\hline & & & & & & & & & & & & & \\
\hline 612000 & 623500 & 590500 & 602000 & 583500 & 604500 & 640000 & 594000 & 605000 & 602000 & 614500 & 609500 & 599000 & 616000 \\
\hline 467500 & 80000 & 000 & 470500 & 504000 & & & & 500 & & & & & \\
\hline 348000 & & & & & & & & & & & & & \\
\hline 207500 & 29000 & 000 & 000 & 189 & 00 & 00 & & 00 & 00 & & & & \\
\hline 174000 & & & & & & & & & & & & & \\
\hline 138500 & 109000 & 134500 & 143000 & 123500 & 5500 & 124500 & 132000 & 149500 & 142000 & & 000 & 000 & \\
\hline 174000 & 182500 & 133000 & 00 & & 500 & 000 & 00 & 500 & 00 & & 000 & 500 & 000 \\
\hline 126500 & & & & & & & & & & & & & \\
\hline 95000 & 147000 & 123500 & 125500 & 136500 & 101000 & 141000 & 150000 & 96500 & 142000 & 102500 & 113500 & 132500 & 122500 \\
\hline 94000 & 000 & 000 & 00 & & 00 & 00 & & 500 & 00 & & 000 & & 500 \\
\hline 89000 & & Pח0 & & & & & & 111000 & 105500 & & 000 & 107000 & 500 \\
\hline 74000 & 114000 & 85500 & 49500 & 64500 & & 95500 & & 86500 & 94500 & & 100000 & 102500 & 76000 \\
\hline 61500 & 70000 & 72000 & 91500 & 110500 & 129500 & 68500 & 89500 & 79500 & 87500 & 93000 & 105500 & 81000 & 80500 \\
\hline & & & & & & & & & & & & & \\
\hline 55500 & 92500 & 65500 & 114500 & 82500 & 61000 & 77500 & 74000 & 91500 & 68000 & 98500 & 103500 & 55500 & 87000 \\
\hline
\end{tabular}

\begin{tabular}{|r|r|r|r|r|r|r|r|r|r|r|}
\hline P 90 & P 100 & P 110 & P 120 & P 130 & P 140 & P 150 & P 160 & P 170 & P 180 & Baseline Average \\
\hline 67000 & 66500 & 63500 & 106000 & 67000 & 66500 & 120500 & 63500 & 89500 & 79500 & 84280 \\
\hline
\end{tabular}




\begin{tabular}{|c|c|c|c|c|c|c|c|c|c|c|}
\hline 53500 & 81500 & 102500 & 122000 & 53500 & 81500 & 111500 & 104500 & 128500 & 92500 & 90095 \\
\hline 81000 & 81000 & 99500 & 106000 & 81000 & 81000 & 103000 & 87500 & 87000 & 96500 & 87234 \\
\hline 106500 & 73000 & 78000 & 60500 & 106500 & 73000 & 60500 & 88000 & 81000 & 77500 & 85395 \\
\hline 86500 & 119000 & 97500 & 103000 & 86500 & 119000 & 110000 & 129000 & 76000 & 69000 & 87310 \\
\hline 71000 & 77000 & 74000 & 64500 & 71000 & 77000 & 106000 & 97000 & 64000 & 109500 & 90249 \\
\hline 100500 & 99000 & 100000 & 106000 & 100500 & 99000 & 124000 & 87500 & 77500 & 81000 & 95860 \\
\hline 128500 & 96500 & 99500 & 88500 & 128500 & 96500 & 119500 & 98000 & 121500 & 89000 & 113875 \\
\hline 113000 & 112500 & 135500 & 101500 & 113000 & 112500 & 105500 & 118000 & 114500 & 128500 & 113875 \\
\hline 136000 & 112000 & 122000 & 98000 & 136000 & 112000 & 93500 & 136500 & 150000 & 134500 & 125265 \\
\hline 108500 & 134000 & 133000 & 145000 & 108500 & 134000 & 123500 & 112500 & 123000 & 121500 & 142990 \\
\hline 170500 & 148000 & 172000 & 175500 & 170500 & 148000 & 157500 & 171500 & 158000 & 172000 & 166560 \\
\hline 202000 & 195500 & 214500 & 192000 & 202000 & 195500 & 214000 & 180500 & 161500 & 230000 & 201545 \\
\hline 249500 & 228000 & 195500 & 218000 & 249500 & 228000 & 225000 & 245000 & 223500 & 263500 & 242525 \\
\hline 291500 & 272000 & 295000 & 303000 & 291500 & 272000 & 318000 & 328500 & 331500 & 309000 & 301145 \\
\hline 373000 & 355000 & 388500 & 351000 & 373000 & 355000 & 397500 & 394000 & 386500 & 348000 & 374715 \\
\hline 519500 & 481500 & 481500 & 464500 & 519500 & 481500 & 516000 & 484000 & 516500 & 475500 & 475655 \\
\hline 606000 & 599500 & 623000 & 586500 & 606000 & 599500 & 615500 & 609500 & 608500 & 566500 & 591375 \\
\hline 810500 & 784000 & 776000 & 751500 & 810500 & 784000 & 794500 & 820000 & 804000 & 795000 & 796010 \\
\hline 765000 & 767000 & 800000 & 795500 & 765000 & 767000 & 778000 & 783500 & 765500 & 801500 & 782495 \\
\hline 789000 & 784500 & 785500 & 771000 & 789000 & 784500 & 822500 & 786000 & 813500 & 768000 & 782495 \\
\hline 701000 & 716000 & 698000 & 688500 & 701000 & 716000 & 731500 & 678000 & 703000 & 716500 & 718150 \\
\hline 604500 & 558000 & 572000 & 616000 & 604500 & 558000 & 594000 & 605000 & 566500 & 614500 & 599945 \\
\hline 462000 & 451000 & 431000 & 469500 & 462000 & 451000 & 481000 & 472500 & 494500 & 474000 & 477615 \\
\hline 379000 & 341500 & 385000 & 391500 & 379000 & 341500 & 373500 & 407500 & 372500 & 377000 & 371940 \\
\hline 222500 & 181000 & 185000 & 212500 & 222500 & 181000 & 224000 & 206500 & 186500 & 204000 & 203325 \\
\hline 213000 & 194000 & 165000 & 168000 & 213000 & 194000 & 188000 & 182500 & 175000 & 175000 & 170595 \\
\hline 96500 & 126000 & 114500 & 131000 & 96500 & 126000 & 126000 & 149500 & 99000 & 117500 & 135890 \\
\hline 148500 & 161000 & 159500 & 179000 & 148500 & 161000 & 151000 & 153500 & 165500 & 138000 & 153940 \\
\hline
\end{tabular}




\begin{tabular}{|r|r|r|r|r|r|r|r|r|r|r|}
\hline 125000 & 123000 & 117500 & 97000 & 125000 & 123000 & 162500 & 135000 & 128500 & 105000 & 129005 \\
\hline 101000 & 80500 & 98000 & 122500 & 101000 & 80500 & 112000 & 96500 & 148000 & 102500 & 114665 \\
\hline 102500 & 78000 & 105000 & 78500 & 102500 & 78000 & 101000 & 72500 & 89500 & 81000 & 99605 \\
\hline 93000 & 82000 & 99000 & 54500 & 93000 & 82000 & 113000 & 111000 & 100000 & 69500 & 92350 \\
\hline 84000 & 108500 & 108000 & 76000 & 84000 & 108500 & 98500 & 86500 & 76000 & 64500 & 92350 \\
\hline 129500 & 113500 & 78000 & 80500 & 129500 & 113500 & 65000 & 79500 & 100000 & 93000 & 81205 \\
\hline 53500 & 49000 & 96500 & 46000 & 53500 & 49000 & 87500 & 79500 & 81500 & 49500 & 75515 \\
\hline 61000 & 59000 & 101000 & 87000 & 61000 & 59000 & 51500 & 91500 & 62500 & 98500 & 82020 \\
\hline
\end{tabular}




\section{B.3: Temperature Data (K)}

\begin{tabular}{|c|c|c|c|c|c|c|c|c|c|c|c|c|c|}
\hline & -180 & -170 & -160 & -150 & -140 & -130 & -120 & -110 & -100 & -90 & -80 & -70 & -60 \\
\hline-180 & 289 & 289 & 289 & 289 & 289 & 289 & 289 & 289 & 289 & 289 & 289 & 289 & 289 \\
\hline-170 & 284 & 253 & 268 & 296 & 268 & 258 & 214 & 303 & 276 & 214 & 273 & 253 & 178 \\
\hline-160 & 301 & 255 & 219 & 310 & 310 & 325 & 343 & 302 & 444 & 342 & 278 & 255 & 370 \\
\hline-150 & 288 & 279 & 185 & 301 & 319 & 332 & 329 & 254 & 251 & 419 & 335 & 279 & 292 \\
\hline-140 & 281 & 187 & 280 & 148 & 250 & 347 & 251 & 261 & 182 & 164 & 371 & 187 & 339 \\
\hline-130 & 286 & 255 & 179 & 179 & 215 & 206 & 304 & 210 & 360 & 316 & 311 & 255 & 371 \\
\hline-120 & 271 & 344 & 268 & 216 & 326 & 361 & 220 & 241 & 257 & 308 & 303 & 344 & 241 \\
\hline-110 & 306 & 299 & 264 & 274 & 227 & 260 & 281 & 255 & 271 & 211 & 261 & 299 & 230 \\
\hline-100 & 300 & 146 & 218 & 288 & 233 & 216 & 260 & 301 & 284 & 295 & 252 & 146 & 299 \\
\hline-90 & 283 & 237 & 243 & 252 & 309 & 313 & 325 & 252 & 229 & 264 & 283 & 237 & 281 \\
\hline-80 & 342 & 290 & 270 & 229 & 292 & 298 & 265 & 331 & 292 & 287 & 272 & 290 & 205 \\
\hline-70 & 290 & 294 & 246 & 312 & 235 & 293 & 257 & 300 & 258 & 231 & 317 & 294 & 238 \\
\hline-60 & 376 & 263 & 250 & 318 & 291 & 244 & 291 & 267 & 266 & 305 & 311 & 263 & 262 \\
\hline-40 & 320 & 306 & 256 & 298 & 328 & 278 & 243 & 325 & 350 & 272 & 281 & 306 & 306 \\
\hline-30 & 456 & 278 & 339 & 292 & 325 & 332 & 310 & 355 & 299 & 335 & 297 & 278 & 334 \\
\hline-20 & 431 & 345 & 315 & 353 & 310 & 311 & 346 & 357 & 333 & 320 & 340 & 345 & 330 \\
\hline-10 & 388 & 358 & 378 & 374 & 367 & 361 & 372 & 359 & 385 & 389 & 358 & 358 & 414 \\
\hline 0 & 531 & 426 & 408 & 424 & 396 & 418 & 435 & 431 & 414 & 401 & 427 & 426 & 411 \\
\hline 10 & 536 & 545 & 532 & 526 & 535 & 544 & 523 & 531 & 515 & 536 & 539 & 545 & 553 \\
\hline 20 & 525 & 536 & 536 & 543 & 560 & 564 & 559 & 549 & 515 & 537 & 551 & 536 & 532 \\
\hline 30 & 539 & 598 & 628 & 631 & 593 & 608 & 607 & 610 & 584 & 591 & 586 & 598 & 620 \\
\hline 40 & 615 & 641 & 631 & 654 & 639 & 634 & 622 & 659 & 658 & 637 & 615 & 641 & 627 \\
\hline 50 & 433 & 623 & 612 & 665 & 646 & 614 & 601 & 620 & 605 & 633 & 602 & 623 & 615 \\
\hline 60 & 470 & 602 & 596 & 584 & 589 & 595 & 536 & 581 & 582 & 573 & 566 & 602 & 585 \\
\hline
\end{tabular}




\begin{tabular}{|c|c|c|c|c|c|c|c|c|c|c|c|c|c|}
\hline 70 & 432 & 494 & 566 & 510 & 551 & 524 & 562 & 527 & 553 & 562 & 515 & 494 & 532 \\
\hline 80 & 342 & 372 & 361 & 441 & 346 & 386 & 313 & 324 & 299 & 369 & 441 & 372 & 291 \\
\hline 90 & 330 & 259 & 289 & 283 & 338 & 305 & 319 & 345 & 366 & 316 & 349 & 259 & 390 \\
\hline 110 & 312 & 403 & 343 & 347 & 331 & 389 & 383 & 303 & 369 & 300 & 373 & 403 & 331 \\
\hline 120 & 331 & 431 & 412 & 350 & 275 & 426 & 307 & 302 & 358 & 339 & 293 & 431 & 397 \\
\hline 130 & 262 & 371 & 262 & 286 & 288 & 333 & 275 & 327 & 313 & 327 & 278 & 371 & 324 \\
\hline 140 & 263 & 410 & 332 & 360 & 241 & 315 & 312 & 231 & 286 & 226 & 345 & 410 & 370 \\
\hline 150 & 283 & 330 & 244 & 296 & 216 & 341 & 308 & 377 & 230 & 346 & 302 & 330 & 349 \\
\hline 160 & 245 & 235 & 210 & 208 & 208 & 203 & 348 & 245 & 174 & 245 & 298 & 235 & 190 \\
\hline 170 & 264 & 309 & 193 & 301 & 307 & 215 & 258 & 284 & 230 & 264 & 319 & 309 & 213 \\
\hline 180 & 261 & 367 & 278 & 251 & 166 & 342 & 323 & 281 & 233 & 307 & 297 & 367 & 226 \\
\hline
\end{tabular}

\begin{tabular}{|c|c|c|c|c|c|c|c|c|c|c|c|c|c|}
\hline-50 & -40 & -30 & -20 & -10 & 0 & 10 & 20 & 30 & 40 & 50 & 60 & 70 & 80 \\
\hline 289 & 289 & 289 & 289 & 289 & 289 & 289 & 289 & 289 & 289 & 289 & 289 & 289 & 289 \\
\hline 342 & 244 & 192 & 261 & 214 & 226 & 251 & 345 & 214 & 360 & 268 & 416 & 281 & 357 \\
\hline 307 & 320 & 283 & 250 & 295 & 179 & 280 & 273 & 350 & 379 & 310 & 302 & 389 & 409 \\
\hline 279 & 294 & 322 & 297 & 193 & 268 & 377 & 301 & 289 & 205 & 319 & 200 & 258 & 350 \\
\hline 390 & 264 & 258 & 216 & 293 & 343 & 416 & 342 & 284 & 319 & 250 & 205 & 372 & 195 \\
\hline 341 & 209 & 176 & 293 & 235 & 269 & 210 & 397 & 402 & 308 & 215 & 254 & 277 & 321 \\
\hline 327 & 216 & 271 & 238 & 321 & 211 & 259 & 211 & 289 & 193 & 326 & 345 & 238 & 192 \\
\hline 209 & 208 & 352 & 314 & 284 & 282 & 331 & 284 & 246 & 316 & 227 & 372 & 239 & 298 \\
\hline 182 & 379 & 243 & 285 & 271 & 336 & 286 & 194 & 256 & 358 & 233 & 284 & 238 & 231 \\
\hline 334 & 228 & 294 & 275 & 192 & 271 & 393 & 190 & 283 & 342 & 309 & 221 & 299 & 244 \\
\hline 201 & 268 & 314 & 245 & 251 & 295 & 302 & 261 & 297 & 269 & 292 & 277 & 260 & 213 \\
\hline 275 & 321 & 301 & 291 & 307 & 210 & 316 & 366 & 218 & 282 & 235 & 270 & 244 & 280 \\
\hline 289 & 272 & 364 & 289 & 272 & 289 & 303 & 299 & 290 & 325 & 291 & 251 & 325 & 297 \\
\hline
\end{tabular}




\begin{tabular}{|c|c|c|c|c|c|c|c|c|c|c|c|c|c|}
\hline 267 & 289 & 254 & 333 & 310 & 295 & 273 & 301 & 264 & 318 & 336 & 315 & 334 & 280 \\
\hline 267 & 293 & 330 & 326 & 264 & 310 & 314 & 280 & 305 & 323 & 328 & 305 & 292 & 271 \\
\hline 342 & 292 & 342 & 313 & 315 & 306 & 317 & 282 & 345 & 319 & 325 & 327 & 335 & 318 \\
\hline 326 & 332 & 366 & 320 & 355 & 333 & 314 & 342 & 351 & 337 & 310 & 373 & 354 & 313 \\
\hline 351 & 339 & 375 & 368 & 346 & 401 & 376 & 346 & 374 & 373 & 367 & 375 & 372 & 359 \\
\hline 412 & 416 & 407 & 424 & 434 & 423 & 404 & 425 & 426 & 395 & 396 & 406 & 433 & 410 \\
\hline 542 & 526 & 533 & 545 & 547 & 546 & 523 & 528 & 552 & 534 & 535 & 542 & 539 & 506 \\
\hline 566 & 534 & 526 & 553 & 529 & 534 & 535 & 578 & 547 & 519 & 560 & 568 & 560 & 556 \\
\hline 607 & 616 & 621 & 638 & 598 & 609 & 601 & 611 & 607 & 619 & 593 & 602 & 631 & 596 \\
\hline 618 & 650 & 587 & 635 & 674 & 625 & 649 & 653 & 605 & 646 & 639 & 621 & 659 & 614 \\
\hline 643 & 655 & 621 & 633 & 613 & 635 & 673 & 624 & 636 & 633 & 646 & 641 & 630 & 647 \\
\hline 581 & 597 & 607 & 585 & 627 & 574 & 601 & 549 & 588 & 579 & 589 & 597 & 579 & 584 \\
\hline 508 & 566 & 527 & 591 & 566 & 554 & 519 & 539 & 595 & 554 & 551 & 586 & 566 & 572 \\
\hline 351 & 388 & 347 & 347 & 321 & 377 & 412 & 359 & 350 & 341 & 346 & 348 & 348 & 360 \\
\hline 301 & 237 & 292 & 311 & 268 & 210 & 270 & 287 & 325 & 308 & 255 & 356 & 324 & 285 \\
\hline 418 & 438 & 319 & 351 & 369 & 357 & 317 & 301 & 369 & 304 & 331 & 298 & 323 & 430 \\
\hline 331 & 490 & 332 & 407 & 324 & 327 & 221 & 384 & 353 & 367 & 275 & 227 & 272 & 254 \\
\hline 267 & 413 & 347 & 352 & 383 & 284 & 396 & 421 & 271 & 399 & 288 & 319 & 372 & 344 \\
\hline 280 & 399 & 274 & 352 & 222 & 305 & 338 & 284 & 216 & 294 & 241 & 315 & 213 & 234 \\
\hline 277 & 226 & 206 & 297 & 258 & 290 & 232 & 263 & 346 & 329 & 216 & 286 & 333 & 170 \\
\hline 239 & 368 & 276 & 160 & 208 & 271 & 308 & 250 & 279 & 305 & 208 & 322 & 330 & 245 \\
\hline 203 & 231 & 238 & 302 & 365 & 428 & 226 & 296 & 263 & 289 & 307 & 348 & 268 & 266 \\
\hline 186 & 171 & 265 & 243 & 225 & 179 & 293 & 275 & 266 & 243 & 166 & 307 & 230 & 154 \\
\hline
\end{tabular}

\begin{tabular}{|r|r|r|r|r|r|r|r|r|r|r|}
\hline 90 & 100 & 110 & 120 & 130 & 140 & 150 & 160 & 170 & 180 & Baseline Temperature \\
\hline 289 & 289 & 289 & 289 & 289 & 289 & 289 & 289 & 289 & 289 & 289 \\
\hline
\end{tabular}




\begin{tabular}{|c|c|c|c|c|c|c|c|c|c|c|}
\hline 226 & 224 & 214 & 357 & 226 & 224 & 406 & 214 & 301 & 268 & 284 \\
\hline 179 & 273 & 343 & 409 & 179 & 273 & 374 & 350 & 431 & 310 & 302 \\
\hline 268 & 268 & 329 & 350 & 268 & 268 & 340 & 289 & 287 & 319 & 288 \\
\hline 343 & 235 & 251 & 195 & 343 & 235 & 195 & 284 & 261 & 250 & 275 \\
\hline 269 & 371 & 304 & 321 & 269 & 371 & 343 & 402 & 237 & 215 & 272 \\
\hline 211 & 229 & 220 & 192 & 211 & 229 & 315 & 289 & 190 & 326 & 268 \\
\hline 282 & 278 & 281 & 298 & 282 & 278 & 348 & 246 & 218 & 227 & 269 \\
\hline 336 & 252 & 260 & 231 & 336 & 252 & 312 & 256 & 318 & 233 & 298 \\
\hline 271 & 270 & 325 & 244 & 271 & 270 & 253 & 283 & 275 & 309 & 273 \\
\hline 295 & 243 & 265 & 213 & 295 & 243 & 203 & 297 & 326 & 292 & 272 \\
\hline 210 & 259 & 257 & 280 & 210 & 259 & 239 & 218 & 238 & 235 & 277 \\
\hline 289 & 251 & 291 & 297 & 289 & 251 & 267 & 290 & 268 & 291 & 282 \\
\hline 295 & 286 & 313 & 280 & 295 & 286 & 313 & 264 & 236 & 336 & 294 \\
\hline 310 & 284 & 243 & 271 & 310 & 284 & 280 & 305 & 278 & 328 & 302 \\
\hline 333 & 317 & 346 & 313 & 333 & 317 & 354 & 351 & 345 & 310 & 334 \\
\hline 401 & 372 & 372 & 359 & 401 & 372 & 399 & 374 & 399 & 367 & 367 \\
\hline 423 & 419 & 435 & 410 & 423 & 419 & 430 & 426 & 425 & 396 & 413 \\
\hline 546 & 528 & 523 & 506 & 546 & 528 & 535 & 552 & 542 & 535 & 536 \\
\hline 534 & 536 & 559 & 556 & 534 & 536 & 543 & 547 & 535 & 560 & 547 \\
\hline 609 & 606 & 607 & 596 & 609 & 606 & 635 & 607 & 628 & 593 & 604 \\
\hline 625 & 638 & 622 & 614 & 625 & 638 & 652 & 605 & 627 & 639 & 640 \\
\hline 635 & 586 & 601 & 647 & 635 & 586 & 624 & 636 & 595 & 646 & 631 \\
\hline 574 & 561 & 536 & 584 & 574 & 561 & 598 & 588 & 615 & 589 & 594 \\
\hline 554 & 499 & 562 & 572 & 554 & 499 & 546 & 595 & 544 & 551 & 543 \\
\hline 377 & 307 & 313 & 360 & 377 & 307 & 379 & 350 & 316 & 346 & 344 \\
\hline 412 & 375 & 319 & 325 & 412 & 375 & 364 & 353 & 338 & 338 & 330 \\
\hline
\end{tabular}




\begin{tabular}{|l|l|l|l|l|l|l|l|l|l|l|}
\hline 357 & 387 & 383 & 430 & 357 & 387 & 363 & 369 & 397 & 331 & \\
\hline 327 & 322 & 307 & 254 & 327 & 322 & 425 & 353 & 336 & 275 & 370 \\
\hline 284 & 226 & 275 & 344 & 284 & 226 & 314 & 271 & 415 & 288 & 337 \\
\hline 305 & 232 & 312 & 234 & 305 & 232 & 300 & 216 & 266 & 241 & 322 \\
\hline 290 & 255 & 308 & 170 & 290 & 255 & 352 & 346 & 311 & 216 & 296 \\
\hline 271 & 350 & 348 & 245 & 271 & 350 & 318 & 279 & 245 & 208 & 288 \\
\hline 428 & 375 & 258 & 266 & 428 & 375 & 215 & 263 & 330 & 307 & 298 \\
\hline 179 & 164 & 323 & 154 & 179 & 164 & 293 & 266 & 273 & 166 & \\
\hline
\end{tabular}




\section{B.4: Pressure Data (bar)}

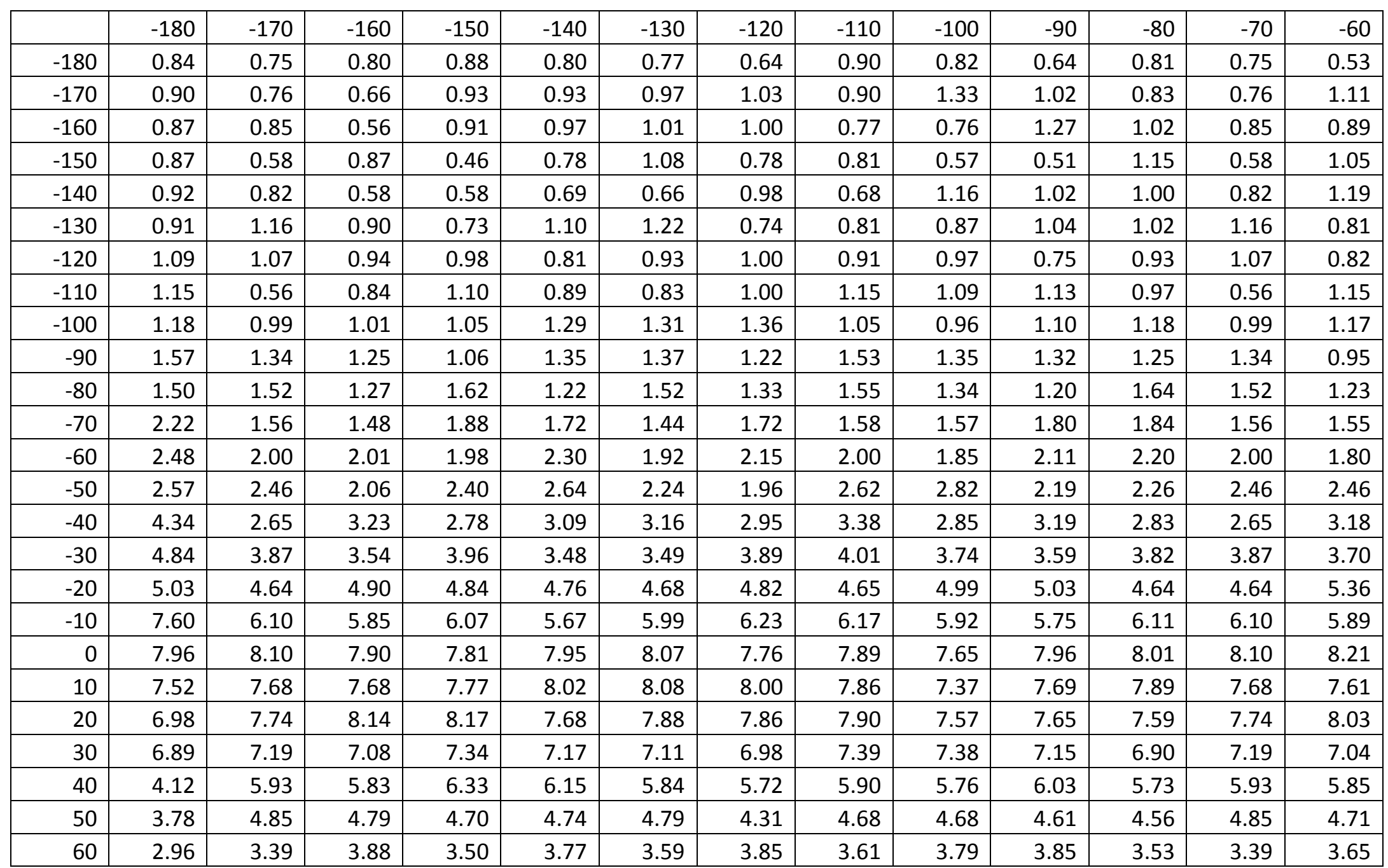




\begin{tabular}{|r|r|r|r|r|r|r|r|r|r|r|r|r|r|}
\hline 70 & 2.02 & 2.20 & 2.13 & 2.61 & 2.04 & 2.28 & 1.85 & 1.91 & 1.77 & 2.18 & 2.61 & 2.20 & 1.72 \\
\hline 80 & 1.71 & 1.34 & 1.50 & 1.47 & 1.75 & 1.58 & 1.65 & 1.79 & 1.90 & 1.64 & 1.81 & 1.34 & 2.02 \\
\hline 90 & 1.39 & 1.63 & 1.24 & 1.26 & 1.18 & 1.53 & 1.15 & 1.12 & 1.25 & 1.48 & 1.31 & 1.63 & 1.27 \\
\hline 100 & 1.30 & 1.68 & 1.43 & 1.45 & 1.38 & 1.62 & 1.60 & 1.26 & 1.54 & 1.25 & 1.56 & 1.68 & 1.38 \\
\hline 110 & 1.27 & 1.65 & 1.58 & 1.34 & 1.05 & 1.63 & 1.18 & 1.16 & 1.37 & 1.30 & 1.12 & 1.65 & 1.52 \\
\hline 120 & 0.93 & 1.32 & 0.94 & 1.02 & 1.03 & 1.19 & 0.98 & 1.17 & 1.12 & 1.17 & 0.99 & 1.32 & 1.16 \\
\hline 130 & 0.88 & 1.38 & 1.12 & 1.21 & 0.81 & 1.06 & 1.05 & 0.78 & 0.96 & 0.76 & 1.16 & 1.38 & 1.25 \\
\hline 140 & 0.91 & 1.06 & 0.79 & 0.95 & 0.70 & 1.10 & 0.99 & 1.21 & 0.74 & 1.11 & 0.97 & 1.06 & 1.12 \\
\hline 150 & 0.76 & 0.73 & 0.65 & 0.65 & 0.65 & 0.63 & 1.08 & 0.76 & 0.54 & 0.76 & 0.93 & 0.73 & 0.59 \\
\hline 160 & 0.80 & 0.94 & 0.59 & 0.91 & 0.93 & 0.65 & 0.78 & 0.86 & 0.70 & 0.80 & 0.97 & 0.94 & 0.65 \\
\hline 170 & 0.78 & 1.10 & 0.83 & 0.75 & 0.50 & 1.02 & 0.97 & 0.84 & 0.70 & 0.92 & 0.89 & 1.10 & 0.68 \\
\hline 180 & 0.82 & 0.72 & 1.06 & 0.72 & 0.99 & 0.88 & 1.01 & 0.78 & 0.77 & 0.80 & 1.06 & 0.72 & 0.81 \\
\hline
\end{tabular}

\begin{tabular}{|c|c|c|c|c|c|c|c|c|c|c|c|c|c|}
\hline-50 & -40 & -30 & -20 & -10 & 0 & 10 & 20 & 30 & 40 & 50 & 60 & 70 & 80 \\
\hline 1.02 & 0.73 & 0.57 & 0.78 & 0.64 & 0.67 & 0.75 & 1.03 & 0.64 & 1.07 & 0.80 & 1.24 & 0.84 & 1.06 \\
\hline 0.92 & 0.96 & 0.85 & 0.75 & 0.88 & 0.54 & 0.84 & 0.82 & 1.05 & 1.13 & 0.93 & 0.90 & 1.16 & 1.22 \\
\hline 0.85 & 0.89 & 0.98 & 0.90 & 0.59 & 0.81 & 1.14 & 0.91 & 0.88 & 0.62 & 0.97 & 0.61 & 0.78 & 1.06 \\
\hline 1.21 & 0.82 & 0.80 & 0.67 & 0.91 & 1.07 & 1.29 & 1.06 & 0.88 & 0.99 & 0.78 & 0.64 & 1.16 & 0.61 \\
\hline 1.10 & 0.67 & 0.57 & 0.94 & 0.76 & 0.87 & 0.68 & 1.28 & 1.29 & 0.99 & 0.69 & 0.82 & 0.89 & 1.03 \\
\hline 1.10 & 0.73 & 0.91 & 0.80 & 1.08 & 0.71 & 0.87 & 0.71 & 0.97 & 0.65 & 1.10 & 1.16 & 0.80 & 0.65 \\
\hline 0.75 & 0.74 & 1.26 & 1.12 & 1.01 & 1.01 & 1.18 & 1.01 & 0.88 & 1.13 & 0.81 & 1.33 & 0.85 & 1.06 \\
\hline 0.70 & 1.45 & 0.93 & 1.09 & 1.04 & 1.29 & 1.10 & 0.74 & 0.98 & 1.37 & 0.89 & 1.09 & 0.91 & 0.89 \\
\hline 1.39 & 0.95 & 1.23 & 1.15 & 0.80 & 1.13 & 1.64 & 0.79 & 1.18 & 1.43 & 1.29 & 0.92 & 1.25 & 1.02 \\
\hline 0.93 & 1.24 & 1.45 & 1.13 & 1.16 & 1.36 & 1.39 & 1.20 & 1.37 & 1.24 & 1.35 & 1.28 & 1.20 & 0.98 \\
\hline 1.42 & 1.66 & 1.56 & 1.51 & 1.59 & 1.09 & 1.64 & 1.89 & 1.13 & 1.46 & 1.22 & 1.40 & 1.26 & 1.45 \\
\hline 1.71 & 1.61 & 2.15 & 1.71 & 1.61 & 1.71 & 1.79 & 1.77 & 1.72 & 1.92 & 1.72 & 1.48 & 1.92 & 1.76 \\
\hline 1.83 & 1.98 & 1.74 & 2.28 & 2.13 & 2.02 & 1.87 & 2.06 & 1.81 & 2.18 & 2.30 & 2.16 & 2.29 & 1.92 \\
\hline
\end{tabular}




\begin{tabular}{|c|c|c|c|c|c|c|c|c|c|c|c|c|c|}
\hline 2.15 & 2.36 & 2.65 & 2.62 & 2.13 & 2.50 & 2.53 & 2.25 & 2.45 & 2.60 & 2.64 & 2.46 & 2.35 & 2.18 \\
\hline 3.26 & 2.78 & 3.25 & 2.98 & 3.00 & 2.92 & 3.02 & 2.68 & 3.29 & 3.04 & 3.09 & 3.12 & 3.19 & 3.03 \\
\hline 3.66 & 3.73 & 4.11 & 3.59 & 3.98 & 3.73 & 3.52 & 3.83 & 3.94 & 3.78 & 3.48 & 4.18 & 3.98 & 3.51 \\
\hline 4.54 & 4.40 & 4.86 & 4.77 & 4.49 & 5.20 & 4.87 & 4.48 & 4.84 & 4.83 & 4.76 & 4.86 & 4.82 & 4.65 \\
\hline 5.90 & 5.96 & 5.83 & 6.08 & 6.21 & 6.06 & 5.78 & 6.09 & 6.10 & 5.65 & 5.67 & 5.81 & 6.21 & 5.87 \\
\hline 8.05 & 7.82 & 7.92 & 8.10 & 8.12 & 8.11 & 7.76 & 7.85 & 8.20 & 7.93 & 7.95 & 8.04 & 8.00 & 7.52 \\
\hline 8.10 & 7.65 & 7.54 & 7.92 & 7.58 & 7.65 & 7.67 & 8.28 & 7.84 & 7.43 & 8.02 & 8.14 & 8.02 & 7.96 \\
\hline 7.86 & 7.98 & 8.04 & 8.26 & 7.74 & 7.89 & 7.79 & 7.91 & 7.86 & 8.02 & 7.68 & 7.79 & 8.17 & 7.71 \\
\hline 6.94 & 7.29 & 6.58 & 7.13 & 7.56 & 7.01 & 7.28 & 7.32 & 6.78 & 7.24 & 7.17 & 6.97 & 7.40 & 6.89 \\
\hline 6.12 & 6.24 & 5.91 & 6.02 & 5.84 & 6.05 & 6.40 & 5.94 & 6.05 & 6.02 & 6.15 & 6.10 & 5.99 & 6.16 \\
\hline 4.68 & 4.80 & 4.88 & 4.71 & 5.04 & 4.62 & 4.83 & 4.42 & 4.73 & 4.66 & 4.74 & 4.80 & 4.66 & 4.70 \\
\hline 3.48 & 3.88 & 3.61 & 4.05 & 3.88 & 3.79 & 3.55 & 3.69 & 4.08 & 3.80 & 3.77 & 4.02 & 3.88 & 3.92 \\
\hline 2.08 & 2.29 & 2.05 & 2.05 & 1.90 & 2.23 & 2.43 & 2.12 & 2.07 & 2.02 & 2.04 & 2.06 & 2.06 & 2.13 \\
\hline 1.74 & 1.88 & 1.18 & 1.63 & 1.66 & 2.13 & 1.73 & 1.43 & 1.83 & 1.36 & 1.75 & 1.50 & 1.57 & 1.68 \\
\hline 1.39 & 1.09 & 1.35 & 1.43 & 1.24 & 0.97 & 1.25 & 1.32 & 1.50 & 1.42 & 1.18 & 1.64 & 1.49 & 1.31 \\
\hline 1.74 & 1.83 & 1.33 & 1.46 & 1.54 & 1.49 & 1.32 & 1.26 & 1.54 & 1.27 & 1.38 & 1.24 & 1.35 & 1.79 \\
\hline 1.27 & 1.88 & 1.27 & 1.56 & 1.24 & 1.25 & 0.85 & 1.47 & 1.35 & 1.41 & 1.05 & 0.87 & 1.04 & 0.97 \\
\hline 0.95 & 1.47 & 1.24 & 1.26 & 1.37 & 1.01 & 1.41 & 1.50 & 0.97 & 1.42 & 1.03 & 1.14 & 1.33 & 1.23 \\
\hline 0.94 & 1.34 & 0.92 & 1.19 & 0.75 & 1.03 & 1.14 & 0.96 & 0.73 & 0.99 & 0.81 & 1.06 & 0.72 & 0.79 \\
\hline 0.89 & 0.73 & 0.66 & 0.96 & 0.83 & 0.93 & 0.75 & 0.85 & 1.11 & 1.06 & 0.70 & 0.92 & 1.07 & 0.55 \\
\hline 0.74 & 1.14 & 0.86 & 0.50 & 0.65 & 0.84 & 0.96 & 0.78 & 0.87 & 0.95 & 0.65 & 1.00 & 1.03 & 0.76 \\
\hline 0.62 & 0.70 & 0.72 & 0.92 & 1.11 & 1.30 & 0.69 & 0.90 & 0.80 & 0.88 & 0.93 & 1.06 & 0.81 & 0.81 \\
\hline 0.56 & 0.51 & 0.79 & 0.73 & 0.67 & 0.54 & 0.88 & 0.82 & 0.80 & 0.73 & 0.50 & 0.92 & 0.69 & 0.46 \\
\hline 0.56 & 0.93 & 0.66 & 1.15 & 0.83 & 0.61 & 0.78 & 0.74 & 0.92 & 0.68 & 0.99 & 1.04 & 0.56 & 0.87 \\
\hline
\end{tabular}

\begin{tabular}{|r|r|r|r|r|r|r|r|r|r|r|}
\hline 90 & 100 & 110 & 120 & 130 & 140 & 150 & 160 & 170 & 180 & Baseline Pressure (bar) \\
\hline 0.67 & 0.67 & 0.64 & 1.06 & 0.67 & 0.67 & 1.21 & 0.64 & 0.90 & 0.80 & 0.84 \\
\hline
\end{tabular}




\begin{tabular}{|c|c|c|c|c|c|c|c|c|c|c|}
\hline 0.54 & 0.82 & 1.03 & 1.22 & 0.54 & 0.82 & 1.12 & 1.05 & 1.29 & 0.93 & 0.90 \\
\hline 0.81 & 0.81 & 1.00 & 1.06 & 0.81 & 0.81 & 1.03 & 0.88 & 0.87 & 0.97 & 0.87 \\
\hline 1.07 & 0.73 & 0.78 & 0.61 & 1.07 & 0.73 & 0.61 & 0.88 & 0.81 & 0.78 & 0.85 \\
\hline 0.87 & 1.19 & 0.98 & 1.03 & 0.87 & 1.19 & 1.10 & 1.29 & 0.76 & 0.69 & 0.87 \\
\hline 0.71 & 0.77 & 0.74 & 0.65 & 0.71 & 0.77 & 1.06 & 0.97 & 0.64 & 1.10 & 0.90 \\
\hline 1.01 & 0.99 & 1.00 & 1.06 & 1.01 & 0.99 & 1.24 & 0.88 & 0.78 & 0.81 & 0.96 \\
\hline 1.29 & 0.97 & 1.00 & 0.89 & 1.29 & 0.97 & 1.20 & 0.98 & 1.22 & 0.89 & 1.14 \\
\hline 1.13 & 1.13 & 1.36 & 1.02 & 1.13 & 1.13 & 1.06 & 1.18 & 1.15 & 1.29 & 1.14 \\
\hline 1.36 & 1.12 & 1.22 & 0.98 & 1.36 & 1.12 & 0.94 & 1.37 & 1.50 & 1.35 & 1.25 \\
\hline 1.09 & 1.34 & 1.33 & 1.45 & 1.09 & 1.34 & 1.24 & 1.13 & 1.23 & 1.22 & 1.43 \\
\hline 1.71 & 1.48 & 1.72 & 1.76 & 1.71 & 1.48 & 1.58 & 1.72 & 1.58 & 1.72 & 1.67 \\
\hline 2.02 & 1.96 & 2.15 & 1.92 & 2.02 & 1.96 & 2.14 & 1.81 & 1.62 & 2.30 & 2.02 \\
\hline 2.50 & 2.28 & 1.96 & 2.18 & 2.50 & 2.28 & 2.25 & 2.45 & 2.24 & 2.64 & 2.43 \\
\hline 2.92 & 2.72 & 2.95 & 3.03 & 2.92 & 2.72 & 3.18 & 3.29 & 3.32 & 3.09 & 3.01 \\
\hline 5.20 & 4.82 & 4.82 & 4.65 & 5.20 & 4.82 & 5.16 & 4.84 & 5.17 & 4.76 & 4.76 \\
\hline 6.06 & 6.00 & 6.23 & 5.87 & 6.06 & 6.00 & 6.16 & 6.10 & 6.09 & 5.67 & 5.91 \\
\hline 8.11 & 7.84 & 7.76 & 7.52 & 8.11 & 7.84 & 7.95 & 8.20 & 8.04 & 7.95 & 7.96 \\
\hline 7.65 & 7.67 & 8.00 & 7.96 & 7.65 & 7.67 & 7.78 & 7.84 & 7.66 & 8.02 & 7.82 \\
\hline 7.89 & 7.85 & 7.86 & 7.71 & 7.89 & 7.85 & 8.23 & 7.86 & 8.14 & 7.68 & 7.82 \\
\hline 7.01 & 7.16 & 6.98 & 6.89 & 7.01 & 7.16 & 7.32 & 6.78 & 7.03 & 7.17 & 7.18 \\
\hline 6.05 & 5.58 & 5.72 & 6.16 & 6.05 & 5.58 & 5.94 & 6.05 & 5.67 & 6.15 & 6.00 \\
\hline 4.62 & 4.51 & 4.31 & 4.70 & 4.62 & 4.51 & 4.81 & 4.73 & 4.95 & 4.74 & 4.78 \\
\hline 3.79 & 3.42 & 3.85 & 3.92 & 3.79 & 3.42 & 3.74 & 4.08 & 3.73 & 3.77 & 3.72 \\
\hline 2.23 & 1.81 & 1.85 & 2.13 & 2.23 & 1.81 & 2.24 & 2.07 & 1.87 & 2.04 & 2.03 \\
\hline 2.13 & 1.94 & 1.65 & 1.68 & 2.13 & 1.94 & 1.88 & 1.83 & 1.75 & 1.75 & 1.71 \\
\hline 0.97 & 1.26 & 1.15 & 1.31 & 0.97 & 1.26 & 1.26 & 1.50 & 0.99 & 1.18 & 1.36 \\
\hline
\end{tabular}




\begin{tabular}{|l|l|l|l|l|l|l|l|l|l|l|}
\hline 1.25 & 1.23 & 1.18 & 0.97 & 1.25 & 1.23 & 1.63 & 1.35 & 1.29 & 1.05 & \\
\hline 1.01 & 0.81 & 0.98 & 1.23 & 1.01 & 0.81 & 1.12 & 0.97 & 1.48 & 1.03 & 1.29 \\
\hline 1.03 & 0.78 & 1.05 & 0.79 & 1.03 & 0.78 & 1.01 & 0.73 & 0.90 & 0.81 & 1.15 \\
\hline 0.93 & 0.82 & 0.99 & 0.55 & 0.93 & 0.82 & 1.13 & 1.11 & 1.00 & 0.70 & 1.00 \\
\hline 0.84 & 1.09 & 1.08 & 0.76 & 0.84 & 1.09 & 0.99 & 0.87 & 0.76 & 0.65 & 0.92 \\
\hline 1.30 & 1.14 & 0.78 & 0.81 & 1.30 & 1.14 & 0.65 & 0.80 & 1.00 & 0.93 & 0.92 \\
\hline 0.54 & 0.49 & 0.97 & 0.46 & 0.54 & 0.49 & 0.88 & 0.80 & 0.82 & 0.50 & 0.81 \\
\hline 0.61 & 0.59 & 1.01 & 0.87 & 0.61 & 0.59 & 0.52 & 0.92 & 0.63 & 0.99 & 0.76 \\
\hline
\end{tabular}




\section{B.5: Frequency $(\mathrm{GHz})$}

\begin{tabular}{|c|c|c|c|c|c|c|c|c|}
\hline Frequency & -180 & -170 & -160 & -150 & -140 & -130 & -120 & -110 \\
\hline-180 & $2.44 \mathrm{E}+09$ & $2.44 \mathrm{E}+09$ & $2.44 \mathrm{E}+09$ & $2.44 \mathrm{E}+09$ & $2.44 E+09$ & $2.44 \mathrm{E}+09$ & $2.45 E+09$ & $2.44 E+09$ \\
\hline-170 & $2.44 \mathrm{E}+09$ & $2.44 \mathrm{E}+09$ & $2.44 \mathrm{E}+09$ & $2.44 \mathrm{E}+09$ & $2.44 E+09$ & $2.44 E+09$ & $2.44 \mathrm{E}+09$ & $2.44 \mathrm{E}+09$ \\
\hline-160 & $2.44 \mathrm{E}+09$ & $2.44 \mathrm{E}+09$ & $2.44 \mathrm{E}+09$ & $2.44 \mathrm{E}+09$ & $2.44 \mathrm{E}+09$ & $2.44 \mathrm{E}+09$ & $2.44 \mathrm{E}+09$ & $2.44 \mathrm{E}+09$ \\
\hline-150 & $2.44 \mathrm{E}+09$ & $2.45 E+09$ & $2.44 \mathrm{E}+09$ & $2.45 E+09$ & $2.44 E+09$ & $2.44 \mathrm{E}+09$ & $2.44 E+09$ & $2.44 \mathrm{E}+09$ \\
\hline-140 & $2.44 \mathrm{E}+09$ & $2.44 \mathrm{E}+09$ & $2.45 E+09$ & $2.44 \mathrm{E}+09$ & $2.44 E+09$ & $2.45 E+09$ & $2.44 \mathrm{E}+09$ & $2.44 E+09$ \\
\hline-130 & $2.44 \mathrm{E}+09$ & $2.44 \mathrm{E}+09$ & $2.44 \mathrm{E}+09$ & $2.44 \mathrm{E}+09$ & $2.44 E+09$ & $2.44 \mathrm{E}+09$ & $2.44 \mathrm{E}+09$ & $2.44 \mathrm{E}+09$ \\
\hline-120 & $2.44 \mathrm{E}+09$ & $2.44 \mathrm{E}+09$ & $2.44 \mathrm{E}+09$ & $2.44 \mathrm{E}+09$ & $2.44 \mathrm{E}+09$ & $2.44 \mathrm{E}+09$ & $2.44 \mathrm{E}+09$ & $2.44 \mathrm{E}+09$ \\
\hline-110 & $2.44 \mathrm{E}+09$ & $2.45 E+09$ & $2.44 \mathrm{E}+09$ & $2.44 \mathrm{E}+09$ & $2.44 \mathrm{E}+09$ & $2.44 E+09$ & $2.44 \mathrm{E}+09$ & $2.44 E+09$ \\
\hline-100 & $2.44 \mathrm{E}+09$ & $2.44 \mathrm{E}+09$ & $2.44 \mathrm{E}+09$ & $2.44 \mathrm{E}+09$ & $2.44 E+09$ & $2.44 \mathrm{E}+09$ & $2.44 \mathrm{E}+09$ & $2.44 \mathrm{E}+09$ \\
\hline-90 & $2.44 \mathrm{E}+09$ & $2.44 \mathrm{E}+09$ & $2.44 \mathrm{E}+09$ & $2.44 \mathrm{E}+09$ & $2.44 E+09$ & $2.44 \mathrm{E}+09$ & $2.44 \mathrm{E}+09$ & $2.44 \mathrm{E}+09$ \\
\hline-80 & $2.44 \mathrm{E}+09$ & $2.44 \mathrm{E}+09$ & $2.44 \mathrm{E}+09$ & $2.44 \mathrm{E}+09$ & $2.44 \mathrm{E}+09$ & $2.44 \mathrm{E}+09$ & $2.44 \mathrm{E}+09$ & $2.44 \mathrm{E}+09$ \\
\hline-70 & $2.43 E+09$ & $2.44 \mathrm{E}+09$ & $2.44 \mathrm{E}+09$ & $2.44 \mathrm{E}+09$ & $2.43 E+09$ & $2.44 \mathrm{E}+09$ & $2.44 \mathrm{E}+09$ & $2.44 \mathrm{E}+09$ \\
\hline-60 & $2.44 \mathrm{E}+09$ & $2.43 E+09$ & $2.43 E+09$ & $2.44 \mathrm{E}+09$ & $2.43 E+09$ & $2.43 E+09$ & $2.43 E+09$ & $2.43 E+09$ \\
\hline-40 & $2.42 \mathrm{E}+09$ & $2.43 \mathrm{E}+09$ & $2.42 \mathrm{E}+09$ & $2.43 E+09$ & $2.43 E+09$ & $2.43 E+09$ & $2.42 \mathrm{E}+09$ & $2.43 E+09$ \\
\hline-30 & $2.43 E+09$ & $2.42 \mathrm{E}+09$ & $2.43 \mathrm{E}+09$ & $2.42 \mathrm{E}+09$ & $2.43 E+09$ & $2.43 E+09$ & $2.42 \mathrm{E}+09$ & $2.43 E+09$ \\
\hline-20 & $2.43 \mathrm{E}+09$ & $2.42 \mathrm{E}+09$ & $2.42 \mathrm{E}+09$ & $2.42 E+09$ & $2.42 E+09$ & $2.42 E+09$ & $2.42 E+09$ & $2.42 E+09$ \\
\hline-10 & $2.41 E+09$ & $2.41 \mathrm{E}+09$ & $2.42 \mathrm{E}+09$ & $2.42 \mathrm{E}+09$ & $2.42 E+09$ & $2.42 E+09$ & $2.42 E+09$ & $2.41 E+09$ \\
\hline 0 & $2.42 \mathrm{E}+09$ & $2.41 \mathrm{E}+09$ & $2.41 \mathrm{E}+09$ & $2.41 E+09$ & $2.41 E+09$ & $2.41 E+09$ & $2.41 E+09$ & $2.41 E+09$ \\
\hline 10 & $2.42 \mathrm{E}+09$ & $2.42 \mathrm{E}+09$ & $2.42 \mathrm{E}+09$ & $2.42 \mathrm{E}+09$ & $2.42 E+09$ & $2.42 E+09$ & $2.42 \mathrm{E}+09$ & $2.42 E+09$ \\
\hline 20 & $2.42 \mathrm{E}+09$ & $2.42 \mathrm{E}+09$ & $2.42 \mathrm{E}+09$ & $2.42 \mathrm{E}+09$ & $2.42 E+09$ & $2.42 \mathrm{E}+09$ & $2.42 \mathrm{E}+09$ & $2.42 E+09$ \\
\hline 30 & $2.42 \mathrm{E}+09$ & $2.42 \mathrm{E}+09$ & $2.43 E+09$ & $2.43 E+09$ & $2.42 E+09$ & $2.43 E+09$ & $2.43 E+09$ & $2.42 \mathrm{E}+09$ \\
\hline 40 & $2.44 \mathrm{E}+09$ & $2.43 E+09$ & $2.43 E+09$ & $2.43 E+09$ & $2.43 E+09$ & $2.43 E+09$ & $2.43 E+09$ & $2.43 E+09$ \\
\hline 50 & $2.43 E+09$ & $2.43 E+09$ & $2.43 E+09$ & $2.44 \mathrm{E}+09$ & $2.43 E+09$ & $2.43 E+09$ & $2.43 E+09$ & $2.43 E+09$ \\
\hline 60 & $2.44 \mathrm{E}+09$ & $2.44 \mathrm{E}+09$ & $2.44 \mathrm{E}+09$ & $2.44 \mathrm{E}+09$ & $2.44 \mathrm{E}+09$ & $2.44 \mathrm{E}+09$ & $2.43 E+09$ & $2.44 \mathrm{E}+09$ \\
\hline
\end{tabular}




\begin{tabular}{|r|r|r|r|r|r|r|r|r|}
\hline 70 & $2.44 \mathrm{E}+09$ & $2.44 \mathrm{E}+09$ & $2.44 \mathrm{E}+09$ & $2.44 \mathrm{E}+09$ & $2.44 \mathrm{E}+09$ & $2.44 \mathrm{E}+09$ & $2.44 \mathrm{E}+09$ & $2.44 \mathrm{E}+09$ \\
\hline 80 & $2.44 \mathrm{E}+09$ & $2.44 \mathrm{E}+09$ & $2.44 \mathrm{E}+09$ & $2.44 \mathrm{E}+09$ & $2.44 \mathrm{E}+09$ & $2.44 \mathrm{E}+09$ & $2.44 \mathrm{E}+09$ & $2.44 \mathrm{E}+09$ \\
\hline 90 & $2.44 \mathrm{E}+09$ & $2.44 \mathrm{E}+09$ & $2.44 \mathrm{E}+09$ & $2.44 \mathrm{E}+09$ & $2.44 \mathrm{E}+09$ & $2.44 \mathrm{E}+09$ & $2.44 \mathrm{E}+09$ & $2.44 \mathrm{E}+09$ \\
\hline 100 & $2.44 \mathrm{E}+09$ & $2.44 \mathrm{E}+09$ & $2.44 \mathrm{E}+09$ & $2.44 \mathrm{E}+09$ & $2.44 \mathrm{E}+09$ & $2.44 \mathrm{E}+09$ & $2.44 \mathrm{E}+09$ & $2.44 \mathrm{E}+09$ \\
\hline 110 & $2.44 \mathrm{E}+09$ & $2.44 \mathrm{E}+09$ & $2.44 \mathrm{E}+09$ & $2.44 \mathrm{E}+09$ & $2.44 \mathrm{E}+09$ & $2.44 \mathrm{E}+09$ & $2.44 \mathrm{E}+09$ & $2.44 \mathrm{E}+09$ \\
\hline 120 & $2.44 \mathrm{E}+09$ & $2.44 \mathrm{E}+09$ & $2.45 \mathrm{E}+09$ & $2.44 \mathrm{E}+09$ & $2.44 \mathrm{E}+09$ & $2.44 \mathrm{E}+09$ & $2.44 \mathrm{E}+09$ & $2.44 \mathrm{E}+09$ \\
\hline 130 & $2.44 \mathrm{E}+09$ & $2.44 \mathrm{E}+09$ & $2.44 \mathrm{E}+09$ & $2.44 \mathrm{E}+09$ & $2.44 \mathrm{E}+09$ & $2.44 \mathrm{E}+09$ & $2.44 \mathrm{E}+09$ & $2.44 \mathrm{E}+09$ \\
\hline 140 & $2.44 \mathrm{E}+09$ & $2.44 \mathrm{E}+09$ & $2.44 \mathrm{E}+09$ & $2.44 \mathrm{E}+09$ & $2.44 \mathrm{E}+09$ & $2.44 \mathrm{E}+09$ & $2.44 \mathrm{E}+09$ & $2.44 \mathrm{E}+09$ \\
\hline 150 & $2.44 \mathrm{E}+09$ & $2.45 \mathrm{E}+09$ & $2.44 \mathrm{E}+09$ & $2.45 \mathrm{E}+09$ & $2.44 \mathrm{E}+09$ & $2.45 \mathrm{E}+09$ & $2.44 \mathrm{E}+09$ & $2.45 \mathrm{E}+09$ \\
\hline 160 & $2.44 \mathrm{E}+09$ & $2.44 \mathrm{E}+09$ & $2.44 \mathrm{E}+09$ & $2.44 \mathrm{E}+09$ & $2.44 \mathrm{E}+09$ & $2.44 \mathrm{E}+09$ & $2.45 \mathrm{E}+09$ & $2.44 \mathrm{E}+09$ \\
\hline 170 & $2.44 \mathrm{E}+09$ & $2.44 \mathrm{E}+09$ & $2.44 \mathrm{E}+09$ & $2.44 \mathrm{E}+09$ & $2.45 \mathrm{E}+09$ & $2.44 \mathrm{E}+09$ & $2.44 \mathrm{E}+09$ & $2.44 \mathrm{E}+09$ \\
\hline 180 & $2.44 \mathrm{E}+09$ & $2.45 \mathrm{E}+09$ & $2.44 \mathrm{E}+09$ & $2.44 \mathrm{E}+09$ & $2.44 \mathrm{E}+09$ & $2.44 \mathrm{E}+09$ & $2.44 \mathrm{E}+09$ & $2.44 \mathrm{E}+09$ \\
\hline
\end{tabular}

\begin{tabular}{|r|r|r|r|r|r|r|r|r|}
\hline-100 & -90 & -80 & -70 & -60 & -50 & -40 & -30 & -20 \\
\hline $2.44 \mathrm{E}+09$ & $2.45 \mathrm{E}+09$ & $2.44 \mathrm{E}+09$ & $2.44 \mathrm{E}+09$ & $2.45 \mathrm{E}+09$ & $2.44 \mathrm{E}+09$ & $2.44 \mathrm{E}+09$ & $2.45 \mathrm{E}+09$ & $2.44 \mathrm{E}+09$ \\
\hline $2.44 \mathrm{E}+09$ & $2.44 \mathrm{E}+09$ & $2.44 \mathrm{E}+09$ & $2.44 \mathrm{E}+09$ & $2.44 \mathrm{E}+09$ & $2.44 \mathrm{E}+09$ & $2.44 \mathrm{E}+09$ & $2.44 \mathrm{E}+09$ & $2.44 \mathrm{E}+09$ \\
\hline $2.45 \mathrm{E}+09$ & $2.44 \mathrm{E}+09$ & $2.44 \mathrm{E}+09$ & $2.44 \mathrm{E}+09$ & $2.44 \mathrm{E}+09$ & $2.44 \mathrm{E}+09$ & $2.44 \mathrm{E}+09$ & $2.44 \mathrm{E}+09$ & $2.44 \mathrm{E}+09$ \\
\hline $2.45 \mathrm{E}+09$ & $2.45 \mathrm{E}+09$ & $2.44 \mathrm{E}+09$ & $2.45 \mathrm{E}+09$ & $2.44 \mathrm{E}+09$ & $2.44 \mathrm{E}+09$ & $2.44 \mathrm{E}+09$ & $2.44 \mathrm{E}+09$ & $2.45 \mathrm{E}+09$ \\
\hline $2.44 \mathrm{E}+09$ & $2.44 \mathrm{E}+09$ & $2.44 \mathrm{E}+09$ & $2.44 \mathrm{E}+09$ & $2.44 \mathrm{E}+09$ & $2.44 \mathrm{E}+09$ & $2.44 \mathrm{E}+09$ & $2.45 \mathrm{E}+09$ & $2.44 \mathrm{E}+09$ \\
\hline $2.44 \mathrm{E}+09$ & $2.44 \mathrm{E}+09$ & $2.44 \mathrm{E}+09$ & $2.44 \mathrm{E}+09$ & $2.45 \mathrm{E}+09$ & $2.44 \mathrm{E}+09$ & $2.44 \mathrm{E}+09$ & $2.44 \mathrm{E}+09$ & $2.44 \mathrm{E}+09$ \\
\hline $2.44 \mathrm{E}+09$ & $2.44 \mathrm{E}+09$ & $2.44 \mathrm{E}+09$ & $2.44 \mathrm{E}+09$ & $2.44 \mathrm{E}+09$ & $2.45 \mathrm{E}+09$ & $2.44 \mathrm{E}+09$ & $2.44 \mathrm{E}+09$ & $2.44 \mathrm{E}+09$ \\
\hline $2.44 \mathrm{E}+09$ & $2.44 \mathrm{E}+09$ & $2.44 \mathrm{E}+09$ & $2.45 \mathrm{E}+09$ & $2.44 \mathrm{E}+09$ & $2.44 \mathrm{E}+09$ & $2.44 \mathrm{E}+09$ & $2.44 \mathrm{E}+09$ & $2.44 \mathrm{E}+09$ \\
\hline $2.44 \mathrm{E}+09$ & $2.44 \mathrm{E}+09$ & $2.44 \mathrm{E}+09$ & $2.44 \mathrm{E}+09$ & $2.44 \mathrm{E}+09$ & $2.43 \mathrm{E}+09$ & $2.44 \mathrm{E}+09$ & $2.44 \mathrm{E}+09$ & $2.44 \mathrm{E}+09$ \\
\hline $2.44 \mathrm{E}+09$ & $2.44 \mathrm{E}+09$ & $2.44 \mathrm{E}+09$ & $2.44 \mathrm{E}+09$ & $2.44 \mathrm{E}+09$ & $2.44 \mathrm{E}+09$ & $2.44 \mathrm{E}+09$ & $2.44 \mathrm{E}+09$ & $2.44 \mathrm{E}+09$ \\
\hline $2.44 \mathrm{E}+09$ & $2.44 \mathrm{E}+09$ & $2.44 \mathrm{E}+09$ & $2.44 \mathrm{E}+09$ & $2.44 \mathrm{E}+09$ & $2.44 \mathrm{E}+09$ & $2.44 \mathrm{E}+09$ & $2.44 \mathrm{E}+09$ & $2.44 \mathrm{E}+09$ \\
\hline $2.44 \mathrm{E}+09$ & $2.43 \mathrm{E}+09$ & $2.44 \mathrm{E}+09$ & $2.44 \mathrm{E}+09$ & $2.44 \mathrm{E}+09$ & $2.44 \mathrm{E}+09$ & $2.44 \mathrm{E}+09$ & $2.43 \mathrm{E}+09$ & $2.44 \mathrm{E}+09$ \\
\hline $2.44 \mathrm{E}+09$ & $2.44 \mathrm{E}+09$ & $2.44 \mathrm{E}+09$ & $2.43 \mathrm{E}+09$ & $2.44 \mathrm{E}+09$ & $2.44 \mathrm{E}+09$ & $2.43 \mathrm{E}+09$ & $2.44 \mathrm{E}+09$ & $2.43 \mathrm{E}+09$ \\
\hline
\end{tabular}




\begin{tabular}{|c|c|c|c|c|c|c|c|c|}
\hline $2.43 E+09$ & $2.44 \mathrm{E}+09$ & $2.44 \mathrm{E}+09$ & $2.43 E+09$ & $2.43 \mathrm{E}+09$ & $2.43 E+09$ & $2.43 \mathrm{E}+09$ & $2.43 E+09$ & $2.43 E+09$ \\
\hline $2.43 E+09$ & $2.43 E+09$ & $2.43 E+09$ & $2.43 E+09$ & $2.43 E+09$ & $2.42 E+09$ & $2.43 E+09$ & $2.43 E+09$ & $2.43 E+09$ \\
\hline $2.42 E+09$ & $2.43 E+09$ & $2.42 \mathrm{E}+09$ & $2.42 E+09$ & $2.43 E+09$ & $2.43 \mathrm{E}+09$ & $2.42 E+09$ & $2.42 E+09$ & $2.43 E+09$ \\
\hline $2.42 \mathrm{E}+09$ & $2.42 \mathrm{E}+09$ & $2.42 \mathrm{E}+09$ & $2.42 \mathrm{E}+09$ & $2.42 \mathrm{E}+09$ & $2.42 \mathrm{E}+09$ & $2.42 \mathrm{E}+09$ & $2.42 \mathrm{E}+09$ & $2.42 \mathrm{E}+09$ \\
\hline $2.42 \mathrm{E}+09$ & $2.42 \mathrm{E}+09$ & $2.41 E+09$ & $2.41 E+09$ & $2.42 \mathrm{E}+09$ & $2.41 \mathrm{E}+09$ & $2.41 \mathrm{E}+09$ & $2.42 \mathrm{E}+09$ & $2.42 \mathrm{E}+09$ \\
\hline $2.41 \mathrm{E}+09$ & $2.41 \mathrm{E}+09$ & $2.41 E+09$ & $2.41 E+09$ & $2.41 E+09$ & $2.41 \mathrm{E}+09$ & $2.41 E+09$ & $2.41 E+09$ & $2.41 E+09$ \\
\hline $2.42 \mathrm{E}+09$ & $2.42 \mathrm{E}+09$ & $2.42 E+09$ & $2.42 \mathrm{E}+09$ & $2.42 E+09$ & $2.42 \mathrm{E}+09$ & $2.42 E+09$ & $2.42 \mathrm{E}+09$ & $2.42 \mathrm{E}+09$ \\
\hline $2.42 E+09$ & $2.42 E+09$ & $2.42 E+09$ & $2.42 E+09$ & $2.42 E+09$ & $2.42 E+09$ & $2.42 E+09$ & $2.42 E+09$ & $2.42 E+09$ \\
\hline $2.42 E+09$ & $2.42 E+09$ & $2.43 E+09$ & $2.42 E+09$ & $2.43 E+09$ & $2.43 E+09$ & $2.43 E+09$ & $2.43 E+09$ & $2.43 E+09$ \\
\hline $2.43 E+09$ & $2.43 E+09$ & $2.43 E+09$ & $2.43 E+09$ & $2.43 E+09$ & $2.43 E+09$ & $2.43 E+09$ & $2.43 E+09$ & $2.43 E+09$ \\
\hline $2.43 E+09$ & $2.43 E+09$ & $2.43 E+09$ & $2.43 E+09$ & $2.43 E+09$ & $2.43 E+09$ & $2.43 E+09$ & $2.43 E+09$ & $2.43 E+09$ \\
\hline $2.44 \mathrm{E}+09$ & $2.44 \mathrm{E}+09$ & $2.44 \mathrm{E}+09$ & $2.44 \mathrm{E}+09$ & $2.44 \mathrm{E}+09$ & $2.44 \mathrm{E}+09$ & $2.44 \mathrm{E}+09$ & $2.44 \mathrm{E}+09$ & $2.44 \mathrm{E}+09$ \\
\hline $2.44 \mathrm{E}+09$ & $2.44 \mathrm{E}+09$ & $2.44 E+09$ & $2.44 E+09$ & $2.44 \mathrm{E}+09$ & $2.44 E+09$ & $2.44 E+09$ & $2.44 E+09$ & $2.44 \mathrm{E}+09$ \\
\hline $2.44 \mathrm{E}+09$ & $2.44 \mathrm{E}+09$ & $2.44 E+09$ & $2.44 \mathrm{E}+09$ & $2.44 \mathrm{E}+09$ & $2.44 \mathrm{E}+09$ & $2.44 E+09$ & $2.44 \mathrm{E}+09$ & $2.44 \mathrm{E}+09$ \\
\hline $2.44 \mathrm{E}+09$ & $2.44 \mathrm{E}+09$ & $2.44 E+09$ & $2.44 E+09$ & $2.44 E+09$ & $2.44 E+09$ & $2.44 E+09$ & $2.44 E+09$ & $2.44 \mathrm{E}+09$ \\
\hline $2.44 \mathrm{E}+09$ & $2.44 \mathrm{E}+09$ & $2.44 E+09$ & $2.44 E+09$ & $2.44 \mathrm{E}+09$ & $2.44 E+09$ & $2.43 E+09$ & $2.44 E+09$ & $2.44 \mathrm{E}+09$ \\
\hline $2.44 \mathrm{E}+09$ & $2.44 E+09$ & $2.44 E+09$ & $2.44 E+09$ & $2.44 \mathrm{E}+09$ & $2.44 \mathrm{E}+09$ & $2.44 E+09$ & $2.44 E+09$ & $2.44 \mathrm{E}+09$ \\
\hline $2.44 \mathrm{E}+09$ & $2.44 \mathrm{E}+09$ & $2.44 E+09$ & $2.44 E+09$ & $2.44 E+09$ & $2.44 E+09$ & $2.44 E+09$ & $2.44 E+09$ & $2.44 \mathrm{E}+09$ \\
\hline $2.44 \mathrm{E}+09$ & $2.45 \mathrm{E}+09$ & $2.44 \mathrm{E}+09$ & $2.44 \mathrm{E}+09$ & $2.44 \mathrm{E}+09$ & $2.44 \mathrm{E}+09$ & $2.44 \mathrm{E}+09$ & $2.44 \mathrm{E}+09$ & $2.44 \mathrm{E}+09$ \\
\hline $2.44 \mathrm{E}+09$ & $2.44 E+09$ & $2.44 E+09$ & $2.44 E+09$ & $2.44 E+09$ & $2.44 E+09$ & $2.45 E+09$ & $2.44 E+09$ & $2.44 \mathrm{E}+09$ \\
\hline $2.45 \mathrm{E}+09$ & $2.45 \mathrm{E}+09$ & $2.44 E+09$ & $2.45 \mathrm{E}+09$ & $2.45 E+09$ & $2.44 \mathrm{E}+09$ & $2.44 E+09$ & $2.44 \mathrm{E}+09$ & $2.45 \mathrm{E}+09$ \\
\hline $2.44 \mathrm{E}+09$ & $2.44 \mathrm{E}+09$ & $2.44 \mathrm{E}+09$ & $2.44 \mathrm{E}+09$ & $2.44 \mathrm{E}+09$ & $2.44 \mathrm{E}+09$ & $2.45 E+09$ & $2.44 \mathrm{E}+09$ & $2.44 \mathrm{E}+09$ \\
\hline $2.44 \mathrm{E}+09$ & $2.44 \mathrm{E}+09$ & $2.44 E+09$ & $2.44 E+09$ & $2.44 E+09$ & $2.44 E+09$ & $2.45 E+09$ & $2.44 E+09$ & $2.44 \mathrm{E}+09$ \\
\hline $2.44 \mathrm{E}+09$ & $2.44 \mathrm{E}+09$ & $2.44 \mathrm{E}+09$ & $2.45 \mathrm{E}+09$ & $2.44 \mathrm{E}+09$ & $2.44 \mathrm{E}+09$ & $2.44 \mathrm{E}+09$ & $2.44 \mathrm{E}+09$ & $2.44 \mathrm{E}+09$ \\
\hline
\end{tabular}

\begin{tabular}{|r|r|r|r|r|r|r|r|r|}
\hline-10 & 0 & 10 & 20 & 30 & 40 & 50 & 60 & 70 \\
\hline $2.45 \mathrm{E}+09$ & $2.45 \mathrm{E}+09$ & $2.44 \mathrm{E}+09$ & $2.44 \mathrm{E}+09$ & $2.45 \mathrm{E}+09$ & $2.44 \mathrm{E}+09$ & $2.44 \mathrm{E}+09$ & $2.44 \mathrm{E}+09$ & $2.44 \mathrm{E}+09$ \\
\hline
\end{tabular}




\begin{tabular}{|c|c|c|c|c|c|c|c|c|}
\hline 2.44E+09 & $2.44 \mathrm{E}+09$ & $2.44 \mathrm{E}+09$ & $2.44 \mathrm{E}+09$ & $2.44 \mathrm{E}+09$ & $2.44 \mathrm{E}+09$ & $2.44 \mathrm{E}+09$ & $2.45 \mathrm{E}+09$ & $2.44 \mathrm{E}+09$ \\
\hline $2.45 E+09$ & $2.44 \mathrm{E}+09$ & $2.44 \mathrm{E}+09$ & $2.44 \mathrm{E}+09$ & $2.44 E+09$ & $2.45 E+09$ & $2.44 E+09$ & $2.45 E+09$ & $2.45 E+09$ \\
\hline $2.44 \mathrm{E}+09$ & $2.44 \mathrm{E}+09$ & $2.44 \mathrm{E}+09$ & $2.44 \mathrm{E}+09$ & $2.44 \mathrm{E}+09$ & $2.44 \mathrm{E}+09$ & $2.44 \mathrm{E}+09$ & $2.44 \mathrm{E}+09$ & $2.44 \mathrm{E}+09$ \\
\hline $2.44 \mathrm{E}+09$ & $2.44 \mathrm{E}+09$ & $2.45 \mathrm{E}+09$ & $2.44 \mathrm{E}+09$ & $2.44 E+09$ & $2.44 \mathrm{E}+09$ & $2.44 \mathrm{E}+09$ & $2.44 \mathrm{E}+09$ & $2.44 \mathrm{E}+09$ \\
\hline $2.44 \mathrm{E}+09$ & $2.44 \mathrm{E}+09$ & $2.44 \mathrm{E}+09$ & $2.45 \mathrm{E}+09$ & $2.44 \mathrm{E}+09$ & $2.45 \mathrm{E}+09$ & $2.44 \mathrm{E}+09$ & $2.44 \mathrm{E}+09$ & $2.44 \mathrm{E}+09$ \\
\hline $2.44 \mathrm{E}+09$ & $2.44 \mathrm{E}+09$ & $2.44 \mathrm{E}+09$ & $2.44 \mathrm{E}+09$ & $2.44 \mathrm{E}+09$ & $2.44 \mathrm{E}+09$ & $2.44 \mathrm{E}+09$ & $2.44 \mathrm{E}+09$ & $2.44 \mathrm{E}+09$ \\
\hline $2.44 \mathrm{E}+09$ & $2.44 \mathrm{E}+09$ & $2.44 \mathrm{E}+09$ & $2.44 \mathrm{E}+09$ & $2.44 \mathrm{E}+09$ & $2.44 \mathrm{E}+09$ & $2.44 \mathrm{E}+09$ & $2.44 \mathrm{E}+09$ & $2.44 \mathrm{E}+09$ \\
\hline $2.44 \mathrm{E}+09$ & $2.44 \mathrm{E}+09$ & $2.44 \mathrm{E}+09$ & $2.44 \mathrm{E}+09$ & $2.44 E+09$ & $2.44 \mathrm{E}+09$ & $2.44 \mathrm{E}+09$ & $2.44 \mathrm{E}+09$ & $2.44 E+09$ \\
\hline $2.44 \mathrm{E}+09$ & $2.44 \mathrm{E}+09$ & $2.44 E+09$ & $2.44 \mathrm{E}+09$ & $2.44 E+09$ & $2.44 \mathrm{E}+09$ & $2.44 E+09$ & $2.44 \mathrm{E}+09$ & $2.44 E+09$ \\
\hline $2.44 \mathrm{E}+09$ & $2.44 \mathrm{E}+09$ & $2.44 E+09$ & $2.43 E+09$ & $2.44 E+09$ & $2.44 \mathrm{E}+09$ & $2.44 E+09$ & $2.44 \mathrm{E}+09$ & $2.44 E+09$ \\
\hline $2.44 \mathrm{E}+09$ & $2.43 E+09$ & $2.44 E+09$ & $2.44 \mathrm{E}+09$ & $2.43 E+09$ & $2.44 \mathrm{E}+09$ & $2.43 E+09$ & $2.44 \mathrm{E}+09$ & $2.43 E+09$ \\
\hline $2.43 \mathrm{E}+09$ & $2.44 \mathrm{E}+09$ & $2.44 \mathrm{E}+09$ & $2.44 \mathrm{E}+09$ & $2.44 \mathrm{E}+09$ & $2.44 \mathrm{E}+09$ & $2.43 \mathrm{E}+09$ & $2.43 \mathrm{E}+09$ & $2.44 \mathrm{E}+09$ \\
\hline $2.44 \mathrm{E}+09$ & $2.43 E+09$ & $2.43 E+09$ & $2.43 E+09$ & $2.43 E+09$ & $2.43 E+09$ & $2.43 E+09$ & $2.43 E+09$ & $2.44 \mathrm{E}+09$ \\
\hline $2.43 E+09$ & $2.43 E+09$ & $2.43 E+09$ & $2.43 E+09$ & $2.43 E+09$ & $2.43 E+09$ & $2.43 E+09$ & $2.43 E+09$ & $2.43 E+09$ \\
\hline $2.42 \mathrm{E}+09$ & $2.42 \mathrm{E}+09$ & $2.43 E+09$ & $2.42 \mathrm{E}+09$ & $2.43 E+09$ & $2.43 E+09$ & $2.43 E+09$ & $2.42 \mathrm{E}+09$ & $2.43 E+09$ \\
\hline $2.42 \mathrm{E}+09$ & $2.42 \mathrm{E}+09$ & $2.42 E+09$ & $2.42 \mathrm{E}+09$ & $2.42 E+09$ & $2.42 \mathrm{E}+09$ & $2.42 E+09$ & $2.42 \mathrm{E}+09$ & $2.42 E+09$ \\
\hline $2.41 \mathrm{E}+09$ & $2.42 \mathrm{E}+09$ & $2.42 \mathrm{E}+09$ & $2.41 \mathrm{E}+09$ & $2.42 E+09$ & $2.42 \mathrm{E}+09$ & $2.42 \mathrm{E}+09$ & $2.42 \mathrm{E}+09$ & $2.42 E+09$ \\
\hline $2.41 E+09$ & $2.41 E+09$ & $2.41 E+09$ & $2.41 E+09$ & $2.41 E+09$ & $2.41 E+09$ & $2.41 E+09$ & $2.41 E+09$ & $2.41 E+09$ \\
\hline $2.42 \mathrm{E}+09$ & $2.42 \mathrm{E}+09$ & $2.42 \mathrm{E}+09$ & $2.42 \mathrm{E}+09$ & $2.42 E+09$ & $2.42 E+09$ & $2.42 \mathrm{E}+09$ & $2.42 \mathrm{E}+09$ & $2.42 E+09$ \\
\hline $2.42 \mathrm{E}+09$ & $2.42 \mathrm{E}+09$ & $2.42 \mathrm{E}+09$ & $2.42 E+09$ & $2.42 E+09$ & $2.42 E+09$ & $2.42 \mathrm{E}+09$ & $2.42 \mathrm{E}+09$ & $2.42 E+09$ \\
\hline $2.42 \mathrm{E}+09$ & $2.43 E+09$ & $2.42 \mathrm{E}+09$ & $2.42 \mathrm{E}+09$ & $2.43 E+09$ & $2.43 E+09$ & $2.42 \mathrm{E}+09$ & $2.43 E+09$ & $2.43 E+09$ \\
\hline $2.43 E+09$ & $2.43 E+09$ & $2.43 E+09$ & $2.43 E+09$ & $2.43 E+09$ & $2.43 E+09$ & $2.43 E+09$ & $2.43 E+09$ & $2.43 E+09$ \\
\hline $2.43 \mathrm{E}+09$ & $2.43 \mathrm{E}+09$ & $2.43 E+09$ & $2.44 \mathrm{E}+09$ & $2.43 E+09$ & $2.43 E+09$ & $2.43 E+09$ & $2.43 \mathrm{E}+09$ & $2.43 E+09$ \\
\hline $2.44 \mathrm{E}+09$ & $2.44 \mathrm{E}+09$ & $2.44 \mathrm{E}+09$ & $2.44 \mathrm{E}+09$ & $2.44 \mathrm{E}+09$ & $2.44 \mathrm{E}+09$ & $2.44 \mathrm{E}+09$ & $2.44 \mathrm{E}+09$ & $2.44 \mathrm{E}+09$ \\
\hline $2.44 \mathrm{E}+09$ & $2.44 \mathrm{E}+09$ & $2.44 \mathrm{E}+09$ & $2.44 \mathrm{E}+09$ & $2.44 E+09$ & $2.44 \mathrm{E}+09$ & $2.44 \mathrm{E}+09$ & $2.44 \mathrm{E}+09$ & $2.44 E+09$ \\
\hline $2.44 \mathrm{E}+09$ & $2.44 \mathrm{E}+09$ & $2.44 \mathrm{E}+09$ & $2.44 \mathrm{E}+09$ & $2.44 \mathrm{E}+09$ & $2.44 \mathrm{E}+09$ & $2.44 \mathrm{E}+09$ & $2.44 \mathrm{E}+09$ & $2.44 \mathrm{E}+09$ \\
\hline $2.44 \mathrm{E}+09$ & $2.45 \mathrm{E}+09$ & $2.44 \mathrm{E}+09$ & $2.44 \mathrm{E}+09$ & $2.44 E+09$ & $2.44 \mathrm{E}+09$ & $2.44 \mathrm{E}+09$ & $2.44 \mathrm{E}+09$ & $2.44 E+09$ \\
\hline $2.44 \mathrm{E}+09$ & $2.44 \mathrm{E}+09$ & $2.44 E+09$ & $2.44 \mathrm{E}+09$ & $2.44 E+09$ & $2.44 \mathrm{E}+09$ & $2.44 \mathrm{E}+09$ & $2.44 \mathrm{E}+09$ & $2.44 \mathrm{E}+09$ \\
\hline
\end{tabular}




\begin{tabular}{|r|r|r|r|r|r|r|r|r|}
\hline $2.44 \mathrm{E}+09$ & $2.44 \mathrm{E}+09$ & $2.44 \mathrm{E}+09$ & $2.44 \mathrm{E}+09$ & $2.44 \mathrm{E}+09$ & $2.44 \mathrm{E}+09$ & $2.44 \mathrm{E}+09$ & $2.44 \mathrm{E}+09$ & $2.44 \mathrm{E}+09$ \\
\hline $2.44 \mathrm{E}+09$ & $2.44 \mathrm{E}+09$ & $2.44 \mathrm{E}+09$ & $2.44 \mathrm{E}+09$ & $2.44 \mathrm{E}+09$ & $2.44 \mathrm{E}+09$ & $2.44 \mathrm{E}+09$ & $2.44 \mathrm{E}+09$ & $2.44 \mathrm{E}+09$ \\
\hline $2.45 \mathrm{E}+09$ & $2.44 \mathrm{E}+09$ & $2.44 \mathrm{E}+09$ & $2.45 \mathrm{E}+09$ & $2.44 \mathrm{E}+09$ & $2.44 \mathrm{E}+09$ & $2.44 \mathrm{E}+09$ & $2.44 \mathrm{E}+09$ & $2.45 \mathrm{E}+09$ \\
\hline $2.44 \mathrm{E}+09$ & $2.44 \mathrm{E}+09$ & $2.45 \mathrm{E}+09$ & $2.44 \mathrm{E}+09$ & $2.44 \mathrm{E}+09$ & $2.44 \mathrm{E}+09$ & $2.44 \mathrm{E}+09$ & $2.44 \mathrm{E}+09$ & $2.44 \mathrm{E}+09$ \\
\hline $2.44 \mathrm{E}+09$ & $2.44 \mathrm{E}+09$ & $2.44 \mathrm{E}+09$ & $2.44 \mathrm{E}+09$ & $2.44 \mathrm{E}+09$ & $2.44 \mathrm{E}+09$ & $2.44 \mathrm{E}+09$ & $2.44 \mathrm{E}+09$ & $2.44 \mathrm{E}+09$ \\
\hline $2.44 \mathrm{E}+09$ & $2.44 \mathrm{E}+09$ & $2.45 \mathrm{E}+09$ & $2.44 \mathrm{E}+09$ & $2.44 \mathrm{E}+09$ & $2.44 \mathrm{E}+09$ & $2.44 \mathrm{E}+09$ & $2.44 \mathrm{E}+09$ & $2.44 \mathrm{E}+09$ \\
\hline $2.45 \mathrm{E}+09$ & $2.45 \mathrm{E}+09$ & $2.44 \mathrm{E}+09$ & $2.44 \mathrm{E}+09$ & $2.44 \mathrm{E}+09$ & $2.44 \mathrm{E}+09$ & $2.45 \mathrm{E}+09$ & $2.44 \mathrm{E}+09$ & $2.44 \mathrm{E}+09$ \\
\hline $2.44 \mathrm{E}+09$ & $2.44 \mathrm{E}+09$ & $2.44 \mathrm{E}+09$ & $2.44 \mathrm{E}+09$ & $2.44 \mathrm{E}+09$ & $2.44 \mathrm{E}+09$ & $2.44 \mathrm{E}+09$ & $2.44 \mathrm{E}+09$ & $2.44 \mathrm{E}+09$ \\
\hline
\end{tabular}

\begin{tabular}{|r|r|r|r|r|r|r|r|r|}
\hline 80 & 90 & 100 & 110 & 120 & 130 & 140 & 150 \\
\hline $2.44 \mathrm{E}+09$ & $2.45 \mathrm{E}+09$ & $2.45 \mathrm{E}+09$ & $2.45 \mathrm{E}+09$ & $2.44 \mathrm{E}+09$ & $2.45 \mathrm{E}+09$ & $2.45 \mathrm{E}+09$ & $2.44 \mathrm{E}+09$ & $2.45 \mathrm{E}+09$ \\
\hline $2.44 \mathrm{E}+09$ & $2.44 \mathrm{E}+09$ & $2.44 \mathrm{E}+09$ & $2.44 \mathrm{E}+09$ & $2.44 \mathrm{E}+09$ & $2.44 \mathrm{E}+09$ & $2.44 \mathrm{E}+09$ & $2.44 \mathrm{E}+09$ & $2.44 \mathrm{E}+09$ \\
\hline $2.44 \mathrm{E}+09$ & $2.44 \mathrm{E}+09$ & $2.44 \mathrm{E}+09$ & $2.44 \mathrm{E}+09$ & $2.44 \mathrm{E}+09$ & $2.44 \mathrm{E}+09$ & $2.44 \mathrm{E}+09$ & $2.44 \mathrm{E}+09$ & $2.44 \mathrm{E}+09$ \\
\hline $2.45 \mathrm{E}+09$ & $2.44 \mathrm{E}+09$ & $2.44 \mathrm{E}+09$ & $2.44 \mathrm{E}+09$ & $2.45 \mathrm{E}+09$ & $2.44 \mathrm{E}+09$ & $2.44 \mathrm{E}+09$ & $2.45 \mathrm{E}+09$ & $2.44 \mathrm{E}+09$ \\
\hline $2.44 \mathrm{E}+09$ & $2.44 \mathrm{E}+09$ & $2.44 \mathrm{E}+09$ & $2.44 \mathrm{E}+09$ & $2.44 \mathrm{E}+09$ & $2.44 \mathrm{E}+09$ & $2.44 \mathrm{E}+09$ & $2.44 \mathrm{E}+09$ & $2.44 \mathrm{E}+09$ \\
\hline $2.45 \mathrm{E}+09$ & $2.44 \mathrm{E}+09$ & $2.45 \mathrm{E}+09$ & $2.44 \mathrm{E}+09$ & $2.45 \mathrm{E}+09$ & $2.44 \mathrm{E}+09$ & $2.45 \mathrm{E}+09$ & $2.44 \mathrm{E}+09$ & $2.44 \mathrm{E}+09$ \\
\hline $2.44 \mathrm{E}+09$ & $2.44 \mathrm{E}+09$ & $2.44 \mathrm{E}+09$ & $2.44 \mathrm{E}+09$ & $2.44 \mathrm{E}+09$ & $2.44 \mathrm{E}+09$ & $2.44 \mathrm{E}+09$ & $2.44 \mathrm{E}+09$ & $2.44 \mathrm{E}+09$ \\
\hline $2.44 \mathrm{E}+09$ & $2.44 \mathrm{E}+09$ & $2.44 \mathrm{E}+09$ & $2.44 \mathrm{E}+09$ & $2.44 \mathrm{E}+09$ & $2.44 \mathrm{E}+09$ & $2.44 \mathrm{E}+09$ & $2.44 \mathrm{E}+09$ & $2.44 \mathrm{E}+09$ \\
\hline $2.44 \mathrm{E}+09$ & $2.44 \mathrm{E}+09$ & $2.44 \mathrm{E}+09$ & $2.44 \mathrm{E}+09$ & $2.44 \mathrm{E}+09$ & $2.44 \mathrm{E}+09$ & $2.44 \mathrm{E}+09$ & $2.44 \mathrm{E}+09$ & $2.44 \mathrm{E}+09$ \\
\hline $2.44 \mathrm{E}+09$ & $2.44 \mathrm{E}+09$ & $2.44 \mathrm{E}+09$ & $2.44 \mathrm{E}+09$ & $2.44 \mathrm{E}+09$ & $2.44 \mathrm{E}+09$ & $2.44 \mathrm{E}+09$ & $2.44 \mathrm{E}+09$ & $2.44 \mathrm{E}+09$ \\
\hline $2.44 \mathrm{E}+09$ & $2.44 \mathrm{E}+09$ & $2.44 \mathrm{E}+09$ & $2.44 \mathrm{E}+09$ & $2.44 \mathrm{E}+09$ & $2.44 \mathrm{E}+09$ & $2.44 \mathrm{E}+09$ & $2.44 \mathrm{E}+09$ & $2.44 \mathrm{E}+09$ \\
\hline $2.44 \mathrm{E}+09$ & $2.43 \mathrm{E}+09$ & $2.44 \mathrm{E}+09$ & $2.44 \mathrm{E}+09$ & $2.44 \mathrm{E}+09$ & $2.43 \mathrm{E}+09$ & $2.44 \mathrm{E}+09$ & $2.44 \mathrm{E}+09$ & $2.43 \mathrm{E}+09$ \\
\hline $2.44 \mathrm{E}+09$ & $2.44 \mathrm{E}+09$ & $2.43 \mathrm{E}+09$ & $2.43 \mathrm{E}+09$ & $2.44 \mathrm{E}+09$ & $2.44 \mathrm{E}+09$ & $2.43 \mathrm{E}+09$ & $2.43 \mathrm{E}+09$ & $2.44 \mathrm{E}+09$ \\
\hline $2.43 \mathrm{E}+09$ & $2.43 \mathrm{E}+09$ & $2.43 \mathrm{E}+09$ & $2.44 \mathrm{E}+09$ & $2.43 \mathrm{E}+09$ & $2.43 \mathrm{E}+09$ & $2.43 \mathrm{E}+09$ & $2.43 \mathrm{E}+09$ & $2.43 \mathrm{E}+09$ \\
\hline $2.43 \mathrm{E}+09$ & $2.43 \mathrm{E}+09$ & $2.43 \mathrm{E}+09$ & $2.42 \mathrm{E}+09$ & $2.43 \mathrm{E}+09$ & $2.43 \mathrm{E}+09$ & $2.43 \mathrm{E}+09$ & $2.43 \mathrm{E}+09$ & $2.43 \mathrm{E}+09$ \\
\hline $2.43 \mathrm{E}+09$ & $2.42 \mathrm{E}+09$ & $2.42 \mathrm{E}+09$ & $2.42 \mathrm{E}+09$ & $2.43 \mathrm{E}+09$ & $2.42 \mathrm{E}+09$ & $2.42 \mathrm{E}+09$ & $2.43 \mathrm{E}+09$ & $2.43 \mathrm{E}+09$ \\
\hline $2.42 \mathrm{E}+09$ & $2.42 \mathrm{E}+09$ & $2.42 \mathrm{E}+09$ & $2.42 \mathrm{E}+09$ & $2.42 \mathrm{E}+09$ & $2.42 \mathrm{E}+09$ & $2.42 \mathrm{E}+09$ & $2.42 \mathrm{E}+09$ & $2.42 \mathrm{E}+09$ \\
\hline
\end{tabular}




\begin{tabular}{|c|c|c|c|c|c|c|c|c|}
\hline $2.42 E+09$ & $2.42 \mathrm{E}+09$ & $2.42 \mathrm{E}+09$ & $2.42 \mathrm{E}+09$ & $2.42 \mathrm{E}+09$ & $2.42 \mathrm{E}+09$ & $2.42 \mathrm{E}+09$ & $2.42 \mathrm{E}+09$ & $2.42 E+09$ \\
\hline $2.41 E+09$ & $2.41 E+09$ & $2.41 E+09$ & $2.41 E+09$ & $2.41 E+09$ & $2.41 E+09$ & $2.41 E+09$ & $2.41 E+09$ & $2.41 E+09$ \\
\hline $2.42 E+09$ & $2.42 \mathrm{E}+09$ & $2.42 \mathrm{E}+09$ & $2.42 \mathrm{E}+09$ & $2.42 \mathrm{E}+09$ & $2.42 \mathrm{E}+09$ & $2.42 \mathrm{E}+09$ & $2.42 \mathrm{E}+09$ & $2.42 E+09$ \\
\hline $2.42 \mathrm{E}+09$ & $2.42 \mathrm{E}+09$ & $2.42 \mathrm{E}+09$ & $2.42 E+09$ & $2.42 \mathrm{E}+09$ & $2.42 \mathrm{E}+09$ & $2.42 \mathrm{E}+09$ & $2.42 \mathrm{E}+09$ & $2.42 \mathrm{E}+09$ \\
\hline $2.43 E+09$ & $2.43 E+09$ & $2.43 \mathrm{E}+09$ & $2.43 \mathrm{E}+09$ & $2.43 E+09$ & $2.43 E+09$ & $2.43 E+09$ & $2.43 \mathrm{E}+09$ & $2.43 \mathrm{E}+09$ \\
\hline $2.43 E+09$ & $2.43 \mathrm{E}+09$ & $2.43 \mathrm{E}+09$ & $2.43 \mathrm{E}+09$ & $2.43 \mathrm{E}+09$ & $2.43 E+09$ & $2.43 E+09$ & $2.43 \mathrm{E}+09$ & $2.43 \mathrm{E}+09$ \\
\hline $2.43 E+09$ & $2.43 E+09$ & $2.43 E+09$ & $2.43 E+09$ & $2.43 E+09$ & $2.43 E+09$ & $2.43 E+09$ & $2.43 E+09$ & $2.43 E+09$ \\
\hline $2.44 \mathrm{E}+09$ & $2.44 \mathrm{E}+09$ & $2.44 \mathrm{E}+09$ & $2.43 E+09$ & $2.44 \mathrm{E}+09$ & $2.44 \mathrm{E}+09$ & $2.44 \mathrm{E}+09$ & $2.44 \mathrm{E}+09$ & $2.44 \mathrm{E}+09$ \\
\hline $2.44 E+09$ & $2.44 \mathrm{E}+09$ & $2.44 \mathrm{E}+09$ & $2.44 \mathrm{E}+09$ & $2.44 \mathrm{E}+09$ & $2.44 \mathrm{E}+09$ & $2.44 \mathrm{E}+09$ & $2.44 \mathrm{E}+09$ & $2.44 \mathrm{E}+09$ \\
\hline $2.44 \mathrm{E}+09$ & $2.44 \mathrm{E}+09$ & $2.44 \mathrm{E}+09$ & $2.44 \mathrm{E}+09$ & $2.44 \mathrm{E}+09$ & $2.44 \mathrm{E}+09$ & $2.44 \mathrm{E}+09$ & $2.44 \mathrm{E}+09$ & $2.44 \mathrm{E}+09$ \\
\hline $2.44 \mathrm{E}+09$ & $2.45 E+09$ & $2.44 \mathrm{E}+09$ & $2.44 \mathrm{E}+09$ & $2.44 \mathrm{E}+09$ & $2.45 E+09$ & $2.44 \mathrm{E}+09$ & $2.44 \mathrm{E}+09$ & $2.44 \mathrm{E}+09$ \\
\hline $2.44 \mathrm{E}+09$ & $2.44 \mathrm{E}+09$ & $2.44 \mathrm{E}+09$ & $2.44 \mathrm{E}+09$ & $2.44 \mathrm{E}+09$ & $2.44 \mathrm{E}+09$ & $2.44 \mathrm{E}+09$ & $2.44 \mathrm{E}+09$ & $2.44 \mathrm{E}+09$ \\
\hline $2.45 E+09$ & $2.44 \mathrm{E}+09$ & $2.44 \mathrm{E}+09$ & $2.44 \mathrm{E}+09$ & $2.45 \mathrm{E}+09$ & $2.44 \mathrm{E}+09$ & $2.44 \mathrm{E}+09$ & $2.44 \mathrm{E}+09$ & $2.44 \mathrm{E}+09$ \\
\hline $2.44 \mathrm{E}+09$ & $2.44 \mathrm{E}+09$ & $2.44 \mathrm{E}+09$ & $2.44 \mathrm{E}+09$ & $2.44 \mathrm{E}+09$ & $2.44 \mathrm{E}+09$ & $2.44 \mathrm{E}+09$ & $2.44 \mathrm{E}+09$ & $2.44 \mathrm{E}+09$ \\
\hline $2.45 \mathrm{E}+09$ & $2.44 \mathrm{E}+09$ & $2.44 \mathrm{E}+09$ & $2.44 \mathrm{E}+09$ & $2.45 \mathrm{E}+09$ & $2.44 \mathrm{E}+09$ & $2.44 \mathrm{E}+09$ & $2.44 \mathrm{E}+09$ & $2.44 \mathrm{E}+09$ \\
\hline $2.45 E+09$ & $2.44 \mathrm{E}+09$ & $2.44 \mathrm{E}+09$ & $2.44 \mathrm{E}+09$ & $2.45 \mathrm{E}+09$ & $2.44 \mathrm{E}+09$ & $2.44 \mathrm{E}+09$ & $2.44 \mathrm{E}+09$ & $2.44 \mathrm{E}+09$ \\
\hline $2.44 \mathrm{E}+09$ & $2.44 \mathrm{E}+09$ & $2.44 \mathrm{E}+09$ & $2.44 \mathrm{E}+09$ & $2.44 \mathrm{E}+09$ & $2.44 \mathrm{E}+09$ & $2.44 \mathrm{E}+09$ & $2.44 \mathrm{E}+09$ & $2.44 \mathrm{E}+09$ \\
\hline $2.44 \mathrm{E}+09$ & $2.44 \mathrm{E}+09$ & $2.44 \mathrm{E}+09$ & $2.45 E+09$ & $2.44 \mathrm{E}+09$ & $2.44 \mathrm{E}+09$ & $2.44 \mathrm{E}+09$ & $2.45 E+09$ & $2.44 \mathrm{E}+09$ \\
\hline $2.45 E+09$ & $2.45 \mathrm{E}+09$ & $2.45 \mathrm{E}+09$ & $2.44 \mathrm{E}+09$ & $2.45 \mathrm{E}+09$ & $2.45 E+09$ & $2.45 \mathrm{E}+09$ & $2.44 \mathrm{E}+09$ & $2.44 \mathrm{E}+09$ \\
\hline $2.44 E+09$ & $2.44 \mathrm{E}+09$ & $2.44 \mathrm{E}+09$ & $2.44 \mathrm{E}+09$ & $2.44 \mathrm{E}+09$ & $2.44 \mathrm{E}+09$ & $2.44 \mathrm{E}+09$ & $2.45 E+09$ & $2.44 \mathrm{E}+09$ \\
\hline
\end{tabular}

\begin{tabular}{|r|r|r|}
\hline 170 & 180 & Baseline Frequency \\
\hline $2.44 \mathrm{E}+09$ & $2.44 \mathrm{E}+09$ & $2.44 \mathrm{E}+09$ \\
\hline $2.44 \mathrm{E}+09$ & $2.44 \mathrm{E}+09$ & $2.44 \mathrm{E}+09$ \\
\hline $2.45 \mathrm{E}+09$ & $2.44 \mathrm{E}+09$ & $2.44 \mathrm{E}+09$ \\
\hline $2.44 \mathrm{E}+09$ & $2.44 \mathrm{E}+09$ & $2.44 \mathrm{E}+09$ \\
\hline $2.44 \mathrm{E}+09$ & $2.44 \mathrm{E}+09$ & $2.44 \mathrm{E}+09$ \\
\hline
\end{tabular}




\begin{tabular}{|l|l|l|}
\hline $2.44 E+09$ & $2.44 E+09$ & $2.44 E+09$ \\
\hline $2.44 E+09$ & $2.44 E+09$ & $2.44 E+09$ \\
\hline $2.44 E+09$ & $2.44 E+09$ & $2.44 E+09$ \\
\hline $2.44 E+09$ & $2.44 E+09$ & $2.44 E+09$ \\
\hline $2.44 E+09$ & $2.44 E+09$ & $2.44 E+09$ \\
\hline $2.44 E+09$ & $2.44 E+09$ & $2.44 E+09$ \\
\hline $2.44 E+09$ & $2.43 E+09$ & $2.44 E+09$ \\
\hline $2.44 E+09$ & $2.43 E+09$ & $2.43 E+09$ \\
\hline $2.43 E+09$ & $2.43 E+09$ & $2.43 E+09$ \\
\hline $2.43 E+09$ & $2.43 E+09$ & $2.43 E+09$ \\
\hline $2.43 E+09$ & $2.43 E+09$ & $2.43 E+09$ \\
\hline $2.42 E+09$ & $2.42 E+09$ & $2.42 E+09$ \\
\hline $2.42 E+09$ & $2.42 E+09$ & $2.42 E+09$ \\
\hline $2.41 E+09$ & $2.41 E+09$ & $2.41 E+09$ \\
\hline $2.42 E+09$ & $2.42 E+09$ & $2.42 E+09$ \\
\hline $2.42 E+09$ & $2.42 E+09$ & $2.42 E+09$ \\
\hline $2.43 E+09$ & $2.42 E+09$ & $2.43 E+09$ \\
\hline $2.43 E+09$ & $2.43 E+09$ & $2.43 E+09$ \\
\hline $2.43 E+09$ & $2.43 E+09$ & $2.43 E+09$ \\
\hline $2.44 E+09$ & $2.44 E+09$ & $2.44 E+09$ \\
\hline $2.44 E+09$ & $2.44 E+09$ & $2.44 E+09$ \\
\hline $2.44 E+09$ & $2.44 E+09$ & $2.44 E+09$ \\
\hline $2.44 E+09$ & $2.44 E+09$ & $2.44 E+09$ \\
\hline $2.43 E+09$ & $2.44 E+09$ & $2.44 E+09$ \\
\hline $2.44 E+09$ & $2.44 E+09$ & $2.44 E+09$ \\
\hline $2.44 E+09$ & $2.44 E+09$ & $2.44 E+09$ \\
\hline $2.45 E+09$ & $2.44 E+09$ & $2.44 E+09$ \\
\hline $2.44 E+09$ & $2.44 E+09$ & $2.44 E+09$ \\
\hline
\end{tabular}




\begin{tabular}{|l|l|l|}
\hline $2.44 \mathrm{E}+09$ & $2.44 \mathrm{E}+09$ & $2.44 \mathrm{E}+09$ \\
\hline $2.44 \mathrm{E}+09$ & $2.44 \mathrm{E}+09$ & $2.44 \mathrm{E}+09$ \\
\hline $2.44 \mathrm{E}+09$ & $2.45 \mathrm{E}+09$ & $2.44 \mathrm{E}+09$ \\
\hline $2.45 \mathrm{E}+09$ & $2.44 \mathrm{E}+09$ & $2.44 \mathrm{E}+09$ \\
\hline
\end{tabular}

\section{B.6: Density}

\begin{tabular}{|c|c|c|c|c|c|c|c|c|}
\hline & -180 & -170 & -160 & -150 & -140 & -130 & -120 & -110 \\
\hline-180 & 1.018 & 0.905 & 0.959 & 1.062 & 0.959 & 0.923 & 0.766 & 1.086 \\
\hline-170 & 1.102 & 1.049 & 0.853 & 1.088 & 1.204 & 1.312 & 1.670 & 1.035 \\
\hline-160 & 1.009 & 1.156 & 0.889 & 1.023 & 1.085 & 1.077 & 1.009 & 0.889 \\
\hline-150 & 1.056 & 0.724 & 1.638 & 0.533 & 0.847 & 1.128 & 0.827 & 1.109 \\
\hline-140 & 1.137 & 1.528 & 0.714 & 1.351 & 0.962 & 0.663 & 1.351 & 0.900 \\
\hline-130 & 1.109 & 1.576 & 1.751 & 1.410 & 1.775 & 2.059 & 0.849 & 1.342 \\
\hline-120 & 1.400 & 1.080 & 1.223 & 1.575 & 0.866 & 0.892 & 1.583 & 1.316 \\
\hline-110 & 1.308 & 0.653 & 1.102 & 1.400 & 1.364 & 1.107 & 1.235 & 1.568 \\
\hline-100 & 1.368 & 2.343 & 1.611 & 1.272 & 1.923 & 2.107 & 1.814 & 1.216 \\
\hline-90 & 1.936 & 1.966 & 1.788 & 1.457 & 1.518 & 1.523 & 1.306 & 2.107 \\
\hline-80 & 1.527 & 1.826 & 1.636 & 2.455 & 1.449 & 1.773 & 1.748 & 1.630 \\
\hline-70 & 2.673 & 1.843 & 2.092 & 2.091 & 2.550 & 1.712 & 2.330 & 1.830 \\
\hline-50 & 2.474 & 2.941 & 2.438 & 2.898 & 2.732 & 2.776 & 2.174 & 3.118 \\
\hline-40 & 4.723 & 3.012 & 4.404 & 3.245 & 3.285 & 3.955 & 4.228 & 3.616 \\
\hline-30 & 3.697 & 4.843 & 3.627 & 4.715 & 3.733 & 3.666 & 4.365 & 3.933 \\
\hline-20 & 4.060 & 4.690 & 5.415 & 4.781 & 5.338 & 5.233 & 4.842 & 4.536 \\
\hline-10 & 6.816 & 5.925 & 5.380 & 5.652 & 5.373 & 5.774 & 5.836 & 5.980 \\
\hline 0 & 5.224 & 6.623 & 6.740 & 6.422 & 6.998 & 6.724 & 6.212 & 6.382 \\
\hline
\end{tabular}




\begin{tabular}{|c|c|c|c|c|c|c|c|c|}
\hline 10 & 4.885 & 4.904 & 5.025 & 5.145 & 5.214 & 5.178 & 5.332 & 5.149 \\
\hline 20 & 4.634 & 5.029 & 5.286 & 5.244 & 4.778 & 4.860 & 4.897 & 5.015 \\
\hline 30 & 4.452 & 4.190 & 3.925 & 4.052 & 4.208 & 4.069 & 4.008 & 4.219 \\
\hline 50 & 3.045 & 2.708 & 2.726 & 2.461 & 2.557 & 2.716 & 2.497 & 2.629 \\
\hline 60 & 2.193 & 1.957 & 2.266 & 2.083 & 2.228 & 2.099 & 2.503 & 2.163 \\
\hline 70 & 1.628 & 1.547 & 1.311 & 1.778 & 1.291 & 1.517 & 1.146 & 1.262 \\
\hline 80 & 1.737 & 1.256 & 1.444 & 1.157 & 1.764 & 1.421 & 1.834 & 1.922 \\
\hline 90 & 1.468 & 2.191 & 1.494 & 1.543 & 1.209 & 1.750 & 1.250 & 1.130 \\
\hline 100 & 1.497 & 1.653 & 1.849 & 1.846 & 1.883 & 1.698 & 2.234 & 1.804 \\
\hline 110 & 1.413 & 1.425 & 1.598 & 1.345 & 1.104 & 1.460 & 1.069 & 1.330 \\
\hline 120 & 0.984 & 1.066 & 0.791 & 1.014 & 1.301 & 0.969 & 1.111 & 1.344 \\
\hline 130 & 1.174 & 1.297 & 1.480 & 1.472 & 0.981 & 1.110 & 1.330 & 0.826 \\
\hline 150 & 0.933 & 0.770 & 0.926 & 0.760 & 1.038 & 0.644 & 1.220 & 0.703 \\
\hline 160 & 1.136 & 1.384 & 0.972 & 1.524 & 1.558 & 1.115 & 0.780 & 1.223 \\
\hline 170 & 1.030 & 1.235 & 1.496 & 0.869 & 0.561 & 1.655 & 1.305 & 1.030 \\
\hline 180 & 1.098 & 0.679 & 1.321 & 0.991 & 2.069 & 0.897 & 1.088 & 0.959 \\
\hline
\end{tabular}

\begin{tabular}{|c|c|c|c|c|c|c|c|c|}
\hline-100 & -90 & -80 & -70 & -60 & -50 & -40 & -30 & -20 \\
\hline 0.990 & 0.766 & 0.978 & 0.905 & 0.640 & 1.225 & 0.875 & 0.688 & 0.935 \\
\hline 1.672 & 1.662 & 1.060 & 1.049 & 2.157 & 0.933 & 1.363 & 1.534 & 0.995 \\
\hline 0.596 & 1.294 & 1.271 & 1.156 & 0.833 & 0.960 & 0.969 & 1.200 & 1.256 \\
\hline 0.784 & 0.424 & 1.195 & 0.724 & 1.251 & 1.510 & 0.972 & 0.865 & 0.785 \\
\hline 2.209 & 2.150 & 0.940 & 1.528 & 1.225 & 0.978 & 0.883 & 0.763 & 1.516 \\
\hline 0.838 & 1.141 & 1.141 & 1.576 & 0.761 & 1.124 & 1.210 & 1.802 & 0.952 \\
\hline
\end{tabular}




\begin{tabular}{|c|c|c|c|c|c|c|c|c|}
\hline 1.307 & 0.849 & 1.068 & 1.080 & 1.186 & 0.793 & 1.195 & 1.615 & 1.640 \\
\hline 1.395 & 1.870 & 1.288 & 0.653 & 1.733 & 1.158 & 2.432 & 0.920 & 1.208 \\
\hline 1.173 & 1.297 & 1.629 & 2.343 & 1.361 & 2.664 & 0.873 & 1.755 & 1.399 \\
\hline 1.592 & 1.452 & 2.104 & 1.826 & 2.087 & 2.462 & 2.155 & 1.726 & 2.136 \\
\hline 2.118 & 2.713 & 2.016 & 1.843 & 2.263 & 2.163 & 1.742 & 2.491 & 2.041 \\
\hline 2.423 & 2.405 & 2.466 & 2.639 & 2.396 & 2.201 & 2.537 & 1.664 & 2.750 \\
\hline 3.629 & 2.476 & 2.450 & 2.941 & 3.259 & 2.810 & 2.843 & 3.632 & 2.741 \\
\hline 2.831 & 4.084 & 3.508 & 3.012 & 3.622 & 4.242 & 3.300 & 3.436 & 3.187 \\
\hline 4.351 & 3.736 & 4.468 & 4.843 & 3.856 & 3.727 & 4.441 & 4.186 & 3.987 \\
\hline 5.214 & 5.474 & 4.752 & 4.690 & 5.660 & 4.846 & 4.610 & 4.621 & 5.198 \\
\hline 5.356 & 5.151 & 5.939 & 5.925 & 4.952 & 5.861 & 6.111 & 5.416 & 5.744 \\
\hline 6.444 & 6.910 & 6.534 & 6.623 & 6.953 & 6.804 & 6.545 & 6.770 & 6.645 \\
\hline 5.119 & 4.964 & 4.800 & 5.029 & 5.259 & 4.836 & 5.199 & 5.318 & 5.198 \\
\hline 4.400 & 4.213 & 4.100 & 4.190 & 3.954 & 3.982 & 4.123 & 3.694 & 3.893 \\
\hline 3.047 & 3.294 & 3.244 & 3.222 & 3.249 & 3.448 & 3.341 & 3.506 & 3.301 \\
\hline 2.695 & 2.536 & 2.635 & 2.708 & 2.666 & 2.532 & 2.552 & 2.739 & 2.590 \\
\hline 2.266 & 2.340 & 2.168 & 1.957 & 2.170 & 2.085 & 2.262 & 2.070 & 2.409 \\
\hline 1.112 & 1.350 & 1.763 & 1.547 & 1.125 & 1.422 & 1.409 & 1.356 & 1.209 \\
\hline 2.208 & 1.543 & 1.425 & 1.256 & 2.409 & 1.725 & 1.684 & 1.184 & 1.635 \\
\hline 1.188 & 1.625 & 1.307 & 2.191 & 1.135 & 1.434 & 1.047 & 2.053 & 1.580 \\
\hline 1.969 & 1.359 & 1.904 & 1.653 & 1.743 & 2.015 & 2.685 & 1.586 & 1.637 \\
\hline 1.295 & 1.503 & 1.045 & 1.425 & 1.598 & 1.055 & 1.490 & 1.385 & 1.545 \\
\hline 1.084 & 1.198 & 1.178 & 1.066 & 1.012 & 1.000 & 1.044 & 1.296 & 1.075 \\
\hline 1.068 & 0.810 & 1.454 & 1.297 & 1.338 & 1.228 & 1.131 & 0.924 & 1.172 \\
\hline
\end{tabular}




\begin{tabular}{|c|c|c|c|c|c|c|c|c|}
\hline 0.816 & 0.766 & 1.067 & 0.770 & 0.589 & 0.930 & 1.759 & 1.449 & 0.580 \\
\hline 1.391 & 1.137 & 1.127 & 1.384 & 1.181 & 0.898 & 0.663 & 0.910 & 1.997 \\
\hline 1.055 & 1.206 & 0.967 & 1.235 & 1.104 & 0.952 & 0.768 & 1.157 & 0.836 \\
\hline
\end{tabular}

\begin{tabular}{|c|c|c|c|c|c|c|c|c|c|}
\hline-10 & 0 & 10 & 20 & 30 & 40 & 50 & 60 & 70 & 80 \\
\hline 0.766 & 0.809 & 0.899 & 1.237 & 0.766 & 1.291 & 0.959 & 1.490 & 1.008 & 1.279 \\
\hline 1.434 & 0.826 & 1.160 & 0.823 & 1.703 & 1.093 & 1.204 & 0.754 & 1.437 & 1.191 \\
\hline 0.691 & 1.574 & 1.419 & 1.161 & 0.871 & 0.570 & 1.085 & 0.699 & 0.699 & 0.903 \\
\hline 1.641 & 1.387 & 1.193 & 1.228 & 1.061 & 1.684 & 0.847 & 1.107 & 1.562 & 0.602 \\
\hline 0.896 & 0.878 & 0.565 & 1.300 & 1.584 & 1.081 & 0.962 & 1.387 & 0.833 & 1.840 \\
\hline 1.095 & 1.658 & 1.588 & 1.666 & 1.056 & 2.027 & 0.866 & 1.338 & 1.244 & 1.925 \\
\hline 1.272 & 1.587 & 1.152 & 0.909 & 1.390 & 1.511 & 1.364 & 1.016 & 1.329 & 1.036 \\
\hline 1.030 & 1.172 & 1.989 & 1.422 & 1.604 & 1.386 & 1.923 & 1.130 & 1.823 & 1.528 \\
\hline 2.094 & 1.746 & 1.233 & 2.203 & 1.678 & 1.262 & 1.518 & 2.010 & 1.392 & 1.401 \\
\hline 2.208 & 1.279 & 1.886 & 2.526 & 1.322 & 1.888 & 1.449 & 1.755 & 1.691 & 2.373 \\
\hline 1.818 & 2.831 & 1.972 & 1.682 & 2.746 & 2.369 & 2.550 & 1.911 & 2.745 & 2.180 \\
\hline 2.385 & 2.946 & 3.220 & 2.605 & 3.237 & 2.839 & 2.732 & 2.717 & 2.447 & 2.708 \\
\hline 3.949 & 3.273 & 3.351 & 3.337 & 3.756 & 3.277 & 3.285 & 3.555 & 3.797 & 3.894 \\
\hline 4.405 & 4.241 & 3.863 & 4.737 & 3.975 & 4.123 & 3.733 & 4.448 & 4.137 & 3.840 \\
\hline 4.403 & 5.441 & 5.400 & 4.570 & 4.799 & 4.994 & 5.338 & 4.538 & 4.732 & 5.170 \\
\hline 6.245 & 5.261 & 5.359 & 6.126 & 5.680 & 5.281 & 5.373 & 5.393 & 5.812 & 5.695 \\
\hline 6.517 & 6.670 & 6.695 & 6.429 & 6.709 & 6.995 & 6.998 & 6.907 & 6.430 & 6.390 \\
\hline 4.828 & 4.882 & 5.109 & 5.459 & 4.942 & 4.846 & 5.214 & 5.233 & 5.185 & 5.475 \\
\hline
\end{tabular}




\begin{tabular}{|c|c|c|c|c|c|c|c|c|c|}
\hline 5.096 & 5.143 & 5.065 & 4.764 & 5.003 & 5.383 & 4.778 & 4.775 & 5.080 & 4.833 \\
\hline 4.405 & 4.007 & 4.215 & 4.174 & 3.891 & 4.074 & 4.208 & 4.033 & 4.082 & 4.028 \\
\hline 3.015 & 3.369 & 3.437 & 3.170 & 3.486 & 3.249 & 3.351 & 3.419 & 3.165 & 3.495 \\
\hline 2.154 & 2.298 & 2.059 & 2.342 & 2.416 & 2.284 & 2.228 & 2.343 & 2.332 & 2.336 \\
\hline 1.166 & 1.400 & 1.633 & 1.370 & 1.209 & 1.266 & 1.291 & 1.221 & 1.265 & 1.295 \\
\hline 1.796 & 1.969 & 1.464 & 1.387 & 1.818 & 1.383 & 1.764 & 1.501 & 1.571 & 1.626 \\
\hline 1.344 & 0.816 & 1.296 & 1.663 & 1.476 & 1.888 & 1.209 & 1.969 & 1.710 & 1.405 \\
\hline 1.993 & 2.468 & 1.700 & 1.525 & 1.647 & 1.429 & 1.883 & 1.212 & 1.448 & 2.191 \\
\hline 1.172 & 1.221 & 0.929 & 1.699 & 1.276 & 1.611 & 1.104 & 1.018 & 1.122 & 0.786 \\
\hline 1.467 & 1.076 & 2.223 & 1.359 & 0.952 & 1.346 & 1.301 & 1.738 & 1.697 & 1.682 \\
\hline 0.677 & 1.259 & 0.999 & 0.790 & 0.932 & 0.865 & 0.981 & 1.159 & 0.670 & 0.795 \\
\hline 1.305 & 1.063 & 0.769 & 1.036 & 1.793 & 1.248 & 1.005 & 1.016 & 1.753 & 0.813 \\
\hline 1.851 & 1.666 & 0.775 & 1.248 & 0.993 & 1.000 & 1.558 & 1.140 & 0.854 & 1.145 \\
\hline 0.639 & 0.436 & 1.347 & 0.966 & 1.055 & 0.874 & 0.561 & 0.915 & 0.892 & 0.603 \\
\hline 1.280 & 1.185 & 0.921 & 0.938 & 1.197 & 0.975 & 2.069 & 1.176 & 0.842 & 1.966 \\
\hline
\end{tabular}

\begin{tabular}{|c|c|c|c|c|c|c|c|c|c|c|c|}
\hline 90 & 100 & 110 & 120 & 130 & 140 & 150 & 160 & 170 & 180 & Baseline Density & $\begin{array}{r}\text { Frequency from } \\
\text { P \& T }\end{array}$ \\
\hline 0.809 & 0.803 & 0.766 & 1.279 & 0.809 & 0.803 & 1.454 & 0.766 & 1.080 & 0.959 & 1.017 & 1.68866131 \\
\hline 0.826 & 1.268 & 1.670 & 1.191 & 0.826 & 1.268 & 0.957 & 1.703 & 1.486 & 1.204 & 1.106 & 1.68866131 \\
\hline 1.574 & 1.033 & 1.009 & 0.903 & 1.574 & 1.033 & 0.960 & 0.871 & 0.704 & 1.085 & 1.007 & 1.68866131 \\
\hline
\end{tabular}




\begin{tabular}{|c|c|c|c|c|c|c|c|c|c|c|c|}
\hline 1.387 & 0.950 & 0.827 & 0.602 & 1.387 & 0.950 & 0.619 & 1.061 & 0.982 & 0.847 & 1.032 & 1.68866131 \\
\hline 0.878 & 1.761 & 1.351 & 1.840 & 0.878 & 1.761 & 1.965 & 1.584 & 1.014 & 0.962 & 1.105 & 1.68866131 \\
\hline 0.918 & 0.724 & 0.849 & 0.701 & 0.918 & 0.724 & 1.078 & 0.841 & 0.942 & 1.775 & 1.156 & 1.68866131 \\
\hline 1.658 & 1.506 & 1.583 & 1.925 & 1.658 & 1.506 & 1.370 & 1.056 & 1.418 & 0.866 & 1.244 & 1.68866131 \\
\hline 1.587 & 1.210 & 1.235 & 1.036 & 1.587 & 1.210 & 1.196 & 1.390 & 1.945 & 1.364 & 1.474 & 1.68866131 \\
\hline 1.172 & 1.553 & 1.814 & 1.528 & 1.172 & 1.553 & 1.176 & 1.604 & 1.255 & 1.923 & 1.332 & 1.68866131 \\
\hline 1.746 & 1.444 & 1.306 & 1.401 & 1.746 & 1.444 & 1.286 & 1.678 & 1.900 & 1.518 & 1.596 & 1.68866131 \\
\hline 1.279 & 1.919 & 1.748 & 2.373 & 1.279 & 1.919 & 2.118 & 1.322 & 1.315 & 1.449 & 1.831 & 2.007278984 \\
\hline 2.831 & 1.990 & 2.330 & 2.180 & 2.831 & 1.990 & 2.297 & 2.746 & 2.314 & 2.550 & 2.098 & 2.007278984 \\
\hline 2.437 & 2.717 & 2.565 & 2.250 & 2.437 & 2.717 & 2.794 & 2.165 & 2.102 & 2.750 & 2.489 & 2.007278984 \\
\hline 2.946 & 2.781 & 2.174 & 2.708 & 2.946 & 2.781 & 2.508 & 3.237 & 3.301 & 2.732 & 2.870 & 2.474585006 \\
\hline 3.273 & 3.342 & 4.228 & 3.894 & 3.273 & 3.342 & 3.960 & 3.756 & 4.155 & 3.285 & 3.479 & 2.474585006 \\
\hline 4.241 & 4.326 & 4.365 & 3.840 & 4.241 & 4.326 & 4.143 & 3.975 & 3.864 & 3.733 & 4.124 & 3.226338304 \\
\hline 5.441 & 5.299 & 4.842 & 5.170 & 5.441 & 5.299 & 5.072 & 4.799 & 5.221 & 5.338 & 4.959 & 4.635875926 \\
\hline 5.261 & 5.616 & 5.836 & 5.695 & 5.261 & 5.616 & 5.380 & 5.680 & 5.314 & 5.373 & 5.608 & 4.635875926 \\
\hline
\end{tabular}




\begin{tabular}{|c|c|c|c|c|c|c|c|c|c|c|c|}
\hline 6.670 & 6.522 & 6.212 & 6.390 & 6.670 & 6.522 & 6.437 & 6.709 & 6.589 & 6.998 & 6.713 & 4.635875926 \\
\hline 4.882 & 5.060 & 5.332 & 5.475 & 4.882 & 5.060 & 5.065 & 4.942 & 4.924 & 5.214 & 5.084 & 3.226338304 \\
\hline 5.143 & 5.101 & 4.897 & 4.833 & 5.143 & 5.101 & 5.272 & 5.003 & 5.300 & 4.778 & 4.987 & 3.226338304 \\
\hline 4.007 & 4.116 & 4.008 & 4.028 & 4.007 & 4.116 & 4.011 & 3.891 & 3.898 & 4.208 & 4.139 & 2.474585006 \\
\hline 3.369 & 3.045 & 3.202 & 3.495 & 3.369 & 3.045 & 3.173 & 3.486 & 3.148 & 3.351 & 3.264 & 2.474585006 \\
\hline 2.533 & 2.679 & 2.497 & 2.526 & 2.533 & 2.679 & 2.684 & 2.589 & 2.893 & 2.557 & 2.639 & 2.007278984 \\
\hline 2.298 & 2.121 & 2.503 & 2.336 & 2.298 & 2.121 & 2.175 & 2.416 & 2.110 & 2.228 & 2.182 & 2.007278984 \\
\hline 1.400 & 1.264 & 1.146 & 1.295 & 1.400 & 1.264 & 1.430 & 1.209 & 1.194 & 1.291 & 1.304 & 2.007278984 \\
\hline 1.969 & 2.204 & 1.834 & 1.626 & 1.969 & 2.204 & 1.726 & 1.818 & 1.930 & 1.764 & 1.726 & 1.68866131 \\
\hline 0.816 & 1.170 & 1.250 & 1.405 & 0.816 & 1.170 & 1.207 & 1.476 & 1.019 & 1.209 & 1.435 & 1.68866131 \\
\hline 2.468 & 2.049 & 2.234 & 2.191 & 2.468 & 2.049 & 1.922 & 1.647 & 2.681 & 1.883 & 1.817 & 1.68866131 \\
\hline 1.221 & 1.108 & 1.069 & 0.786 & 1.221 & 1.108 & 1.561 & 1.276 & 1.126 & 1.104 & 1.216 & 1.68866131 \\
\hline 1.076 & 0.872 & 1.111 & 1.682 & 1.076 & 0.872 & 0.918 & 0.952 & 1.534 & 1.301 & 1.184 & 1.68866131 \\
\hline 1.259 & 1.202 & 1.330 & 0.795 & 1.259 & 1.202 & 1.119 & 0.932 & 0.750 & 0.981 & 1.078 & 1.68866131 \\
\hline 1.063 & 1.231 & 1.104 & 0.813 & 1.063 & 1.231 & 1.310 & 1.793 & 1.309 & 1.005 & 1.086 & 1.68866131 \\
\hline
\end{tabular}




\begin{tabular}{|r|r|l|l|l|l|l|l|l|l|r|r|}
\hline 1.010 & 1.480 & 1.220 & 1.560 & 1.010 & 1.480 & 0.975 & 0.872 & 0.850 & 1.038 & 1.68866131 \\
\hline 1.666 & 1.130 & 0.780 & 1.145 & 1.666 & 1.130 & 0.713 & 0.993 & 1.422 & 1.558 & 1.119 & 0.950 \\
\hline 0.436 & 0.455 & 1.305 & 0.603 & 0.436 & 0.455 & 1.420 & 1.055 & 0.860 & 0.561 & 1.68866131 \\
\hline 1.185 & 1.252 & 1.088 & 1.966 & 1.185 & 1.252 & 0.612 & 1.197 & 0.797 & 2.069 & 1.981 & 1.129 \\
\hline
\end{tabular}




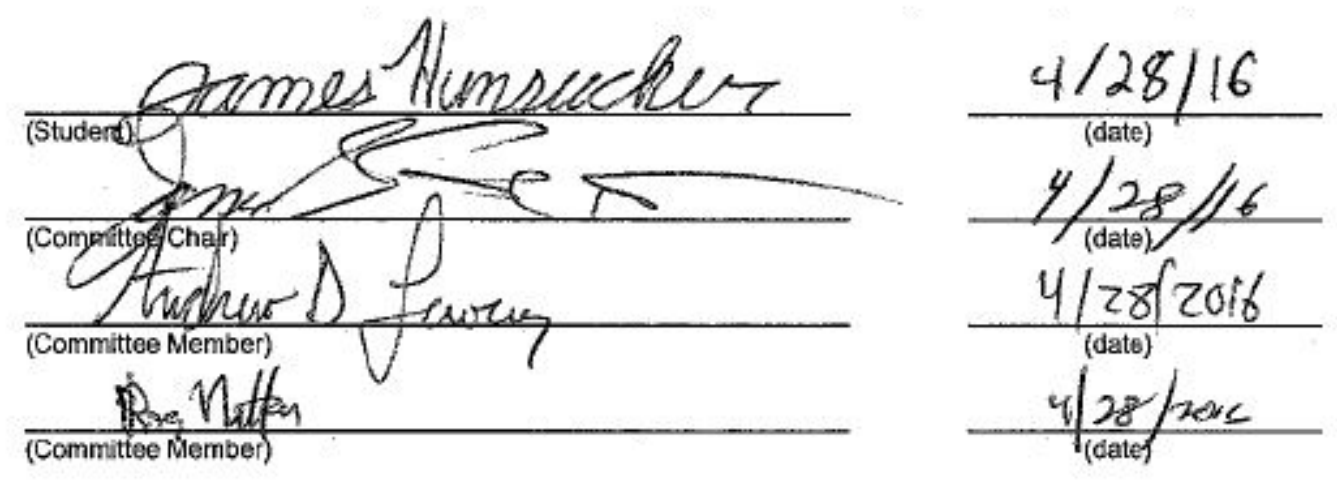

89 